UNIVERSIDADE DE SÃO PAULO

ESCOLA POLITÉCNICA

PHILLIP LUIZ VIANA

USO DE COMPOSIÇÃO AUTOMÁTICA DE SERVIÇOS E SIMILARIDADE PARA ANÁLISE DE INTEGRAÇÃO DE PROCESSOS DE NEGÓCIO

São Paulo

2013 
PHILLIP LUIZ VIANA

USO DE COMPOSIÇÃO AUTOMÁTICA DE SERVIÇOS E SIMILARIDADE PARA ANÁLISE DE INTEGRAÇÃO DE PROCESSOS DE NEGÓCIO

São Paulo

2013 
PHILLIP LUIZ VIANA

\section{USO DE COMPOSIÇÃO AUTOMÁTICA DE SERVIÇOS E SIMILARIDADE PARA ANÁLISE DE INTEGRAÇÃO DE PROCESSOS DE NEGÓCIO}

Dissertação apresentada à Escola Politécnica da Universidade de São Paulo para obtenção do título de mestre em Engenharia

Área de concentração:

Engenharia de Computação

Orientador: Prof. Dr. Jorge Luis Risco Becerra

São Paulo

2013 


\section{FICHA CATALOGRÁFICA}

\section{Viana, Phillip Luiz}

Uso de composição automática de serviços e similaridade para análise de integração de processos de negócio/ P.L. Viana. -- São Paulo, 2013.

107 p.

Dissertação (Mestrado) - Escola Politécnica da Universidade de São Paulo. Departamento de Engenharia de Computação e Sistemas Digitais.

1. Arquitetura de software 2. Arquitetura orientada a serviços I. Universidade de São Paulo. Escola Politécnica. Departamento de Engenharia de Computacão e Sistemas Digitais II. t. 


\section{DEDICATÓRIA}

Dedico este trabalho à minha família e aos meus amigos, que sempre acreditaram na minha competência e me apoiaram em todas as decisões. 


\section{AGRADECIMENTOS}

À Professora Dra. Selma Shin Shimizu Melnikoff, professora e amiga, por acreditar na qualidade da minha pesquisa desde o primeiro momento.

Ao orientador e amigo Prof. Dr. Jorge Luis Risco Becerra, pela orientação e entusiasmo desde que me aceitou como seu orientado.

A todos aqueles que contribuíram com o projeto de maneira indireta, através de críticas, sugestões, apoio e incentivo. 


\section{RESUMO}

Com a tendência de aumento do uso de tecnologias móveis conectadas à web, é comum que empresas (provedores) provejam seus serviços na web para que possam atender requisições de usuários em diversas situações. Muitas vezes é necessário que serviços de dois ou mais provedores sejam compostos automaticamente para que uma única requisição de usuário seja atendida no momento imediatamente anterior à execução do serviço: é a composição automática de serviços. Quando uma composição de serviços é executada, ela está automatizando um processo de negócio relativo à requisição do usuário. $\mathrm{O}$ objetivo dessa pesquisa é contribuir com um modelo arquitetural de sistema básico de composição automática de serviços baseado em semântica. Este modelo contempla a utilização de similaridade entre conceitos de uma ontologia de um domínio específico, desta maneira possibilitando que uma mesma requisição de um usuário possa ser atendida de diversas maneiras distintas e com serviços heterogêneos. A proposta é validada através de um protótipo em software e a experimentação é aplicada no domínio do turismo. 


\begin{abstract}
With the trend towards increased use of mobile technologies over the web, companies (providers) have been increasingly providing their services on the web to fulfill user requests in various situations. It is often necessary that two or more services from different providers are automatically composed in order to meet a single user request at the moment immediately previous to the service execution: this is called automatic composition of services. The objective of this research is to contribute with a semanticsbased automatic composition model that uses similarity between concepts of an ontology to generate alternative business processes, thus enabling a single user request to be met in several different ways using heterogeneous services. The proposal is validated through a software prototype and the experimentation is applied in the tourism domain.
\end{abstract}




\section{LISTA DE FIGURAS}

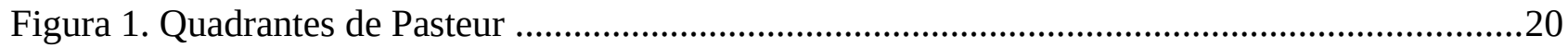

Figura 2. Exemplo de serviço e suas operações..........................................................................26

Figura 3. Exemplo esquemático de composição de serviços...............................................................27

Figura 4. Exemplo de processo de negócio...............................................................................29

Figura 5. Representação em árvore dos conceitos de uma ontologia...............................................31

Figura 6. Associação entre requisição e conceitos ontológicos............................................................33

Figura 7. Associação entre operações, parâmetros e conceitos ontológicos....................................33

Figura 8. Ciclo de vida da composição automática de serviços....................................................34

Figura 9. Diagrama de classes das relações entre requisição, ontologia e serviços semânticos........40

Figura 10. Exemplo de cálculo de similaridade entre conceitos...................................................46

Figura 11. Requisição R que pode ser resolvida pelos processos de negócio PN2, PN3 e PN5........47

Figura 12. Similaridade utilizada em sistemas atuais...............................................................47

Figura 13. O processo de negócio PN1 resolve parcialmente a requisição R, pois C1.1 e C1.2 estão

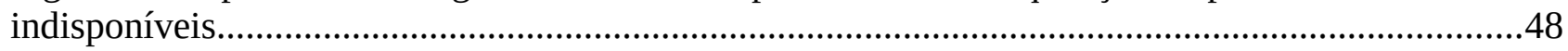

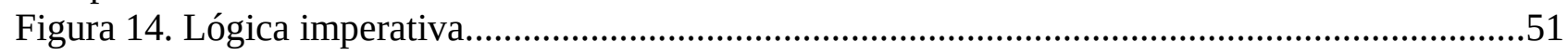

Figura 15. Relação entre requisições, semântica e linguística...........................................................52

Figura 16. Diagrama UML de estrutura composta com os dois componentes principais do modelo 55

Figura 17. Diagrama de classes UML para o modelo proposto.....................................................59

Figura 18. Ordem de busca conceitual em abordagens não focadas em similaridade.......................65

Figura 19. Proposta de nova ordem de busca conceitual..........................................................66

Figura 20. Exemplo de processo de negócio simplificado.........................................................70

Figura 21. Processo experimental para Engenharia de Software..............................................72

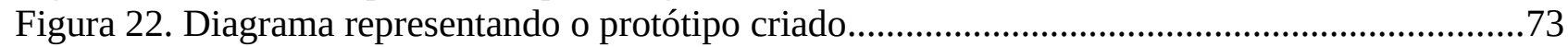

Figura 23. Similaridade gerando novos processos de negócio...................................................76

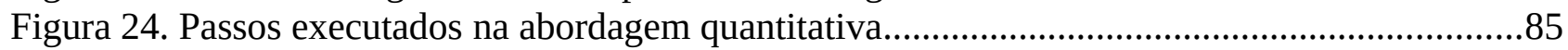

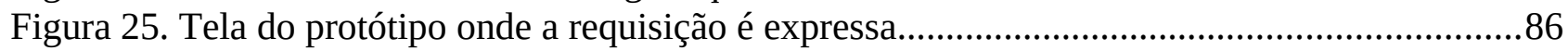

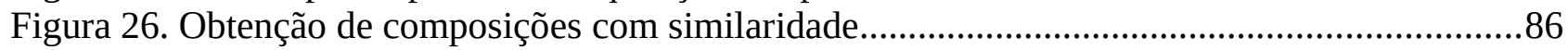

Figura 27. Primeiro passo: variação do primeiro substantivo.........................................................87

Figura 28. Serviços associados aos conceitos encontrados no passo anterior.................................87

Figura 29. Serviços com entradas e saídas similares aos encontrados no passo 2 ..........................87

Figura 30. Complementação de entradas......................................................................................8

Figura 31. Composições geradas automaticamente são mostradas no protótipo.............................88

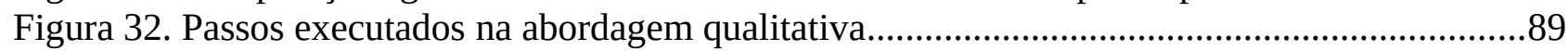

Figura 33. Razão de mudança para os diferentes graus de similaridade testados.............................91

Figura 34. Distribuição das composições geradas de acordo com as mudanças nos processos de negócio do usuário......................................................................................................................91

Figura 35. Distribuição das composições geradas de acordo com as mudanças nos processos de

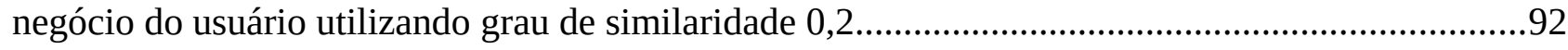

Figura 36. Distribuição das composições geradas de acordo com as mudanças nos processos de

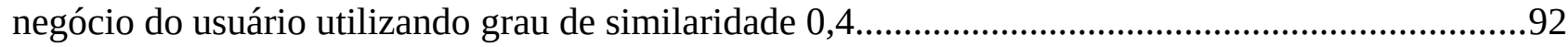

Figura 37. Distribuição das composições geradas de acordo com as mudanças nos processos de

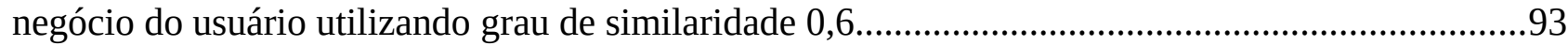

Figura 38. Distribuição das composições geradas de acordo com as mudanças nos processos de 
negócio do usuário utilizando grau de similaridade 0,8

Figura 39. Distribuição das composições geradas de acordo com as mudanças nos processos de

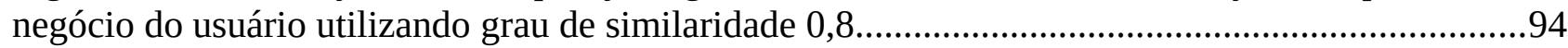
Figura 40. Distribuição das composições geradas de acordo com as mudanças nos processos de negócio do usuário utilizando grau de similaridade 1,0 (sem similaridade)..................................94 Figura 41. Composições que não correspondiam ao requisito, mas satisfaziam a necessidade COM

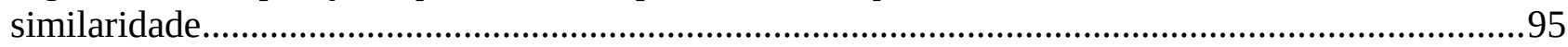

Figura 42. Composições que correspondiam exatamente a necessidade COM similaridade.............96

Figura 43. Composições que satisfaziam parcialmente a necessidade COM similaridade................96

Figura 44. Composições que não correspondiam ao requisito, mas satisfaziam a necessidade SEM

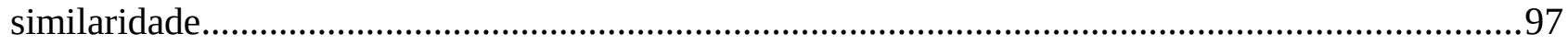

Figura 45. Composições que correspondiam exatamente a necessidade SEM similaridade..............97

Figura 46. Composições que satisfaziam parcialmente a necessidade SEM similaridade.................98

Figura 47. A utilização da similaridade deve ter um ponto ótimo entre 0 e 1 .................................100 


\section{LISTA DE TABELAS}

Tabela 1. Exemplo de construção de requisição em linguagem natural...........................................38

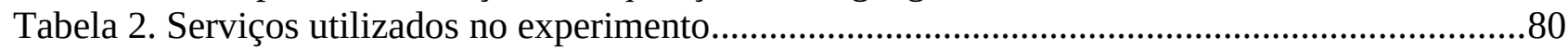

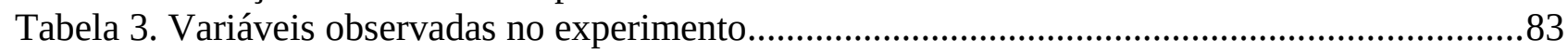

Tabela 4. Critérios para definir a diferença entre processos de negócio.........................................84 


\section{SUMÁRIO}

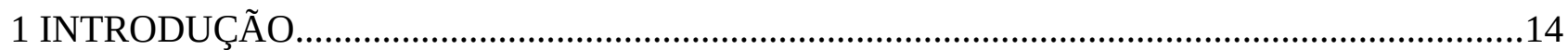

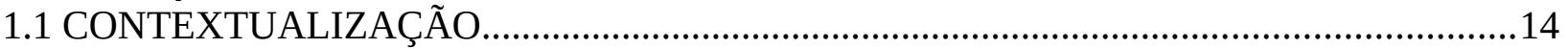

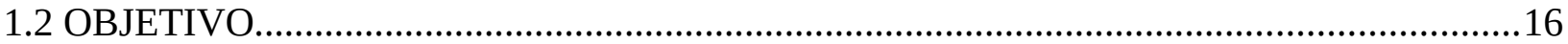

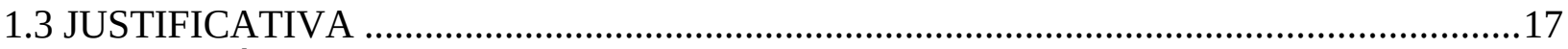

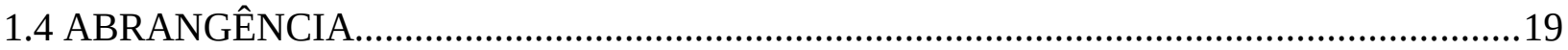

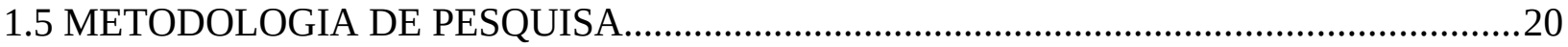

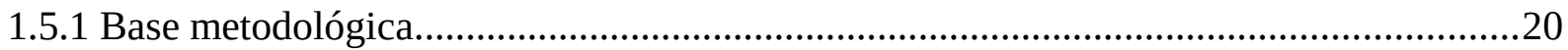

1.5.2 Etapas da metodologia.........................................................................................21

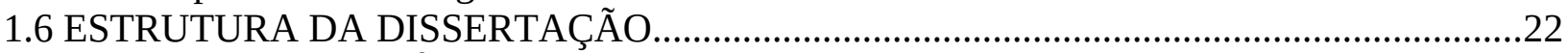

2 COMPOSIÇÃO AUTOMÁTICA E SIMILARIDADE DE SERVIÇOS...........................................24

2.1 FUNDAMENTOS DE SOA E COMPOSIÇÃO AUTOMÁTICA............................................24

2.1.1 Arquiteturas orientadas a serviço......................................................................................24

2.1.2 Composição de serviços............................................................................................26

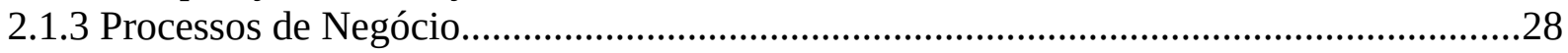

2.1.4 Composição automática de serviços semânticos...................................................................29

2.2 PROCESSO DE APLICAÇÃO DA COMPOSIÇÃO AUTOMÁTICA......................................34

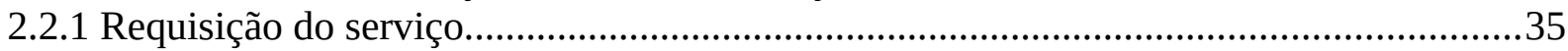

2.2.2 Descoberta e composição de serviços.............................................................................38

2.3 FUNDAMENTOS DA SIMILARIDADE ENTRE CONCEITOS.........................................44

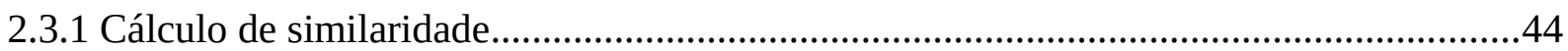

2.3.2 Consideração sobre a proposta do uso da similaridade....................................................46

3 MODELO DE COMPOSIÇÃO AUTOMÁTICA COM SIMILARIDADE NO NÍVEL DE

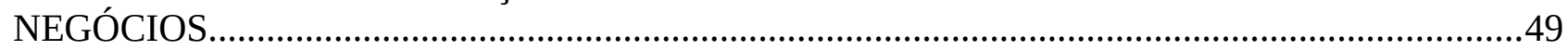

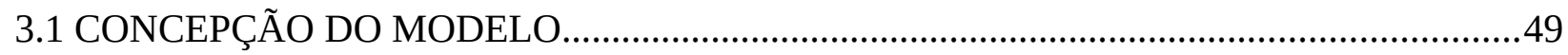

3.1.1 Requisitos da pesquisa que levaram à concepção do modelo............................................49

3.1.2. Teoria linguística das frases imperativas.........................................................................50

3.1.3 Características observadas no modelo proposto...............................................................53

3.1.4 Decisões de integração do modelo proposto.....................................................................54

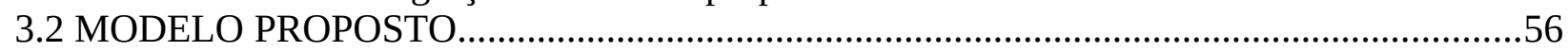

3.2.1 Visão geral do modelo proposto...................................................................................56

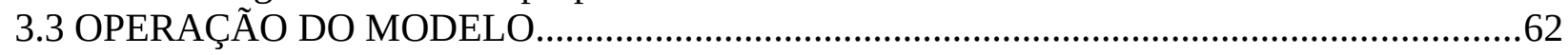

3.3.2 Aplicação da similaridade semântica da requisição..........................................................62

3.3.3 Visão completa da composição automática de serviços com variação semântica............66

3.4 MAPEAMENTO ENTRE SERVIÇOS E PROCESSOS DE NEGÓCIO..................................68

4 APLICAÇÃO EXPERIMENTAL............................................................................................71

4.1 ENGENHARIA DE SOFTWARE EXPERIMENTAL........................................................71

4.2 PROTÓTIPO DE COMPOSIÇÃO AUTOMÁTICA COM SIMILARIDADE.........................72

4.3 DOMÍNIO DO TURISMO...........................................................................................

4.4 OPERAÇÃO DA APLICAÇÃO EXPERIMENTAL..............................................................75

4.4.1 Definição dos Requisitos..................................................................................................75

4.4.2 Planejamento do Projeto.................................................................................................77

4.4.3 Execução do experimento ……………………………………………………………...85

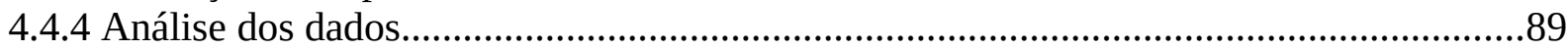




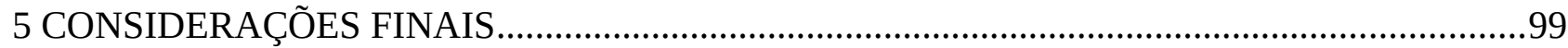

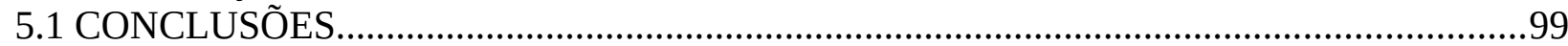

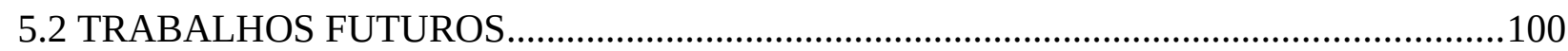

6 REFERÊNCIAS BIBLIOGRÁFICAS.................................................................................102 


\section{INTRODUÇÃO}

Neste capítulo será apresentado o problema que a pesquisa se propõe a resolver, a solução, as pesquisas relacionadas e a abrangência do trabalho. Na última seção será apresentada a estrutura da dissertação, com breve descrição do conteúdo por capítulo.

\subsection{CONTEXTUALIZAÇÃO}

No campo de arquitetura de software, o paradigma computacional que contém os princípios de projeto que viabilizam a utilização de serviços é o paradigma da orientação a serviços, comumente chamado na literatura de SOA, ou Service-Oriented Architecture.

Com a tendência de aumento do uso de tecnologias conectadas à web, incluindo dispositivos móveis, é comum que empresas (provedores) provejam serviços na web para que possam atender requisições diversas de usuários com agilidade. Em alguns casos é necessário que serviços de dois ou mais provedores sejam compostos automaticamente, integrando provedores imediatamente anteriormente ao momento do provimento do serviço para que uma requisição de usuário seja atendida.

Toda composição de serviços, ao ser executada, está implicitamente automatizando um processo de negócio relativo a uma requisição, o que permite inclusive tratar composições de serviços através de um modelo de processos (GUO, CHEN-BURGER e ROBERTSON, 2004). Um processo de negócio é um conjunto de atividades relacionadas e estruturadas para servirem um determinado objetivo. As atividades de um processo de negócio podem ser associadas sequencialmente (uma atividade acontece após a atividade anterior ser finalizada), paralelamente (duas atividades acontecem simultaneamente), ou estruturadas de outras maneiras para garantir que um determinado propósito seja alcançado. Uma atividade de um processo de negócio pode ser automatizada por um serviço (ou uma composição de serviços) e, portanto, um processo 
de negócio como um todo pode também ser automatizado por uma composição de serviços.

Pode-se enxergar a composição, o processo de negócio e a requisição em três níveis crescentes de abstração:

- a composição de serviços pode ser vista como uma maneira de realizar um processo de negócio

- um processo de negócio pode ser visto como um conjunto de atividades necessárias para se atender uma requisição

- uma requisição é uma maneira de representar-se o desejo de um usuário

Quando a composição de serviços é construída pelo próprio software em tempo de execução (a composição pode ser executada tão logo é construída), é chamada composição automática de serviços. No campo da composição automática de serviços é comum a utilização de ontologias computacionais, de maneira que os serviços e suas operações são associados a conceitos ontológicos, o que auxilia a máquina a realizar as composições. Um serviço associado a conceitos ontológicos é chamado serviço semântico. Há também a composição pré-definida (manual) de serviços, quando a composição é construída por um ser humano anteriormente à execução do software.

Existem atualmente modelos de arquiteturas de composição automática de serviços que suportam a geração de composições alternativas face à indisponibilidade ou inexistência de serviços. No entanto, estes modelos geram diferentes composições que estão todas associadas ao mesmo processo de negócio. Há a possibilidade de criar-se modelos que gerem composições associadas a processos de negócio diferentes, desta maneira oferecendo formas significativamente diferentes de resolver uma mesma requisição. Isto leva a um número maior de composições possíveis para atender uma requisição, com um eventual impacto na qualidade de serviço ou na requisição original em si. Existem na pesquisa atual trabalhos que se encaminham no sentido da utilização de similaridade entre conceitos ontológicos para a substituição de serviços indisponíveis, como por exemplo em Fujii e Suda (2009). Existem trabalhos que também se encaminham no 
sentido de mapear as composições realizadas automaticamente para processos de negócio, como por exemplo em Feng, Veeramini e Kanagasabai (2012), e Markou e Refanidis (2012).

Sendo assim, nas pesquisas atuais de composição automática de serviços há a tendência pelo estudo de modelos de arquitetura de composição automática de serviço capazes de utilizar similaridade conceitual com diversos objetivos e também observar os processos de negócio gerados pelas composições. Nesta proposta aborda-se a utilização sistemática da similaridade ontológica para gerar composições associadas a diversos processos de negócio similares que podem atender a uma dada requisição. A utilização de outros processos de negócio envolve uma eventual flexibilização da requisição, ou seja, o processo de negócio alternativo pode atender apenas parte da requisição original, ou com alterações na qualidade de serviço.

\subsection{OBJETIVO}

O objetivo da pesquisa é propor um modelo arquitetural para um sistema básico de composição automática de serviços que utilize similaridade entre conceitos ontológicos para gerar composições de serviço alternativas. A utilização da similaridade foi pensada de maneira que as composições de serviço alternativas pudessem atender a outros processos de negócio.

O modelo da pesquisa partirá do modelo de arquitetura de composição automática de serviços de Fujii e Suda (2009), que utiliza conceitos ontológicos e gera composições de serviço que atendem a uma determinada requisição expressa por um usuário em linguagem natural. O modelo será acrescido de um componente que utilizará o cálculo de similaridade entre conceitos ontológicos de Ganjisaffar et al. (2006), que proverá maior variabilidade nas composições geradas. $O$ produto da pesquisa será um modelo de arquitetura de composição automática de serviços que integra um componente de similaridade conceitual para gerar composições alternativas. Pretende-se observar a 
geração de novas das composições similares com o intuito de avaliar o impacto que a mudança nas composições causou no nível dos processos de negócio.

O modelo proposto será implementado como protótipo e experimentado no domínio de aplicação do turismo. Embasou-se a experimentação no modelo de engenharia de software experimental proposto por Goulão et al. (2007), de modo a prover ênfase científica ao exercício do protótipo.

\subsection{JUSTIFICATIVA}

Foram pesquisadas propostas de composição automática de serviços entre 2004 e 2013 nos principais jornais e periódicos de arquitetura de software e computação orientada a serviços (e as principais referências dos trabalhos encontrados) que utilizassem linguagem natural e ontologia para gerar composições automaticamente.

Foram encontradas diversas propostas de modelos de composição automática de serviços cuja requisição é expressa por um usuário. Tais modelos, no entanto, não possuem mecanismos que viabilizam a geração de composições alternativas e, portanto, não são capazes de oferecer composições que automatizam processos de negócio alternativos.

Bilbao e Herrero (2009) e Paganelli, Parlanti e Giuli (2010) propõem modelos em que a requisição é captada através de um conjunto de requisições pré-definidas em banco de dados e selecionada via ferramentas gráficas. Liu, Peng e Chen (2006) propõem especificação dos parâmetros de entrada das operações do serviço, parâmetros de saída das operações do serviço e capacidades do serviço final desejado. Outras pesquisas propõem utilização manual e explícita de ontologias por parte do usuário, como por exemplo em Lin, Guo e Yin (2005). Li, He e Chen (2010) e Fujii e Suda (2009) propõem a expressão da requisição em linguagem natural escrita, de forma que as palavras da requisição são mapeadas para conceitos de uma ontologia cujos conceitos estão 
mapeados também para serviços e suas operações.

Propostas como a de Ganjisaffar et al. (2006) e Qu et al. (2009) definem métricas de similaridade entre serviços para auxiliar o mecanismo de descoberta de serviços. $O$ primeiro utiliza ontologias, e o segundo utiliza mecanismos de mineração de dados sobre um banco de dados léxico.

O modelo proposto neste trabalho foi inspirado principalmente nos modelos de Fujii e Suda (2009) e Ganjisaffar et al. (2006). O modelo de composição automática de serviços de Fujii e Suda (2009) permite a criação de sistemas que obtém a requisição em linguagem natural por parte do usuário, mapeiam as palavras-chave para conceitos de uma ontologia do domínio, buscam os serviços de interesse em um repositório e então realizam a composição de serviços. O modelo de similaridade de Ganjisaffar et al. (2006) define a similaridade de acordo com o relacionamento entre os conceitos em uma ontologia, desta forma provendo funções matemáticas para calcular a similaridade entre dois conceitos.

Diversos sistemas de composição automática de serviços para o domínio do turismo foram analisados, como Bilbao e Herrero (2009), Tran e Tsuji (2009), Choi et al. (2006), Paganelli, Parlanti e Giuli (2010), Liu, Peng e Chen (2006), Zachos e Maiden (2008), entre outros. Estes sistemas em geral são guias turísticos que compõem serviços em tempo de execução para atender a uma demanda com rapidez. Nenhum desses sistemas, porém, sugere composições alternativas, embora utilizem serviços similares no caso de indisponibilidade de algum serviço necessário à composição.

Portanto, constatou-se que as pesquisas atuais de composição automática tendem à mesma direção do tema da presente pesquisa, porém avançaram até um certo ponto de uso limitado da similaridade, que pode ser expandido para a geração de novas composições de serviços que se associam também a processos de negócio diferentes. É nesta seara que se situa a presente pesquisa: da utilização da similaridade ontológica para a geração de novas composições de serviço que estão associadas a processos de negócio alternativos. É devido à geração de processos de negócio alternativos que se 
acredita que o desenvolvimento de um novo trabalho nesta área representará uma contribuição significativa para a área de composição automática.

\subsection{ABRANGÊNCIA}

A pesquisa abrange um modelo arquitetônico que permite a composição de serviços utilizando similaridade conceitual. A pesquisa busca resolver o problema da geração de composições associadas a processos de negócio alternativos, se comparada a outras pesquisas da área.

O modelo criado contem a adição de um componente de similaridade entre conceitos ontológicos para oferecer similaridade nas composições geradas. Houve uma modificação no algoritmo de composição automática, de maneira a habilitar as funcionalidades deste novo componente da arquitetura, e flexibilizar a requisição do usuário para gerar novas composições que, como consequência, definem outros processos de negócio.

A experimentação será aplicada sob o domínio do turismo. Foi utilizada uma ontologia específica ao domínio do turismo, que foi baseada em ontologias de outros sistemas de composição automática para o domínio. Será definido o grau de similaridade entre conceitos ontológicos, e o protótipo será exercitado dentro dos limites desta ontologia com graus de similaridade que variam entre 0 (conceitos totalmente diferentes) e 1 (conceitos idênticos). Entende-se que outros domínios potencialmente se beneficiarão da contribuição aqui proposta, no entanto não foram realizados testes em outros domínios de aplicação.

A abrangência da experimentação compreendeu um conjunto finito de serviços fictícios (18 serviços), experimentados em duas abordagens: uma abordagem quantitativa, onde observou-se as composições e processos de negócio obtidos através de 23 requisições exercitadas em laboratório, e uma abordagem qualitativa, onde 23 indivíduos vindos de 11 
países, com idades entre 17 e 42 anos, receberam treinamento e foram expostos ao software em campo.

\subsection{METODOLOGIA DE PESQUISA}

Nesta seção é abordado o estudo metodológico feito para a elaboração da pesquisa, bem como as etapas seguidas na pesquisa.

\subsubsection{Base metodológica}

Stokes (1997) fala sobre o Quadrante de Pasteur e a pesquisa científica. Pode-se dividir os tipos de pesquisa em quatro quadrantes, divididos pelos eixos da teoria e da aplicação, como mostrado na figura 1.

\section{Busca de conhecimento fundamental}
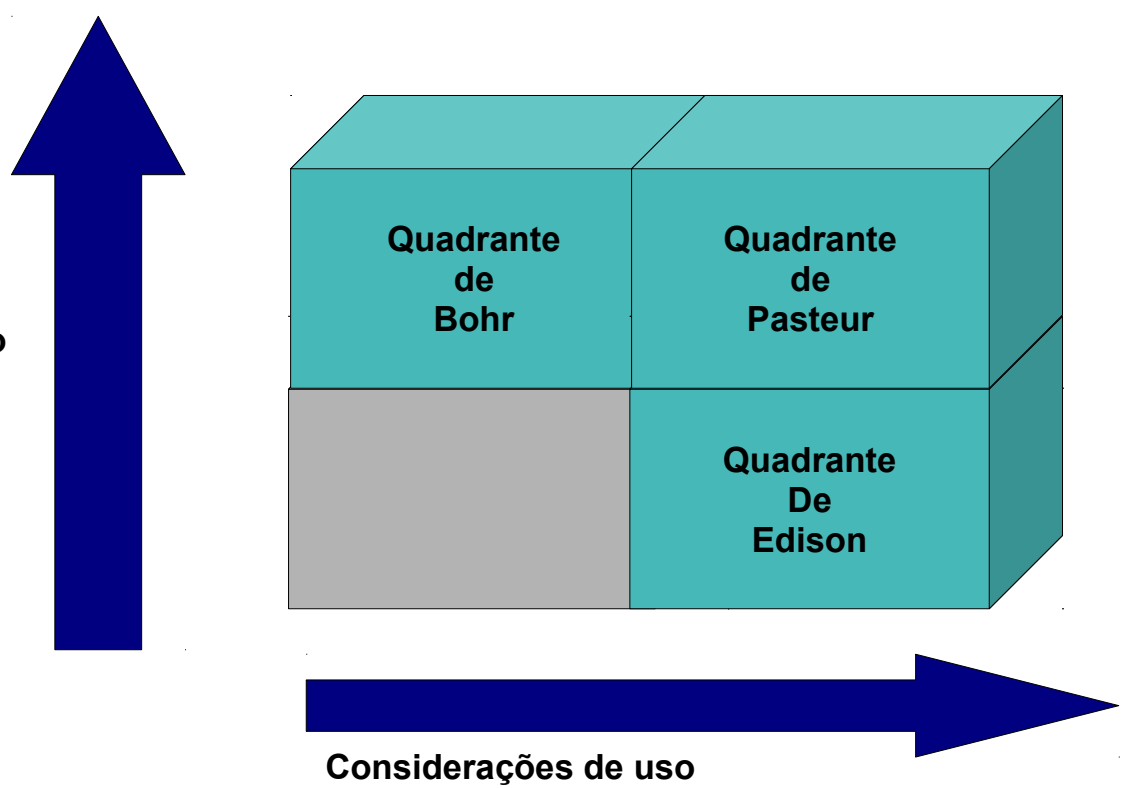

Figura 1. Quadrantes de Pasteur 
No eixo da teoria (busca de conhecimento fundamental) encontra-se a busca pelo conhecimento puro, o entendimento sobre o mundo real sem a necessidade de uma utilidade prática imediata. Já no eixo da aplicação (considerações de uso) encontra-se a busca pela utilidade prática imediata através de conhecimentos existentes, sem a geração de novo conhecimento.

O quadrante de Bohr se baseia na busca de conhecimento fundamental, sem ter como foco uma aplicação prática para a pesquisa. O quadrante de Pasteur visa o aumento do entendimento da realidade, ligado a uma aplicação prática. No quadrante de Edison considera-se a aplicabilidade da pesquisa em questão, sem levar em consideração a aquisição de um novo conhecimento fundamental.

A pesquisa deste trabalho pode ser considerada pertencente ao quadrante de Pasteur, tendo como foco tanto o ganho de novos conhecimentos fundamentais quanto a aplicação prática.

Nesta pesquisa, como componente do eixo do conhecimento fundamental pode-se citar a criação de um modelo cujo objetivo é permitir a geração de composições de serviço similares, visando uma alteração também no nível dos processos de negócio. Como componente do eixo de considerações de uso, pode-se citar a geração de um protótipo que foi exercitado sob um modelo de engenharia de software experimental, diferenciandose de um teste laboratorial simplificado.

As hipóteses que se deseja testar na pesquisa são: se a geração de composições de serviço similares é possível no âmbito da composição automática; e se a geração de novas composições de serviço geram como consequência novos processos de negócio.

\subsubsection{Etapas da metodologia}

A metodologia deste trabalho é dividida nas seguintes etapas: 
1. Identificação do problema: identificação de uma área teórica (composição automática de serviços) e prática (domínio do turismo) a serem exploradas pela pesquisa. Definição da abrangência.

2. Definição da contribuição: define-se como serão alinhadas as pesquisas de similaridade e composição automática de serviços e qual ganho será obtido no modelo produzido.

3. Geração do modelo: inserção da similaridade no modelo de composição automática de serviços, gerando um novo modelo.

4. Implementação de protótipo: geração de um protótipo em software que realiza o modelo proposto.

5. Aplicação da experimentação do protótipo: experimentação do protótipo no domínio do turismo. Coleta dos resultados.

6. Análise dos resultados: análise dos resultados, mensuração da contribuição e validação da pesquisa.

7. Elaboração da dissertação: empacotamento de todas as etapas acima em formato de dissertação.

\subsection{ESTRUTURA DA DISSERTAÇÃO}

Esta dissertação está dividida nas seguintes seções:

- Capítulo 1 - Apresenta introdução e contextualização de SOA e composição automática de serviços, apresentação do objetivo, contribuição da pesquisa, justificativa baseada em outros estudos, abrangência e metodologia.

- Capítulo 2 - São apresentados o estado da arte da composição automática de serviços, detalhamento do ciclo de vida e introdução à composição automática de serviços com similaridade.

- Capítulo 3 - É mostrada a proposta da pesquisa, é dada a explicação do papel da 
similaridade na composição automática de serviços e é feita a apresentação do modelo semântico utilizado.

- Capítulo 4 - Localiza-se o domínio do turismo como limite experimental da pesquisa, são apresentados o modelo da aplicação experimental e os passos seguidos na experimentação.

- Capítulo 5 - São apresentadas as conclusões obtidas através da pesquisa, bem como futuras melhorias que podem ser implementadas.

- Capítulo 6 - São listadas em ordem alfabética de sobrenome do autor as referências bibliográficas usadas no desenvolvimento da pesquisa. 


\section{COMPOSIÇÃO AUTOMÁTICA E SIMILARIDADE DE SERVIÇOS}

Neste capítulo serão abordadas as teorias de composição automática de serviços e similaridade conceitual, em particular os modelos sob os quais a pesquisa se baseia.

\subsection{FUNDAMENTOS DE SOA E COMPOSIÇÃO AUTOMÁTICA}

Nesta seção serão revistos alguns dos conceitos mais relevantes da computação orientada a serviços, focando-se nos aspectos da composição automática de serviços.

\subsubsection{Arquiteturas orientadas a serviço}

O termo arquitetura orientada a serviço, mais comumente mencionado como SOA Service-Oriented Architecture - é utilizado para descrever arquiteturas que estão sob o paradigma da computação orientada a serviços. Segundo Erl (2010), uma implementação de SOA pode consistir de uma combinação de tecnologias, produtos, APIs (application programming interface), infraestrutura de suporte e diversas outras partes.

O paradigma da orientação a serviços tem como elemento fundamental o serviço. Um serviço é um software independente com capacidades próprias (operações) que podem ser invocadas publicamente por programas externos através de um contrato (API). Um mesmo serviço pode prover diversas operações, e essas são agregadas em um mesmo serviço por fazerem parte de um mesmo contexto funcional, ou seja, estarem relacionadas funcionalmente. Uma arquitetura orientada a serviço compreende não apenas as características funcionais do serviço (software), como também as características de negócio, de implantação (por exemplo, distribuição de serviços em rede), governança, entre outros aspectos. 
Todo serviço é fornecido por um provedor, que é uma entidade (geralmente uma empresa) que foi responsável pela criação, publicação e manutenção do serviço, e que deseja fornecer algumas de suas capacidades de maneira a interagir com consumidores e outras empresas.

Um serviço compreende uma interface pela qual ele provê suas operações. As operações de um serviço recebem um conjunto parâmetros de entrada e fornecem um conjunto de parâmetros de saída. O conjunto coeso de funções e recursos que um serviço provê através de suas operações é chamado de capacidades do serviço (OBJECT MANAGEMENT GROUP, 2012).

Diferentemente da computação orientada a objetos ou baseada em componentes, um serviço possui como objetivo automatizar um ou mais processos de negócio da empresa que o provê, bem como combinar-se com serviços de outras empresas para integrar processos de negócio de empresas diferentes. Zimmermann, Krogdahl e Gee (2004) apontam que a orientação a objetos, bem como a modelagem de processos de negócio (BPM) e as arquiteturas corporativas (EA) apenas cobrem parte dos requisitos necessários para suportar o paradigma de orientação a serviços, sendo necessária uma modelagem explícita de alguns aspectos como os repositórios de serviços (que permitem a publicação, busca e descoberta de serviços), a coreografia de serviços (coordenação colaborativa entre serviços de uma composição) e o patterns de middleware.

Na figura 2 pode-se ver um exemplo em notação SoaML (OBJECT MANAGEMENT GROUP, 2012) da representação de um serviço. Na SoaML considera-se que um serviço possui uma capacidade e uma interface que expõe a capacidade do serviço para outros serviços e softwares. Suponha que o serviço da figura 2 seja disponibilizado pelos correios, e seu contexto funcional é o da obtenção de dados de endereço e entrega. Ele possui três operações: a operação obterEnderecoEntrega(), que retorna o endereço (logradouro, número, complemento, bairro), dado um CEP; calcularValorFrete(), que calcula o valor de uma entrega, recebendo como entrada: origem, destino e peso da entrega; e obterDadosEntrega(), que provê dados sobre uma entrega, por exemplo a 
unidade dos correios em que a entrega se encontra no momento atual e prazo estimado para entrega.

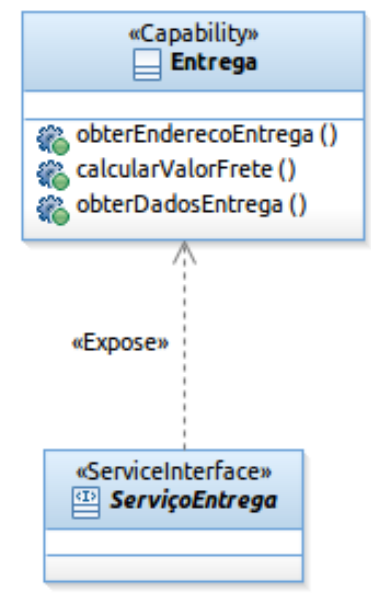

Figura 2. Exemplo de serviço e suas operações

Todas essas operações são conhecidas publicamente, isto é, suas interfaces (parâmetros entradas e saídas) são divulgadas pelo próprio provedor do serviço (correios) para que usuários e sistemas possam acessá-las.

\subsubsection{Composição de serviços}

Um dos princípios de projeto da computação orientada a serviços é a capacidade que os serviços possuem de serem compostos. Uma composição de serviços é "um agregado coordenado de serviços cujo escopo funcional está usualmente associado com a automação de um processo de negócio" (ERL, 2010). Sendo assim, uma composição compreende as capacidades combinadas de todos os serviços que estão contidos nela.

Serviços são compostos porque muitas vezes uma requisição apenas pode ser atendida mediante a utilização de mais de um serviço. Cria-se, assim, uma composição de vários serviços que atende a uma única requisição e pode se comportar como um serviço único, e que integra os serviços componentes através de suas interfaces. Pode-se considerar o serviço composto como se fosse um serviço único, que pode ser executado de maneira 
transparente, sem que o consumidor do serviço tome conhecimento que se trata de um serviço composto.

Na figura 3 há um exemplo em SoaML em que as capacidades de três serviços são compostas. Três provedores distintos - livraria virtual, banco e correios - proveem seus serviços para utilização. Esses três serviços podem ser compostos em um serviço único que agrega funcionalidades dos três provedores. Através deste serviço composto, está-se integrando os processos de negócio de cada provedor em um único processo de negócio que realiza do início ao fim uma requisição de compra de livro, incluindo o pagamento e fornecimento dos dados de entrega. Um sistema de compra virtual de livros pode, por exemplo, combinar as operações buscaPorAutor() do serviço de busca, obterEnderecoEntrega() e calcularValorFrete() do serviço de entrega e pagarComBoleto() do serviço de pagamento e oferecê-las como uma composição de serviços em um sistema web para um usuário final que deseja adquirir um livro.

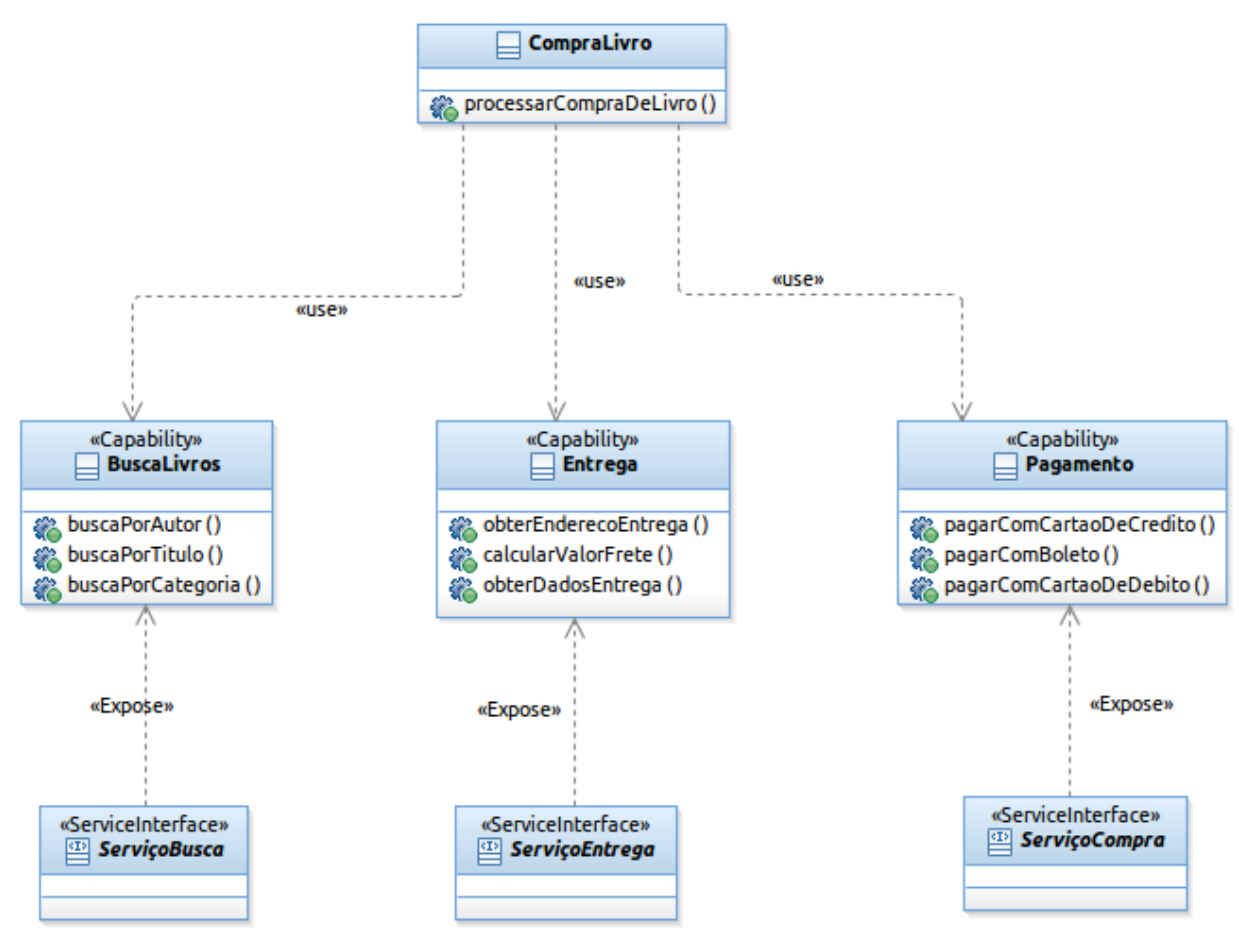

Figura 3. Exemplo esquemático de composição de serviços

Ao aplicar-se decomposição funcional no problema - quebrar o problema principal em um conjunto de problemas menores, possibilitando que as soluções também possam ser 
decompostas em um conjunto de unidades lógicas relacionadas (ERL, 2010) - vê-se que cada serviço contribui com uma solução que resolve uma parcela do problema principal, e que a integração dessas soluções resolve o problema principal integralmente.

\subsubsection{Processos de Negócio}

Segundo a Object Management Group (2011), um processo de negócio é "um conjunto definido de atividades de negócio que representam os passos necessários para alcançar um objetivo de negócio. Inclui o fluxo e o uso de informação e recursos". A definição dada pelo Gartner Group (2013) explica o processo de negócio como "um caminho de processamento fim-a-fim, dirigindo a eventos, que começa com uma requisição de cliente e termina com um resultado para o cliente. Processos de negócio comumente cruzem fronteiras departamentais e organizacionais". A partir das duas definições, nota-se que fundamentalmente um processo de negócio está relacionado a um cliente ou consumidor, e que consiste em um conjunto de atividades ordenadas de alguma maneira, muitas vezes integrando duas ou mais empresas.

No campo das arquiteturas orientadas a serviço considera-se que uma composição de serviços realiza um processo de negócio. Num nível de abstração, o processo de negócio é uma ideia abstrata que contem passos necessários para se atingir um objetivo de negócio. Num nível mais baixo de abstração, uma composição de serviços é um conjunto de serviços concretos que proveem funcionalidades que podem realizar o mesmo objetivo do processo de negócio. Um conjunto de um ou mais serviços pode realizar no mundo real um conjunto de atividades de um processo de negócio.

Na figura 4 pode-se ver um exemplo de processo de negócio relativo à composição de serviço mostrada na figura 3. Pode-se enxergar o exemplo de compra em uma livraria virtual como um processo de negócio com quatro atividades: Buscar livro, Fornecer dados de entrega, Pagar com cartão de crédito (atividades realizadas por um usuário) e Validar pagamento (atividade realizada pela operadora do cartão de crédito). 


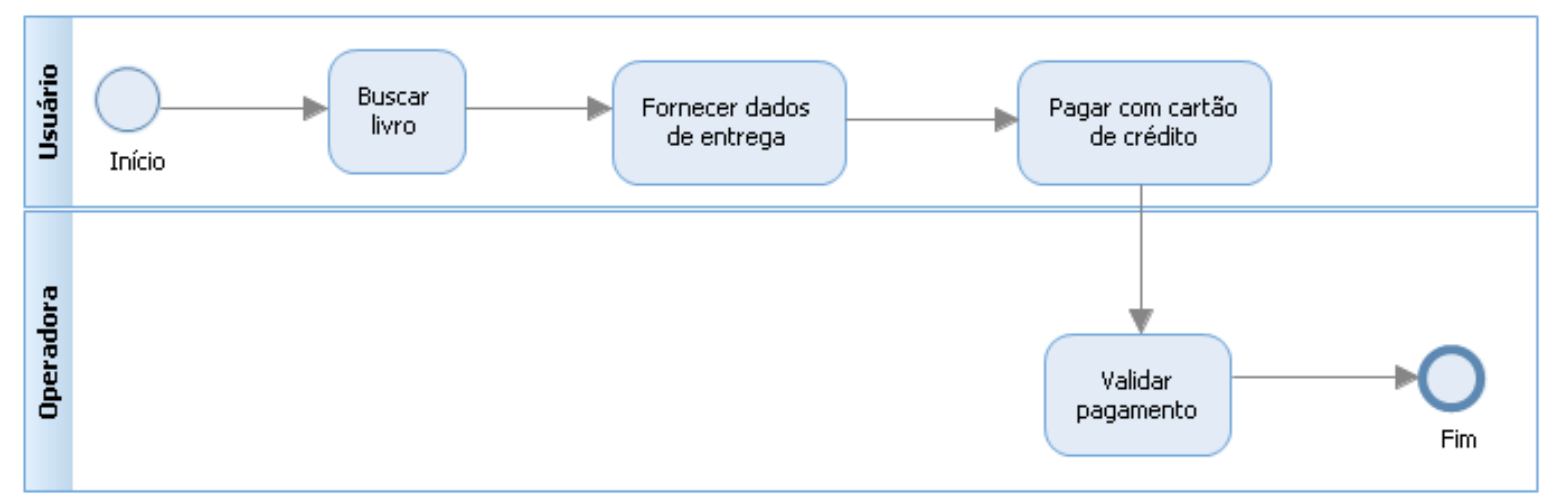

Figura 4. Exemplo de processo de negócio

Nota-se que a atividade "Buscar livro" é realizada pelas operações do serviço BuscaLivro da figura 3. A atividade "Fornecer dados de entrega" é realizada pelas operações do serviço Entrega, e, por fim, as atividades relativas ao pagamento com cartão de crédito são realizadas pelo serviço Pagamento.

\subsubsection{Composição automática de serviços semânticos}

Há situações em que o processo de negócio a ser automatizado por uma composição de serviços é bem conhecido e executado recorrentemente sem necessidade de alterações. Nestes casos a composição de serviços pode estar definida e armazenada anteriormente ao momento de execução do software (composição pré-definida de serviços).

Há casos em que a requisição que será atendida por uma composição de serviços não é conhecida até o momento em que a composição deve ser oferecida, ou não é uma requisição que ocorre com frequência e por isso não há composições previamente conhecidas para satisfazê-la. Nessas situações, caso as capacidades dos serviços sejam conhecidas pela máquina, é possível realizar a composição automaticamente, combinando-se as capacidades dos serviços para atender a requisição. É a chamada composição automática de serviços. 
Existem alguns desafios na composição automática de serviços no tocante à padronização das informações entre provedores. Cada provedor de serviço possui sua nomenclatura própria, e portanto não há garantias de que o vocabulário utilizado nos nomes dos serviços, operações e parâmetros de entrada e saída dos diversos provedores será uniforme. Faz-se necessário, portanto, uma padronização dos conceitos e do vocabulário dos provedores.

Por exemplo, ao contabilizar um valor de entrega, uma livraria virtual pode utilizar o termo "entrega", enquanto os correios podem utilizar o nome "frete" para representar a mesma ideia. O mecanismo que realiza a composição automática de serviços precisa compreender, por exemplo, que o conceito "entrega" do serviço da livraria é equivalente ao conceito "frete" do serviço de entrega dos correios, para que possa integrar os serviços corretamente. Diversas propostas de composição automática utilizam ontologias para resolver o problema da padronização dos nomes utilizados nos serviços, suas operações e parâmetros (Lin, Guo e Yin (2005), Silva et al. (2008), Li et al. (2007), Wu et al. (2010), Silva, Pires e van Sinderen (2007), Li e Wu (2009)).

\subsubsection{Ontologias e serviços semânticos}

Uma ontologia é uma representação explícita de uma conceitualização compartilhada (Gruber, 1993), ou seja, é uma forma de representar-se conceitos de maneira explícita (por exemplo, através de um documento) para que possam ser compartilhados e servir de base semântica comum para diversos utilizadores.

Uma ontologia é formada por conceitos, e cada conceito relaciona-se a um conceito-pai por uma relação do tipo é-um (conceito filho é-um tipo especializado do conceito-pai). Há apenas um único conceito na ontologia, denominado conceito-raiz, que não possui pai. Desta forma, uma ontologia pode ser representada na forma de árvore, cuja raiz é o conceito-raiz e cada conceito está associado ao seu conceito-pai através de uma aresta, como mostrado na figura 5. 


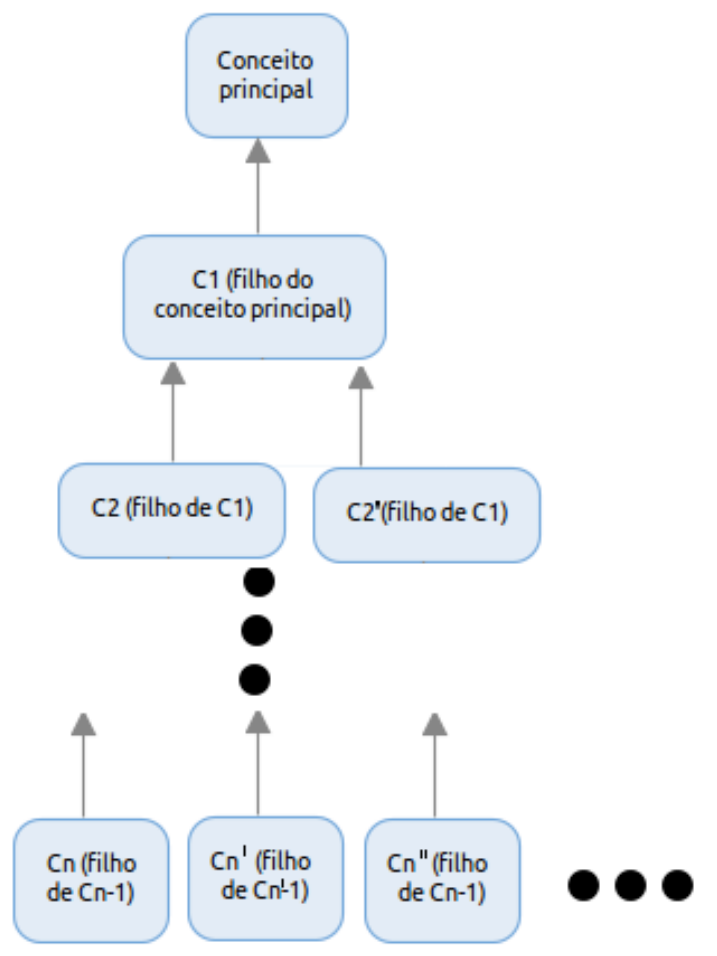

Figura 5. Representação em árvore dos conceitos de uma ontologia

Através de uma ontologia pode-se representar a palavra "entrega", por exemplo, de modo que deixa de ser apenas uma palavra e passa a representar o conceito próprio, aquilo que uma entrega significa, ou seja, atribui-se um valor semântico à palavra. Existem linguagens específicas como o OWL (W3 CONSORTIUM, 2009) e o OWL-S (W3 CONSORTIUM, 2004) que representam ontologias em computadores, desta maneira tornando esses conceitos compreensíveis à máquina.

Um serviço semântico é um serviço cujas operações, parâmetros de entrada e parâmetros de saída estão associados a conceitos de uma ontologia, e portanto as capacidades do serviço são compreensíveis à máquina. Facilita-se alguns passos do ciclo de vida de uma arquitetura orientada a serviços (tais como a descoberta de serviços e a composição de serviços) dadas as relações entre os conceitos da ontologia e o fato de que outros serviços estão também associados à mesma ontologia. 
2.1.4.2 Importância da ontologia na composição automática de serviços

Na composição automática de serviços a ontologia é usada para que a máquina possa compreender tanto a requisição quanto os serviços e, portanto, é o que viabiliza que serviços possam ser detectados como candidatos a satisfazer uma requisição.

Especificamente no caso onde a requisição é expressa em linguagem natural, a ontologia torna-se um elemento central para a realização da composição. Supondo-se que as palavras de uma requisição são expressas em linguagem natural, é possível buscar-se em uma ontologia os conceitos cujo nome é igual às palavras da requisição. Sendo assim, dada uma requisição contendo uma palavra $\mathrm{P}$, pode-se buscar na ontologia pelo conceito de nome "P", sub-conceitos de "P" e super-conceitos de "P". Da mesma forma, pode-se buscar no repositório por serviços cujas operações e parâmetros estejam associados a algum desses conceitos.

Portanto, é através da busca por conceitos da ontologia que as palavras da requisição são compreendidas pela máquina e também através da ontologia que os serviços são buscados para realizar a composição.

Supondo-se um sistema em que as requisições são passadas em linguagem natural, cada palavra da requisição pode ser associada a um conceito ontológico, como mostrado na figura 6. Sendo assim, nota-se que as palavras da requisição fornecem possíveis conceitos de uma ontologia, e através dessas palavras a máquina poderá interpretar o desejo que está sendo expresso pelo usuário.

Por exemplo, na requisição "calcule o frete para o pedido 15", cada palavra pode estar associada a um conceito ontológico, por exemplo, aos conceitos cálculo, frete e pedido. 


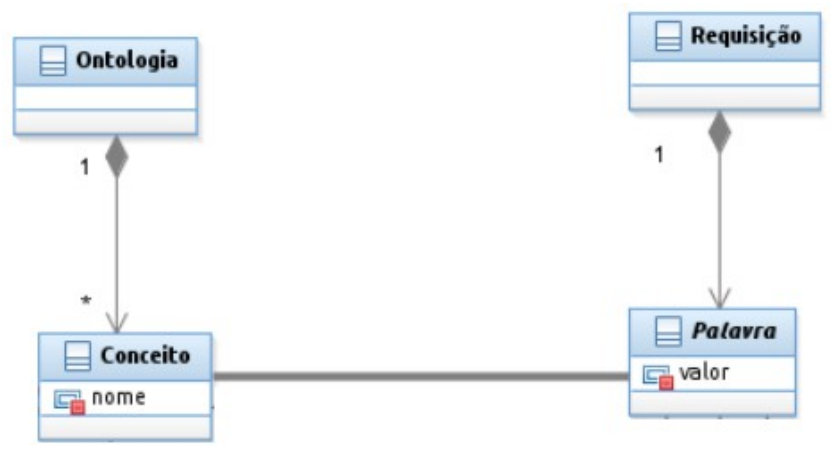

Figura 6. Associação entre requisição e conceitos ontológicos

Na figura 7 há um diagrama UML que representa a associação entre operações e parâmetros de entrada e saída com conceitos de uma ontologia. Através de um determinado conjunto de conceitos, pode-se buscar serviços associados a esses conceitos para uma potencial composição. No caso da composição automática com linguagem natural, pode-se usar os próprios conceitos vindos da requisição.

Por exemplo, um serviço semântico de entrega que contém a operação calcularValorFrete() pode receber um parâmetro de entrada associado ao conceito ontológico frete.

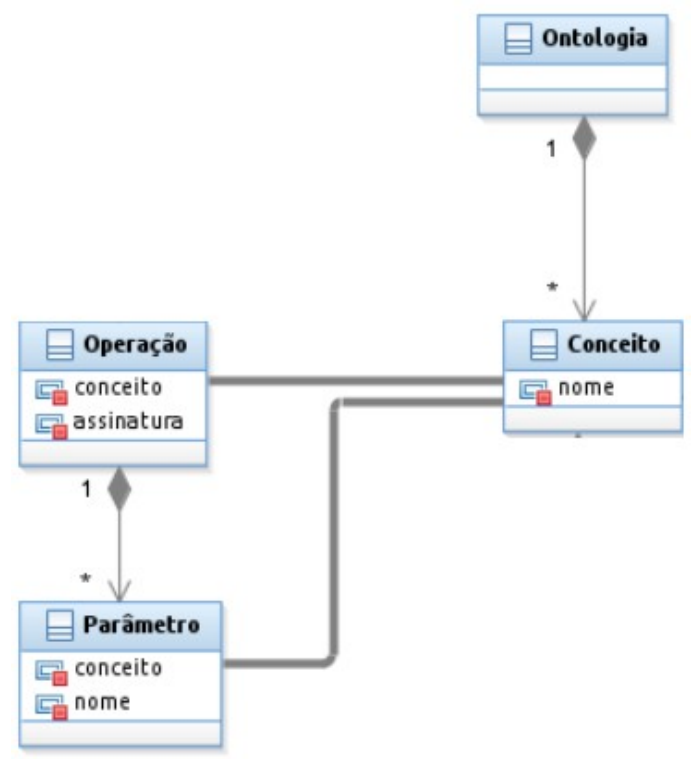

Figura 7. Associação entre operações, parâmetros e conceitos ontológicos 
Desta maneira, é possível buscar por serviços que utilizem os mesmos conceitos presentes na requisição e, assim, gerar composições associadas à requisição. Nota-se que o conceito, portanto, atua como um veículo, ou como um produto intermediário, fornecido pela requisição e consumido pelo mecanismo que realiza a composição automática.

\subsection{PROCESSO DE APLICAÇÃO DA COMPOSIÇÃO AUTOMÁTICA}

Silva et al. (2008) definem o ciclo de vida da composição automática para serviços semânticos, mostrado na figura 8 - mostra-se a vida de uma composição de serviços desde a especificação da requisição até a execução da composição gerada, que deixa de existir após a execução.

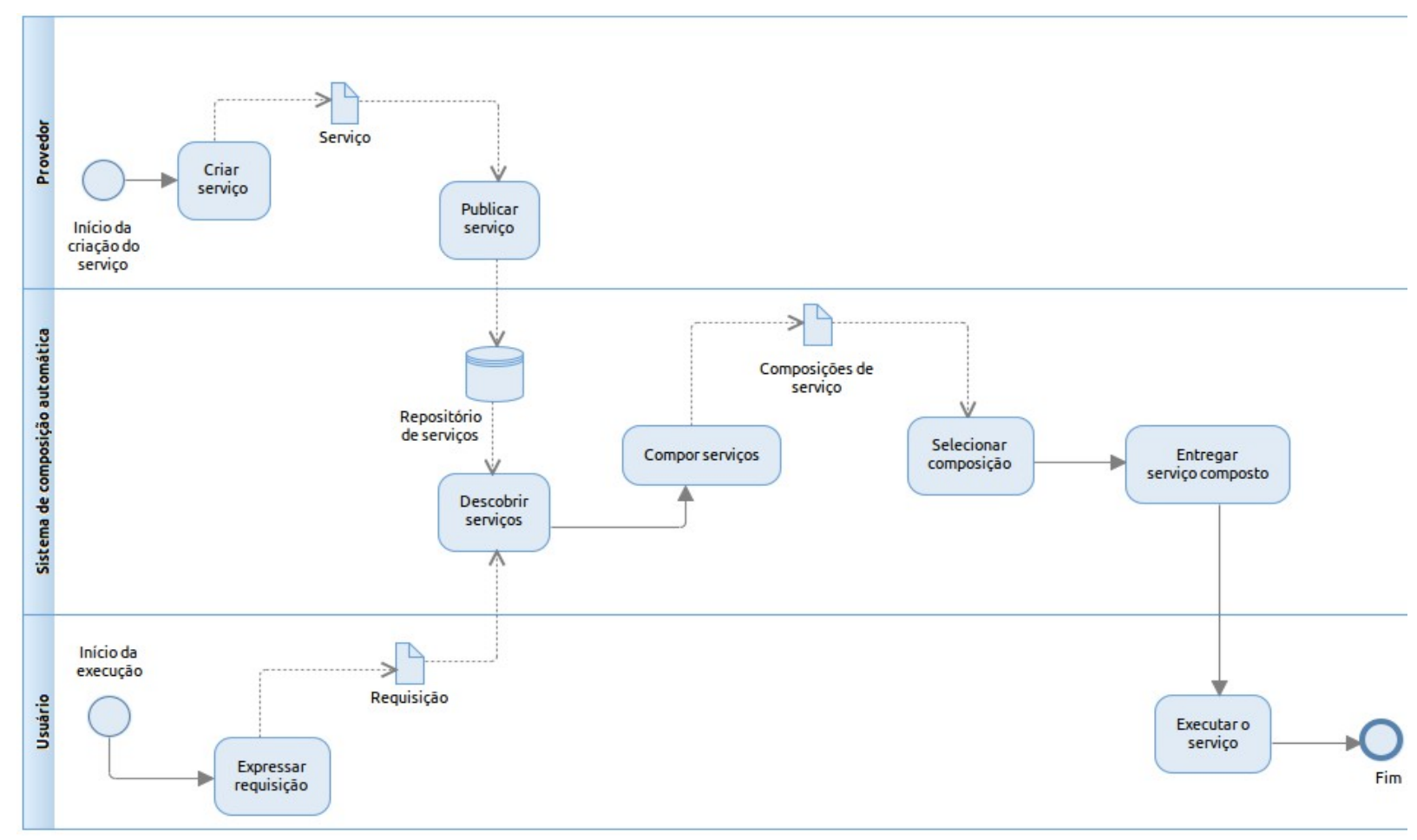

Figura 8. Ciclo de vida da composição automática de serviços

Nota-se que do ponto de vista do provedor o processo de criação e publicação de um 
serviço é equivalente ao de uma arquitetura de serviços semânticos sem composição automática, com a criação e publicação do serviço no repositório de serviços. Para o sistema de composição automática e o usuário que expressa sua requisição, algumas etapas são diferenciadas: a requisição do serviço, a composição de serviços dos serviços e a seleção da composição de serviços realizada. Essas três etapas serão detalhadas nas seções 2.2.1 e 2.2.2.

\subsubsection{Requisição do serviço}

A requisição do serviço pode ser expressa de diferentes maneiras, como será descrito nesta seção, de acordo com o tipo de usuário e o objetivo do sistema. Sistemas que servem operações entre empresas, por exemplo, podem ser operados por usuários especializados que especificam a interface (entradas e saídas) do serviço final que desejam; sistemas que servem usuários finais geralmente possuem um mecanismo de maior usabilidade para a especificação da requisição.

A especificação da requisição em alguns casos é realizada sintaticamente. Nestes casos o usuário descreve diretamente os parâmetros de entrada e saída que deseja nas operações do serviço final. O mecanismo de composição automática buscará por serviços que recebem as entradas e fornecem as saídas especificadas pelo usuário e tentará compô-los.

Em outros casos, a especificação se dá semanticamente. Nestes casos, a requisição é interpretada pela máquina e mapeada para conceitos de uma ontologia. O objetivo é que a requisição possa ser passada de maneira menos técnica em comparação com a requisição sintática, e que o significado da requisição seja compreendido automaticamente pela máquina. 
2.2.1.1 Requisição especificada sintática e manualmente

Pode-se realizar a requisição da maneira mais concreta possível, isto é, o usuário especifica os parâmetros de entrada e saída, capacidades e parâmetros de qualidade do serviço que deseja e o sistema busca e compõe automaticamente um serviço que realize a tarefa com tais características.

Em Liu, Peng e Chen (2006) e Lin, Guo e Yin (2005), por exemplo, o usuário especifica um "serviço objetivo" (goal service), ou seja, o serviço final que deseja em termos de parâmetros de entrada, saída, capacidades, restrições e qualidade de serviço. O sistema busca diversos serviços e cria composições para atingir esse objetivo - ao gerar uma composição de serviços equivalente à especificação passada, essa composição de serviços é oferecida ao usuário.

\subsubsection{Requisição especificada sintaticamente utilizando templates}

Um template é um modelo abstrato pré-definido de composição de serviços. Abstrato porque define em alto nível a capacidade da composição de serviços, no entanto sem especificar quais serviços específicos realizarão as sub-tarefas. Pré-definido porque ele existe anteriormente à execução do software, e deve ser selecionado pelo usuário. $\mathrm{O}$ usuário seleciona o template que deseja e o sistema escolhe os serviços que irão preencher o template em tempo de execução. Neste caso a requisição é pré-definida e a composição é realizada automaticamente.

A abordagem em templates é encontrada em algumas pesquisas de composição automática de serviços como em Doshi et al. (2004), Sivashanmugem et al. (2004) e Liu (2010). Duas desvantagens dos sistemas baseados em templates são a complexidade da criação de novos templates e a necessidade de criação de um template caso um template adequado não seja encontrado de antemão. 
Segundo Eid et al. (2008), tais sistemas são mais adequados para aplicações businessto-business (tanto o provedor quanto o consumidor final do serviço são empresas), onde as interações são geralmente repetitivas e recorrentes, mas menos adequados para aplicações móveis onde as requisições tendem a evoluir em tempo real.

2.2.1.3 Requisição semântica baseada em linguagem natural

A requisição pode ser expressa através de linguagem natural. Nessa abordagem as palavras são mapeadas para uma ontologia do domínio ao qual pertence o sistema. No modelo de Fujii e Suda (2009) captura-se palavras-chave expressas em linguagem natural e busca-se no repositório serviços que utilizam essas palavras como parâmetros de entrada e saída. A especificação da requisição obedece a uma regra de construção fixa:

\section{Requisição $=$ Verbo Substantivo (Ligação Substantivo) ${ }^{*}$}

Os elementos da regra entre parênteses deve vir necessariamente juntos, e o asterisco indica que a multiplicidade pode ser de zero ou mais elementos. Sendo assim, pode-se ler a expressão como "um requisito equivale a um verbo seguido de um substantivo seguidos de zero ou mais conjuntos contendo uma ligação seguida de um substantivo". Uma ligação é geralmente uma preposição, e sua função é a de qualificar um substantivo ao ligá-lo a outro. $\mathrm{Na}$ ontologia as ligações servem para associar dois conceitos. Por exemplo, a ligação "from" pode associar os conceitos "direction" e "origin", indicando que uma direção parte "de uma" origem; a ligação "to" pode associar os conceitos "direction" e "destination", indicando que uma direção vai "para um" destino.

Um exemplo de requisição é a frase "Show directions from office to home". A requisição seria interpretada da seguinte maneira: 
Tabela 1. Exemplo de construção de requisição em linguagem natural

\begin{tabular}{|c|c|}
\hline Palavra & Símbolo na construção \\
\hline show & verbo \\
\hline direction & substantivo \\
\hline from & ligação \\
\hline office & substantivo \\
\hline to & ligação \\
\hline home & substantivo \\
\hline
\end{tabular}

Neste caso as ligações from e to (ambas preposições) qualificam os substantivos office e home, indicando que a direção pedida possui origem em office e destino em home.

\subsubsection{Descoberta e composição de serviços}

O mecanismo de busca e descoberta de serviços pode também se basear na sintaxe ou semântica que vem do mecanismo de requisição.

2.2.2.1 Descoberta e composição de serviços de forma sintática

$\mathrm{Na}$ composição de serviços realizada sintaticamente, como a requisição também é especificada sintaticamente, sabe-se de antemão a interface (entradas e saídas) do serviço que o usuário deseja. Primeiramente, busca-se por um ou mais serviços capazes de fornecer as saídas desejadas e receber as entradas desejadas. De posse dos serviços que contem as entradas e saídas especificadas, é necessário combinar estes serviços em uma composição, podendo ser necessário também compor outros serviços entre eles. Essa abordagem é vista em Liu, Peng e Chen (2006) e Lin, Guo e Yin (2005). 


\subsubsection{Descoberta semântica}

Em sistemas de composição automática baseados em semântica tanto a requisição quanto os serviços estão associados a conceitos ontológicos. Primeiramente a requisição é mapeada para conceitos ontológicos. O mecanismo de descoberta, como visto na figura 8, busca em um repositório os serviços semânticos associados a esses conceitos vindos da requisição.

Na figura 9 pode-se ver um diagrama de classes da UML que representa o mecanismo de descoberta de serviços semânticos no modelo de Fujii e Suda (2009), onde a requisição é expressa em linguagem natural.

O retângulo pontilhado 1 (à esquerda) contem os elementos da etapa de descoberta relacionados aos serviços. Um serviço atômico é composto por ao menos uma operação. Uma operação possui uma assinatura e é composta por zero ou mais parâmetros de entrada ou saída.

O retângulo central (2) representa os elementos da etapa de descoberta relativos à base semântica. Uma ontologia é composta por conceitos. Todo conceito possui um nome e pode estar associado a outros conceitos pela relação de especialização, ou relação é-um. Na proposta de Fujii e Suda (2009) todo conceito pode ainda possuir a propriedade de atuar como curinga. Conceitos que atuam como curinga são considerados no passo de descoberta como substitutos (ou similares) a quaisquer outros conceitos da ontologia.

O retângulo da direita (3) representa os elementos da etapa de descoberta relativos à requisição expressa em linguagem natural. Toda requisição é composta por duas ou mais palavras, conforme a regra Requisição = Verbo Substantivo (Ligação Substantivo)*. Verbo, substantivo e ligação são todos subtipos de palavra. Cada palavra possui um valor, que é o conteúdo da palavra em si (uma cadeia de caracteres).

Nota-se na figura 9 que a ligação entre os elementos relativos aos serviços e os 
elementos relativos à requisição acontece através do conceito, isto é, ele é o único elemento comum associado aos retângulos da esquerda e da direita. $\mathrm{O}$ conceito é um elemento fundamental num sistema de composição automática, pois é o caminho entre a requisição e a composição final de serviços.

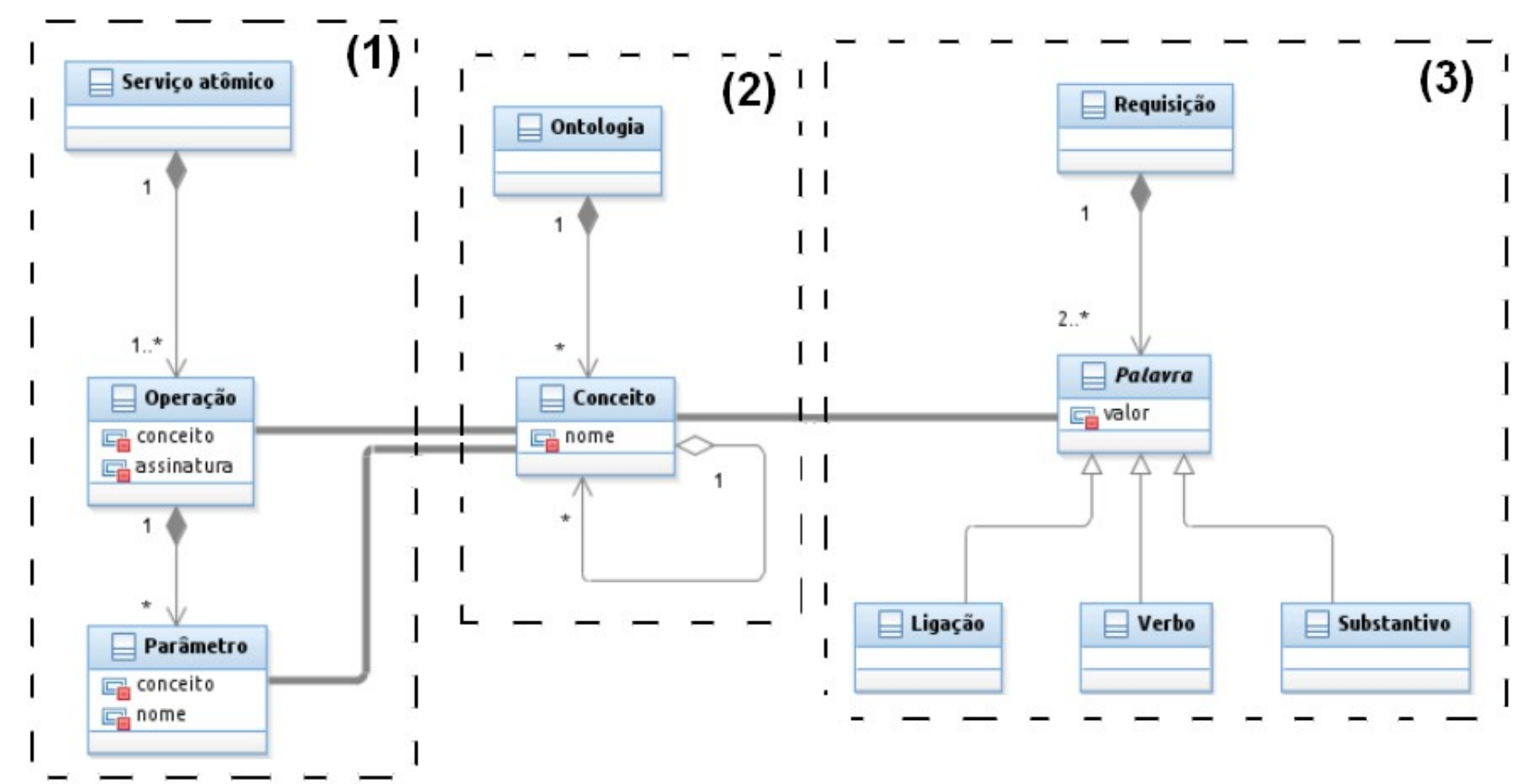

Figura 9. Diagrama de classes das relações entre requisição, ontologia e serviços semânticos

\subsubsection{Composição automática baseada em semântica}

O mecanismo de composição automática de serviços possui a tarefa de gerar composições a partir dos serviços semânticos descobertos no repositório de serviços e da especificação da requisição. A presente pesquisa foi baseada no trabalho de Fujii e Suda (2009), cujo principal passo do algoritmo de composição automática é um algoritmo chamado complementação de entradas. Este algoritmo busca por elementos que possam alimentar uma operação, isto é, fornecer seus parâmetros de entrada. Estes elementos podem ser saídas de operações de outros serviços ou palavras da própria requisição, caso o parâmetro de entrada seja do tipo curinga. Ao se complementar as entradas de um determinado serviço $A$ com um serviço $B$, o serviço $B$ também necessitará de 
complementos, e assim por diante, o que faz com que o algoritmo de complementação de entradas possua, geralmente, natureza recursiva. Os complementos devem estar de acordo com a semântica expressa na requisição.

No trabalho de Fujii e Suda (2009) a composição automática de serviços é realizada nos seguintes passos abaixo, que estão detalhados incluindo os passos de requisição e descoberta para melhor entendimento:

1. A requisição é expressa em linguagem natural segundo a regra Requisição $=$ Verbo Substantivo (Ligação Substantivo)*. Caso a requisição não respeite esta regra, ela será rejeitada e o software deve retornar um erro.

2. Caso a requisição seja aceita, é iniciado o passo de descoberta. São buscados serviços que possuem operações e parâmetros de entrada e saída associados a conceitos cujos nomes são iguais aos valores das palavras da requisição.

3. Inicia-se o algoritmo de composição automática, cujo primeiro passo é o algoritmo de complementação de entradas para o serviço $S_{1}$ associado ao verbo da requisição.

4. Se o elemento for a saída de uma operação de um serviço $S_{2}$, será necessário também alimentar os parâmetros de entrada da operação de $S_{2}$. Os serviços tem suas entradas complementadas recursivamente até que não seja mais necessário complementar entradas.

5. São checadas as ligações entre conceitos para garantir que a complementação de entradas está de acordo com a semântica da requisição.

Por exemplo, dada a requisição expressa em linguagem natural mostrada na tabela 1:

\section{Show directions from office to home}

- No passo 1 é testado se a requisição está de acordo com a regra de construção. É checado na ontologia se a palavra "show" (que deve ser um verbo) existe na ontologia como um verbo, se as palavras "direction", "office", "home", "from" e "to" existem como conceitos. 
- No passo 2 inicia-se o passo de descoberta. São buscados todos os serviços que contem ao menos uma operação associada ao conceito "show", todos os serviços que contem parâmetros de entrada e saída associados aos conceitos "direction", "office" e "home". Suponha que foram encontrados os seguintes serviços:

- Serviço DisplayDirection, que contem:

- operação showlmage(), associada ao conceito "show" (mostra na tela de um computador um mapa entre duas localidades), que:

- recebe um parâmetro de entrada que representa o conceito "direction";

- Serviço DirectionGenerator, que contem:

- operação generate() (gera as direções entre uma origem e um destino), que:

- recebe dois parâmetros de entrada chamados "origin" e "destination" que representam o conceito "address"

- fornece um parâmetro de saída que representa o conceito "direction"

- Serviço Agenda, que contem:

- operação getAddress(), que:

- fornece um parâmetro de saída que representa o conceito "address"

- recebe um parâmetro de entrada que representa o conceito "string" (curinga)

- No passo 3 inicia-se o algoritmo de complementação de entradas pelo serviço associado ao verbo da requisição, isto é, o serviço DisplayDirection. É preciso complementar as entradas da operação showlmage(). Essa operação possui apenas um parâmetro de entrada, que representa o conceito "direction". Dentre os serviços encontrados no passo 2, apenas o serviço DirectionGenerator pode complementar DisplayDirection. Sendo assim, já se sabe que a interface de saída de DirectionGenerator estará ligada à interface de entrada de DisplayDirection.

- No passo 4 o algoritmo detecta se ainda há entradas que devem ser complementadas, e no caso há. O serviço DirectionGenerator fornece entradas 
para DisplayDirection, mas ele recebe dois parâmetros de entrada ("origin" e "destination") que representam o conceito "address", e ainda não se sabe como esses parâmetros serão alimentados. Novamente se complementa as entradas desse serviço, e portanto a operação getAddress() do serviço Agenda pode complementar o serviço DirectionGenerator.

- Ainda no passo 4, a operação getAddress(), por sua vez, também precisa ter seus parâmetros de entrada complementados. Este é um caso em que as entradas do serviço representam o conceito "string" - neste caso especial, por ser um curinga, é possível utilizar as palavras vindas da requisição como entrada, e portanto "office" e "home" são utilizados para complementar o serviço Agenda. Nota-se que agora não há mais necessidade de complementação de entradas. Nota-se também que tanto "office" como "home" podem servir como strings e, portanto, ainda não se garantiu que as direções geradas tem "office" como origem e "home" como destino - esta checagem faz parte do passo de verificação semântica

- No passo 5 é feita a verificação semântica das composições geradas em relação à composição. No passo 4, como "office" e "home" são strings (e portanto, curingas), quatro composições foram consideradas candidatas, porém nem todas estão de acordo com a requisição. É possível que as composições geradas possuam qualquer combinação de origem e destino, e portanto resolvam outras requisições como por exemplo:

- Print direction from office to office

- Print direction from home to home

- Print direction from home to office

É durante a verificação semântica que são processados as ligações e substantivos da requisição. Na ontologia as ligações também são conceitos, e servem como associação entre dois outros conceitos. No exemplo, pode-se dizer que o conceito "direction" possui duas ligações, "from" e "to", sendo que ambas associam o conceito "direction" a um conceito "address" - semanticamente, portanto, está-se representando que uma direção é sempre de um endereço para outro endereço. 


\subsection{FUNDAMENTOS DA SIMILARIDADE ENTRE CONCEITOS}

A similaridade é uma medida que representa o grau de semelhança entre dois conceitos ontológicos. Nesta seção será feita uma revisão sobre a similaridade entre conceitos ontológicos.

\subsubsection{Cálculo de similaridade}

Existem propostas que calculam o grau de semelhança (similaridade) entre serviços semânticos e entre conceitos de ontologia. O cálculo da similaridade entre serviços se dá também utilizando a similaridade entre os conceitos ontológicos, porém a similaridade é consolidada em um único valor que representa a similaridade entre os dois serviços integralmente.

Ganjisaffar et al. (2006) propuseram um método para medir a similaridade entre conceitos ontológicos. Supondo-se uma árvore de conceitos ontológicos como mostrado na figura 10, considera-se:

- I(c): a distância entre um conceito c e a raiz da ontologia (adimensional). Pode-se definir a distância à raiz de maneira recursiva: a distância do conceito raiz à raiz é 0 , e $\mathrm{I}\left(\mathrm{c}_{\mathrm{a}}\right)=\mathrm{I}\left(\mathrm{c}_{\mathrm{b}}\right)+1$, se $\mathrm{c}_{\mathrm{a}}$ está ligado diretamente $\mathrm{a} \mathrm{c}_{\mathrm{b}}$ na árvore, isto é, herda diretamente do conceito $\mathrm{c}_{\mathrm{b}}$, sem conceitos intermediários

- $\omega(\mathrm{c})$ : peso de um conceito c. O peso de um conceito é dado pela fórmula:

$$
\omega(c)=\frac{1}{2^{l(c)+1}}
$$

Nota-se que o peso diminui exponencialmente à medida que sua distância até a raiz aumenta. 
- Considere-se a relação de parentesco, dada de forma recursiva: a raiz é parente de todos os conceitos da ontologia. Se $c_{a}$ é filho de $c_{b}, c_{b}$ e todos os parentes de $c_{b}$ são parentes de $\mathrm{c}_{\mathrm{a}}$.

- $\operatorname{ccp}\left(\mathrm{C}_{1}, \mathrm{C}_{2}\right)$ : parente mais próximo comum a $\mathrm{c}_{1}$ e $\mathrm{C}_{2}$. O parente mais próximo comum a $c_{1}$ e $c_{2}$ é o conceito que é parente de $c_{1}$ e $c_{2}$ simultaneamente com menor distância à raiz.

- $\delta\left(\mathrm{C}_{1}, \mathrm{C}_{2}\right)$ : distância ponderada entre dois conceitos. É uma distância relativa entre conceitos, e depende da distância à raiz e do conceito herdado comumente por $\mathrm{c}_{1}$ $\mathrm{e}_{2}$ mais distante da raiz. É dada pela fórmula:

$$
\delta\left(c_{1}, c_{2}\right)=\left[\omega\left(c c p\left(c_{1}, c_{2}\right)\right)-\omega\left(c_{1}\right)\right]+\left[\omega\left(c c p\left(c_{1}, c_{2}\right)\right)-\omega\left(c_{2}\right)\right]
$$

- $\sigma\left(\mathrm{c}_{1}, \mathrm{C}_{2}\right)$ : similaridade entre os conceitos $\mathrm{c}_{1}$ e $\mathrm{c}_{2}$, calculada a partir da distância ponderada entre os conceitos

$$
\sigma\left(c_{1}, c_{2}\right)=1-\delta\left(c_{1}, c_{2}\right)
$$

Na figura 10 pode-se ver um exemplo de cálculo de similaridade conceitual pelo modelo de Ganjisaffar et al. (2006). É calculada a similaridade entre os conceitos Caminhão e Carro esportivo.

- $\mathrm{I}($ Veículo $)=0$ (raiz) $\mathrm{I}($ Caminhão $)=1, \mathrm{I}($ Carro esportivo $)=2$

- A função $\omega(n)$ calcula o peso dos conceitos na ontologia. $\omega$ (Veículo) $=1 / 2=0,5$; $\omega($ Caminhão $)=1 /\left(2^{1+1}\right)=0,25 ; \omega$ (Carro esportivo $)=1 /\left(2^{2+1}\right)=0,125$.

- O parente mais próximo comum a Caminhão e Carro esportivo é o conceito Veículo. $\delta($ Caminhão, Carro esportivo $)=[\omega($ Veículo $)-\omega($ Caminhão $)]+[\omega($ Veículo $)$ $-\omega$ (Carro esportivo)] $=0,625$.

A similaridade entre os conceitos Caminhão e Carro esportivo é, portanto, $\sigma\left(\mathrm{c}_{1}, \mathrm{C}_{2}\right)=1-$ $\delta\left(\mathrm{c}_{1}, \mathrm{C}_{2}\right)=0,375$ 


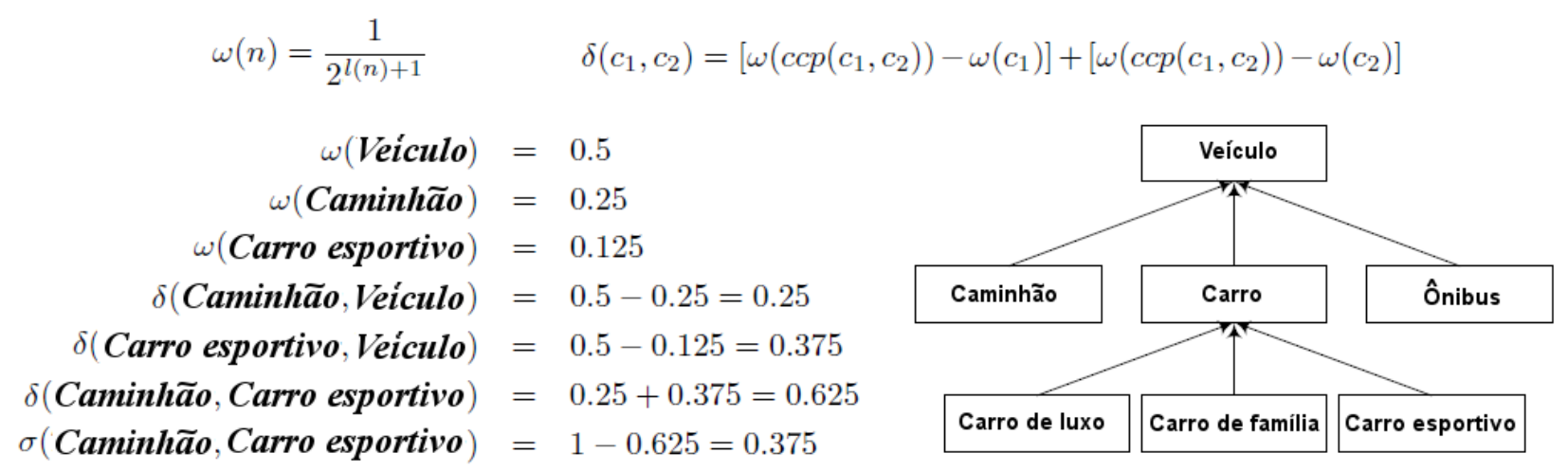

Figura 10. Exemplo de cálculo de similaridade entre conceitos

Extraído de Ganjisaffar et al. (2006)

2.3.2 Consideração sobre a proposta do uso da similaridade

Pesquisas atuais de composição automática de serviços utilizam a similaridade para gerar e verificar composições (FUJII E SUDA, 2009). No entanto, a similaridade é utilizada para a verificação das composições ou em situações limitadas ao nível de serviços e não com o intuito de gerar novas composições que automatizarão processos de negócio alternativos.

Seja $\mathrm{R}$ uma requisição de usuário em um sistema de composição automática de serviços e considere-se um universo de processos de negócio: $\{$ PN1, PN2, PN3, PN4 e PN5 $\}$. Suponha que os processos de negócio PN2, PN3 e PN5 resolvam a requisição $\mathrm{R}$, como mostrado na figura 11.

Suponha que um sistema de composição automática de serviços encontrou uma composição de serviços $\mathrm{C} 1.1$ que atende à requisição $\mathrm{R}$ ao automatizar o PN5, como mostrado na figura 12. No entanto, um dos serviços da composição de serviços $\mathrm{C} 1.1$ não está disponível, porém uma composição de serviços C1.2, que também automatiza PN5, possui todos os serviços disponíveis. Sistemas atuais de composição automática de serviços possuem suporte para reconhecer a similaridade entre C1.1 e C1.2, como 
mostrado na figura 12, isto é, modelos atuais de composição automática possuem suporte à similaridade no nível dos serviços.

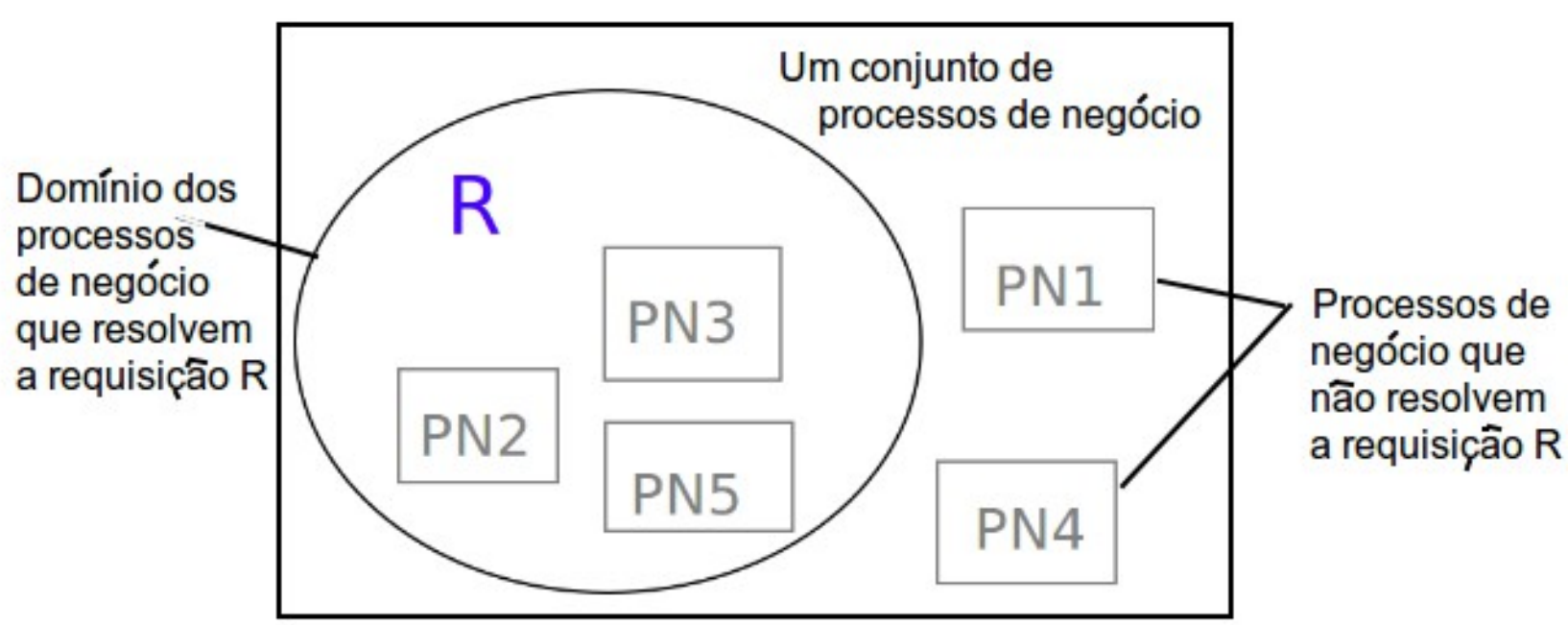

Figura 11. Requisição R que pode ser resolvida pelos processos de negócio PN2, PN3 e PN5

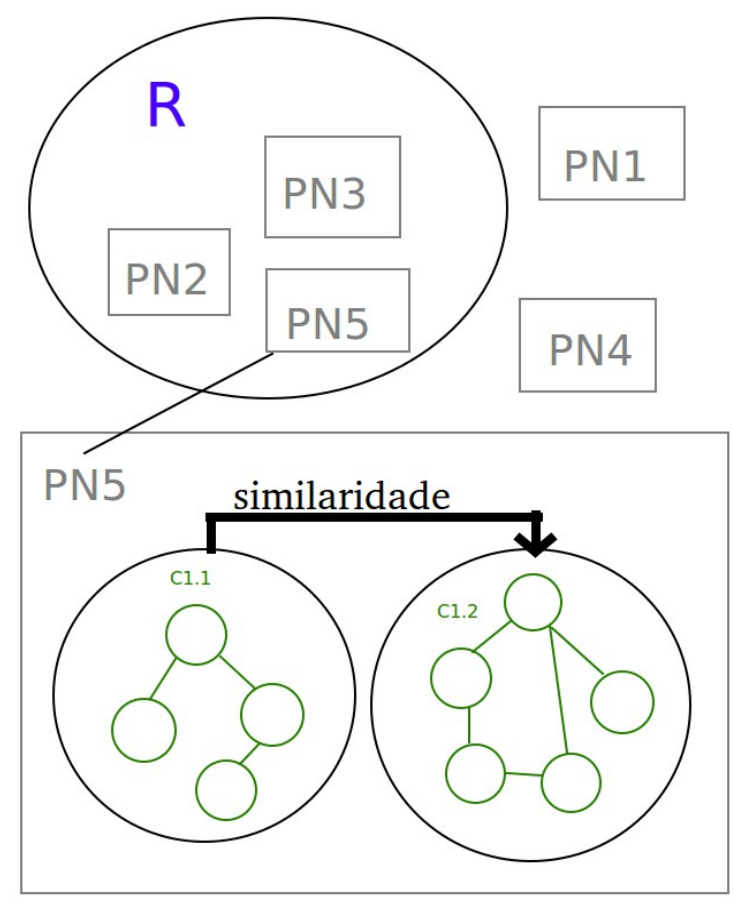

Figura 12. Similaridade utilizada em sistemas atuais

Uma funcionalidade não encontrada nos modelos atuais de composição automática de serviços é a de detectar não apenas composições similares que automatizam um mesmo processo de negócio, mas também outros processos de negócio que podem servir como 
uma alternativa caso alguns dos serviços não possam ser compostos. Isto é, modelos atuais de composição automática há pouco ou nenhum suporte à similaridade no nível dos processos de negócio.

Suponha, por exemplo, que o processo de negócio PN1 atende parcialmente a requisição R. Na indisponibilidade das duas composições $\mathrm{C} 1.1$ e C1.2, como mostrado na figura 13, podem ser encontradas composições que resolvem $\mathrm{R}$ parcialmente do ponto de vista de funcionalidade ou de qualidade, e que estão associados a PN1.

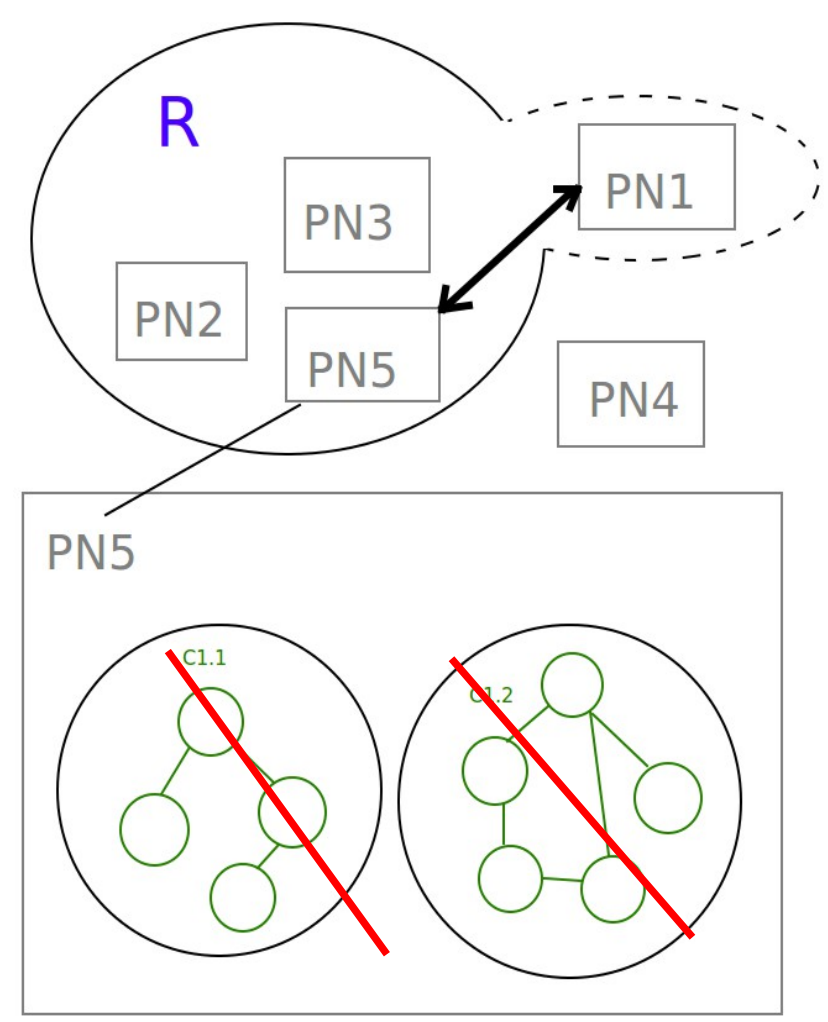

Figura 13. O processo de negócio PN1 resolve parcialmente a requisição R, pois C1.1 e C1.2 estão indisponiveis 


\section{MODELO DE COMPOSIÇÃO AUTOMÁTICA COM SIMILARIDADE NO NÍVEL DE NEGÓCIOS}

Neste capítulo será mostrada a proposta de modelo arquitetural básico de composição automática de serviços com similaridade. O modelo aqui proposto foi inspirado na pesquisa de composição automática de serviços utilizando linguagem natural e semântica de Fujii e Suda (2009), na pesquisa de similaridade entre conceitos de Ganjisaffar et al. (2006) e sistemas de composição automática de serviços para o domínio do turismo.

\subsection{CONCEPÇÃO DO MODELO}

Nesta seção será explicado como o modelo foi concebido a partir das teorias de composição automática de serviços e similaridade conceitual.

3.1.1 Requisitos da pesquisa que levaram à concepção do modelo

A presente pesquisa possui como requisito a criação de um modelo de composição automática de serviços capaz de atender a requisições expressas em linguagem natural. Essas requisições devem ser compreendidas pela máquina para que as composições possam ser geradas, e ontologias são usadas para este propósito. Além disso, o modelo deverá permitir que composições de serviço alternativas possam ser geradas através do uso de similaridade, e que essas composições alternativas possam estar associadas a processos de negócio alternativos. Desta forma os processos de negócio poderão atender a apenas parte da requisição original expressa em linguagem natural, ou ainda se desviarem ligeiramente da requisição original, atendendo de maneira alternativa à necessidade expressa na requisição. 
Um modelo de composição automática de serviços onde as requisições são expressas em linguagem natural e compreendidas através de uma ontologia foi encontrado na proposta de Fujii e Suda (2009). Tal modelo, no entanto, não possui suporte à utilização de similaridade para gerar processos de negócio alternativos.

Dentre os modelos mais recentes de composição automática de serviços estudados (Bilbao e Herrero (2009) e Paganelli, Parlanti e Giuli (2010), Fujii e Suda (2009), Markou e Refanidis (2012), Feng, Veeramani e Kanagasabai (2012), Ordonez, Corrales e Falcarin (2012)), alguns geravam composições alternativas associadas a um mesmo processo de negócio, e em todos os casos faziam o cálculo da similaridade entre os serviços compostos, e não entre os conceitos associados à requisição. Para que haja similaridade nas composições é interessante variar-se as palavras da própria requisição associadas a conceitos da ontologia, e para isso se faz necessário utilizar um modelo de cálculo de similaridade entre conceitos ontológicos, em vez de um modelo de cálculo de similaridade entre serviços. Um modelo de cálculo de similaridade entre conceitos ontológicos, aos moldes do requisito da presente pesquisa, foi encontrado na proposta de Ganjisaffar et al. (2006).

Faz-se necessária a integração entre o modelo de composição automática de serviços e o modelo de cálculo de similaridade conceitual, de maneira a utilizar-se a similaridade conceitual durante o processo de composição para a geração de novas composições, que satisfazem a requisição expressa ou requisições variantes da original.

\subsubsection{Teoria linguística das frases imperativas}

Foi realizada uma pesquisa na área da teoria linguística, com objetivo de compreender como a variação dos conceitos da ontologia deveria ser feita. Como os conceitos ontológicos são alimentados pelas palavras da requisição, e a requisição do vem na forma de uma frase imperativa (isto é, o verbo da requisição está conjugado no imperativo) pesquisou-se sobre a semântica de frases imperativas e suas relações 
potenciais com a composição automática de serviços.

Na teoria linguística, Kenny (1966) define o critério da preservação do desejo nas frases imperativas. Segundo o autor, as frases imperativas não carregam inferências verdadeiras ou falsas (ou seja, não são verdadeiras ou falsas), mas sim desejos daquele que profere a frase (imperador). Este desejo pode ser transformado em uma sentença declarativa do tipo "A deseja que B faça isto". Neste sentido, diz-se que A possui um conjunto de desejos e B possui um conjunto de mudanças possíveis para satisfazer 0 desejo de A.

Uma frase imperativa representa um desejo de A para que um desejo seja atendido através de uma ação de $B$ que provoca uma mudança de estado. Um estado é uma determinada condição em que se encontra aquilo sobre o que recai o desejo. Tanto $A$ quanto B são chamados agentes. Um agente é um elemento que possui um desejo por uma mudança de estado ou que é capaz de realizar uma mudança de estado.

Na figura 14 pode-se ver dois agentes: A, que deseja uma mudança de estado (de "porta aberta" para "porta fechada") e B, que é capaz de realizar uma mudança de estado (fechar a porta).

declaraçôes

A-> "Feche a porta"-> B

A quer que $B$ feche a porta dominio do discurso

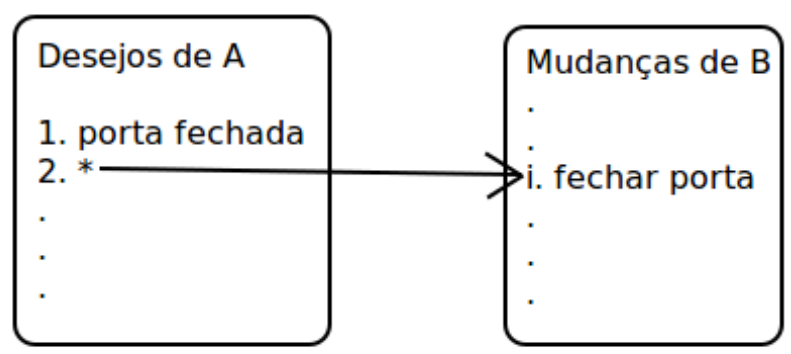

Figura 14. Lógica imperativa 
Sendo assim, na lógica de frases imperativas tem-se:

- Um conjunto de estados $S=\{r, s, t, \ldots\}$

- Um conjunto de agentes $A=\left\{a_{1}, a_{2}, \ldots, a_{n}\right\}$, capazes de provocar mudanças de estado

- $\quad$ A definição de desejo $D\left(a_{i}\right)=(s, u)$

- No estado $\mathrm{s}$, o agente $a_{i}$ quer atingir o estado $u$

- $A$ definição de mudança $M\left(a_{i}\right)=(s, u)$

- No estado s, o agente $a_{i}$ pode causar o estado u

Trazendo para o contexto da pesquisa, pode-se dizer que no modelo aqui proposto, como ilustrado na figura 15:

- o usuário é um agente $a_{i}$ cujas requisições são desejos $D\left(a_{i}\right)$

- as capacidades das operações dos serviços semânticos presentes no repositório são possíveis mudanças $M\left(a_{i}\right)$ que podem ser atingidas

- cada estado $S$ representa um estado que o agente está (condições antes e depois do desejo ser atingido) ou que os serviços estão (condições antes e depois das composições serem executadas)

- o produto cartesiano $\mathrm{P}(\mathrm{S} \times \mathrm{S})$ de todas as transições de estados possíveis equivale a todas as composições possíveis dados os serviços do repositório

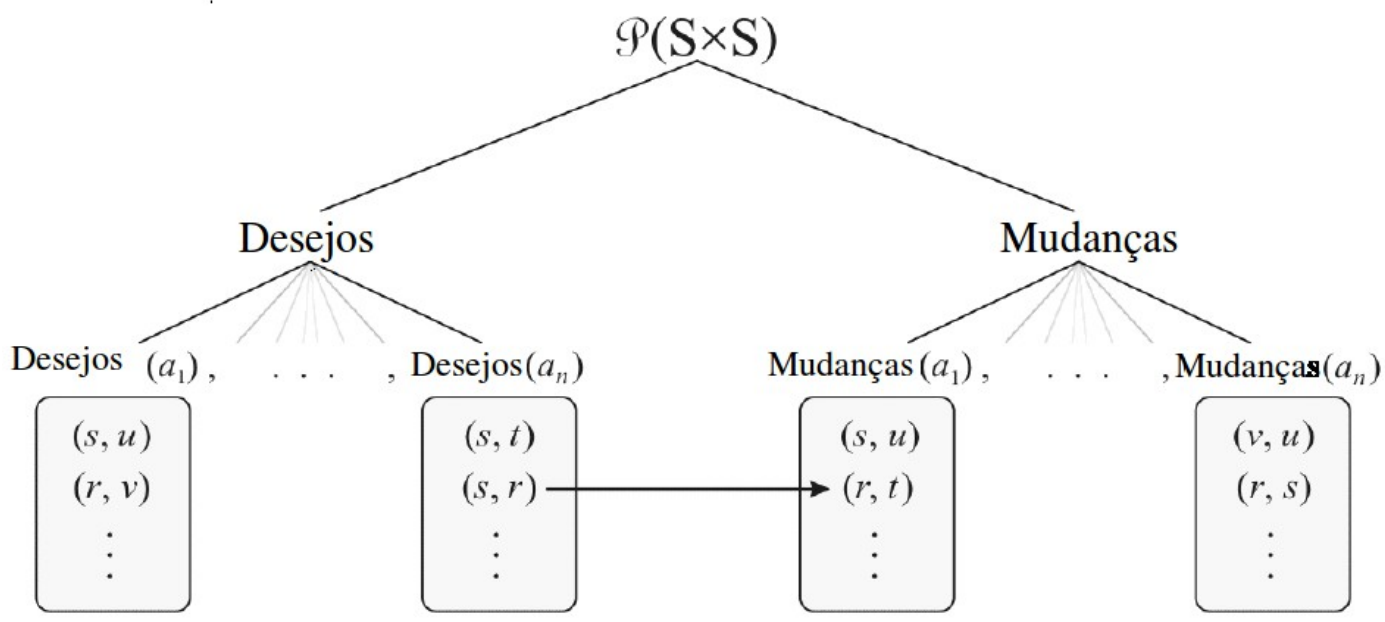

Figura 15. Relação entre requisições, semântica e linguística 


\subsubsection{Características observadas no modelo proposto}

O modelo que propõe-se na presente pesquisa deverá integrar um modelo de similaridade conceitual com um modelo de composição automática de serviços de maneira a gerar novas composições. Uma característica importante é que a utilização de similaridade acaba alterando o processo de negócio associado à composição, o que pode significar uma ligeira mudança na própria semântica da requisição, porém limitada a um certo ponto, para que ainda se garanta um atendimento parcial da requisição ou uma variação na qualidade de serviço prestada.

Desta maneira, a arquitetura deve possuir suporte à utilização de similaridade em diversos níveis, preferencialmente deve-se poder configurar qual o grau mínimo de similaridade que será utilizado pelo algoritmo de composição automática ao se passar uma requisição: ele limitará o quanto a semântica variará, e quanto mais a semântica variar maiores as chances do processo de negócio variar também. Define-se taxa de mudança como a razão entre o número de processos de negócio diferentes do original e todos os processos de negócio associados às composições geradas, para uma requisição $\mathrm{R}$ gerada com grau mínimo de similaridade $\sigma$.

$$
R M=\frac{\text { Núm. de PN para R diferentes do original vindos de composições com similaridade mín. } \sigma}{\text { Número total de PN }}
$$

Ou seja, dada uma requisição $R$, obtém-se uma composição $C$ associada a um processo de negócio $P$ sem a utilização de similaridade. Usando-se a mesma requisição $R$ com grau mínimo de similaridade $\sigma$, serão geradas $n$ composições $C 1, C 2, \ldots, C n$, associadas a $\mathrm{m}$ processos de negócio diferentes de P: P1, P2, ... Pm e n-m processos de negócio equivalentes a P. Neste caso, a razão de mudança será $\mathrm{m} / \mathrm{n}$. A razão de mudança para uma dada requisição $R$, portanto, representa o quanto o processo de negócio é capaz de mudar à medida que se varia o grau mínimo de similaridade na composição.

Sabendo-se da necessidade de integração entre os dois modelos, deve-se determinar de 
que maneira essa integração deve ocorrer, isto é, em que passo exatamente o cálculo de similaridade conceitual deve ocorrer, quais são os critérios para aceitação ou rejeição de uma composição de serviços similar e quais os impactos da similaridade conceitual no decorrer do processo de composição. É necessário compreender de que maneira as palavras da requisição (verbo, substantivos e ligações) deverão variar para que o objetivo da similaridade seja alcançado. Esta questão pode ser respondida através da teoria linguística, particularmente da teoria de frases imperativas (isto é, frases que contem uma ordem ou requisição), que é o formato no qual as requisições são passadas. $O$ trabalho de Kenny (1966) na área da teoria linguística foi usado como guia, e de acordo com suas observações determinou-se como a similaridade ontológica deveria ocorrer no modelo.

\subsubsection{Decisões de integração do modelo proposto}

Partirá-se do modelo arquitetural de composição automática de Fujii e Suda (2009), cujos componentes arquiteturais estão documentados em diagramas da UML. A partir do estudo de como a similaridade deverá ser aplicada, integrar-se-á o modelo de Ganjisaffar et al. (2006) como um componente da arquitetura, o componente de similaridade semântica. O componente de similaridade semântica será inserido ao modelo arquitetural e será invocado no momento em que a composição está sendo criada, de acordo com a teoria linguística das frases imperativas.

Em alto nível, pode-se dizer que o modelo proposto partirá da integração de dois componentes macro, como mostrado no diagrama UML de estrutura composta da figura 16: o componente de composição automática sem similaridade, baseado em Fuji e Suda (2009) e o componente de similaridade semântica, baseado em Ganjisaffar et al. (2006). Estes componentes se relacionam a partir das seguintes interfaces:

- Grau mínimo de similaridade: interface pela qual o componente de composição automática sem similaridade, que recebe a requisição e o grau mínimo de similaridade do usuário, passa o grau mínimo de similaridade expresso pelo 
usuário. Essa interface é fornecida pelo componente de composição automática e consumida pelo componente de similaridade semântica

- Conceitos a serem variados: interface pela qual o componente de composição automática passa os conceitos que deverão ser variados através de similaridade pelo componente de similaridade semântica. Essa interface é fornecida pelo componente de composição automática e consumida pelo componente de similaridade semântica

- Conceitos similares: interface pela qual os conceitos similares são passados ao componente de composição automática para que composições similares possam ser geradas. Essa interface é fornecida pelo componente de similaridade semântica e consumido pelo componente de composição automática

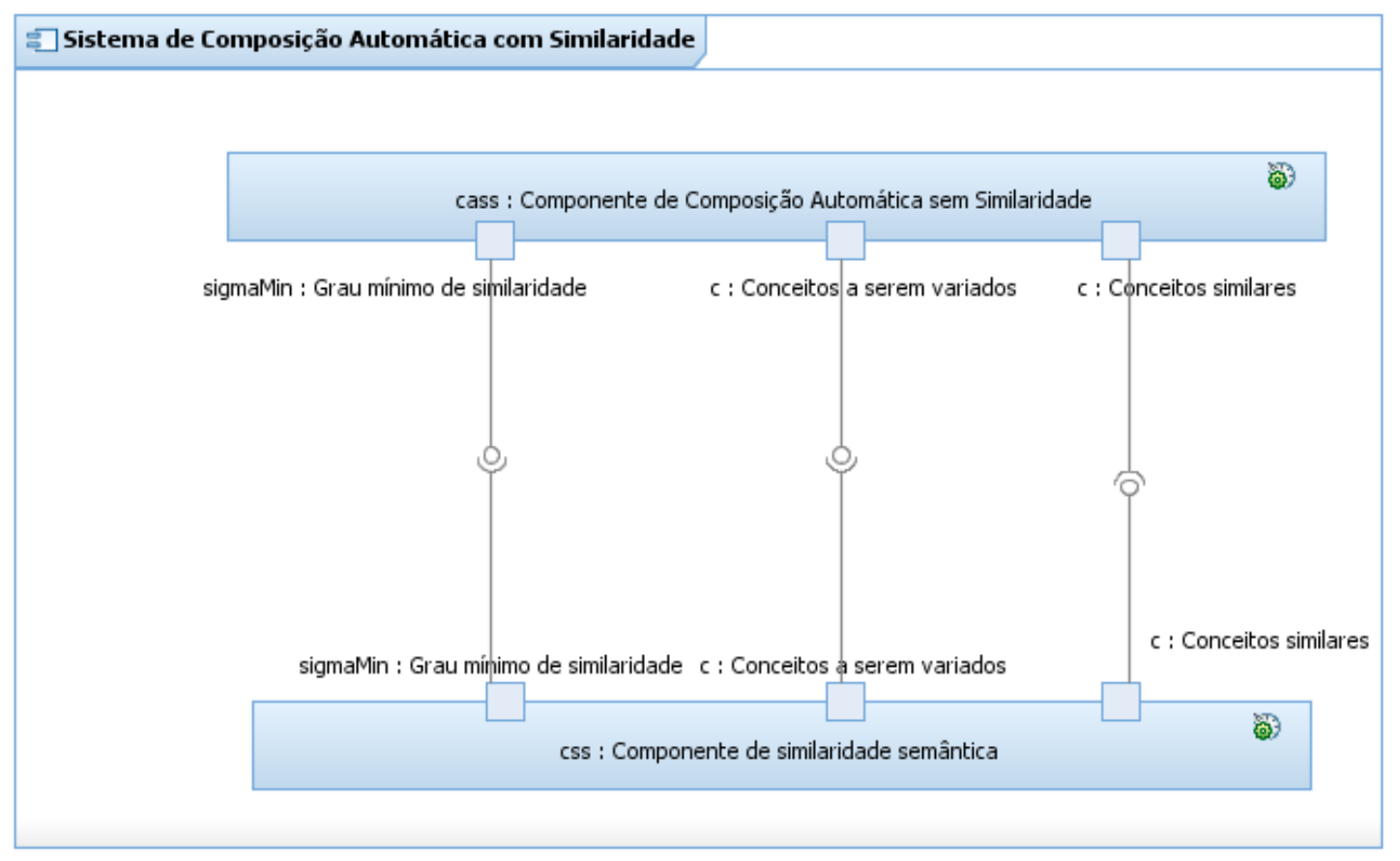

Figura 16. Diagrama UML de estrutura composta com os dois componentes principais do modelo

Sendo assim, a integração dos dois componentes macro gera um sistema de composição automática capaz de variar a semântica da requisição. Nas seções 3.2 e 3.3 esses componentes serão detalhados internamente, bem como a integração de suas interfaces e como essa integração é feita. 


\subsection{MODELO PROPOSTO}

Nesta seção será explicado o modelo proposto: seus principais elementos, a representação dos conceitos ontológicos, a representação dos serviços e como ocorre a aplicação da similaridade semântica da requisição.

3.2.1 Visão geral do modelo proposto

Na figura 17 pode-se ver o diagrama UML de classes do modelo proposto. A partir deste diagrama pode-se ver os principais elementos presentes no modelo e seus relacionamentos. O papel de cada classe é dado a seguir:

- Conceito: corresponde a um conceito da ontologia.

- Similaridade: um valor inteiro que representa o grau de semelhança entre dois conceitos da árvore ontológica.

- Requisição: requisição que deve ser atendida pelo sistema. É passada em linguagem natural escrita.

- Ontologia: um conjunto de conceitos e as relações entre eles.

- Serviço atômico: serviço computacional com operações que contem interfaces (entradas e saídas), e que não é composto de subserviços. As operações e seus parâmetros de entrada e saída estão associados a conceitos da ontologia.

- Serviço composto: serviço computacional composto de serviços atômicos e/ou outros serviços compostos. 
- Usuário: agente do sistema que representa sua requisição em linguagem natural, com o objetivo de tê-la atendida através de uma composição de serviços.

- Requisição: requisição do usuário que deve ser atendida pelo sistema. É passada em linguagem natural escrita.

- Regra de Similaridade: regras utilizadas pelo algoritmo de composição de serviços para determinar o grau de similaridade entre dois conceitos.

- Regra de Correspondência: regras utilizadas pelo algoritmo de composição de serviços para determinar se dois conceitos são correspondentes, isto é, se a similaridade entre eles é 1.

- Algoritmo de Composição: algoritmo responsável por buscar serviços no repositório que atendam à semântica passada pelo usuário e sugerir composições de serviços de acordo com a requisição passada. Os serviços do repositório devem estar definidos semanticamente de acordo com a ontologia do domínio.

- Componente de Descoberta: componente computacional responsável pela busca de serviços semânticos de acordo com os conceitos vindos da requisição.

- Componente de Composição: componente computacional responsável por realizar e oferecer composições. Utiliza o algoritmo de composição automática de serviços.

- Componente de Execução: componente computacional responsável por executar o serviço composto oferecido pelo componente de composição de serviços.

- Reasoner: componente computacional que verifica os serviços compostos gerados pelo componente de composição de serviços, selecionando aqueles cuja semântica satisfaz a requisição do usuário. 
A seção 1 na figura 17 contém as classes que são mais importantes para a execução do serviço composto gerado. A seção 2 da figura contém as classes mais importantes para o passo de descoberta, ao passo que a seção 3 destaca as classes mais importantes para a requisição. Finalmente, a seção mais à direita (4) contém as classes principais necessárias para a composição de serviços.

\subsubsection{Representação dos serviços e da ontologia}

Nesta seção será apresentada a estrutura com a qual a ontologia está definida, e também os serviços. Essa estrutura é uma linguagem de marcação própria que estende a linguagem $\mathrm{XML}^{1}$, e a ontologia e os serviços são guardados em arquivos neste formato.

\subsubsection{Representação da ontologia}

Um conceito da ontologia é representado através da tag "concept", e seu nome está definido dentro do atributo "name". Um conceito de nome C1, portanto, representa-se:

$<$ concept name="C1"/>

Uma ligação de nome "L" é representada através da tag "link"

$$
<\text { link name="L"/> }
$$

$\mathrm{Na}$ ontologia também são definidas as ações, que nada mais são do que um tipo de conceito que representa uma ação do mundo real. As ações são utilizadas para mapear as operações dos serviços para a ontologia, isto é, definir que tipo de efeito uma operação gera. Do ponto de vista de definição, uma ação se dá da mesma maneira que

1 Extensible Markup Language (XML). http://www.w3.org/XML. Acessado em 05/12/2011 


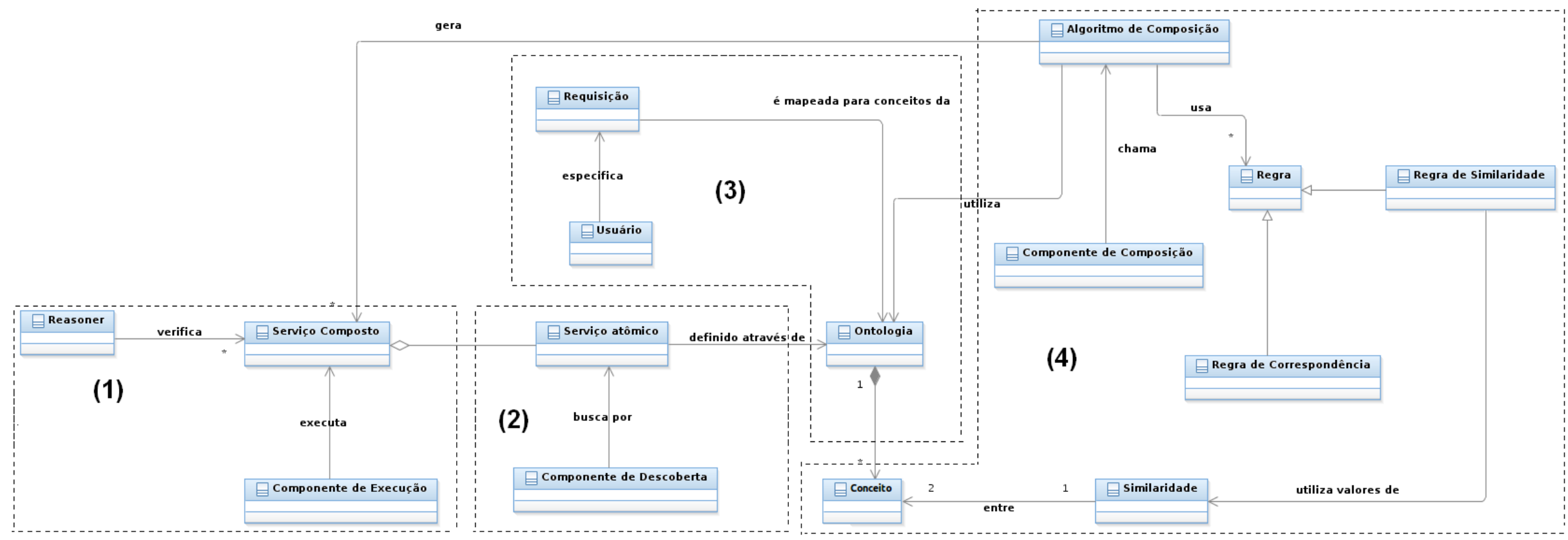

Figura 17. Diagrama de classes UML para o modelo proposto 
um conceito, usando-se a tag "action".

$<$ action name $=" \mathrm{~A}^{\prime} />$

Uma ligação sempre se dá entre dois conceitos, indicando que um conceito está relacionado a outro. Essa ligação se dá através da tag "binding", e está embutida dentro da tag "concept". Dado que um conceito $C 2$ ligado a um conceito $C 1$ através da ligação $L$, representa-se a ligação desta maneira:

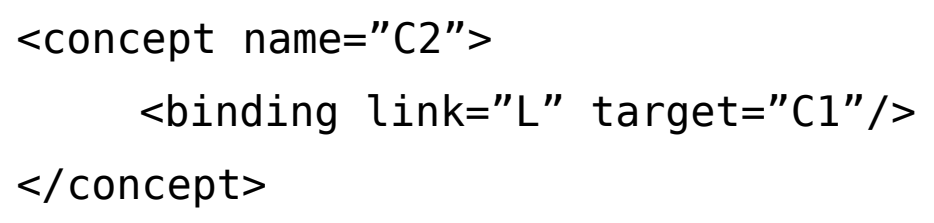

Ainda, existe uma propriedade dos conceitos de ser conceitos curinga, ou seja, um conceito que pode atuar como qualquer outro conceito, cuja similaridade a todos os outros consequentemente é sempre 1. Esta propriedade é dada pelo atributo XML "wildcard", e pode ser "true" (indicando que o conceito é um curinga), ou "false" (indicando que o conceito não é um curinga). Na omissão desse atributo, considera-se que o conceito não é um curinga. Um conceito $\mathrm{C} 3$ que é um curinga, portanto, é representado como:

<concept name="\#C3" wildcard="true"/>

\subsubsection{Representação dos serviços}

Como mencionado, os serviços também são representados em formato XML. Dado um serviço $S$ que contém $m$ operações $\left\{\mathrm{O}_{1}, \mathrm{O}_{2}, \ldots, \mathrm{O}_{\mathrm{m}}\right\}$, cada operação contendo $n$ parâmetros de entrada $\left\{\mathbb{I P}_{1}, \mathbb{I P}_{2}, \ldots \mathbb{I}_{\mathrm{n}}\right\}$, com cada parâmetro $\mathbb{I P}_{\mathrm{i}}$ do tipo $\operatorname{TIP}_{\mathrm{i}}$ representando um conceito $\mathrm{CIP}_{\mathrm{i}}$; e $p$ parâmetros de saída $\left\{\mathrm{OP}_{1}, \mathrm{OP}_{2}, \ldots, \mathrm{OP}_{\mathrm{p}}\right\}$, cada parâmetro $\mathrm{OP}_{\mathrm{i}}$ do tipo $\mathrm{TOP}_{\mathrm{i}}$ representando um conceito $\mathrm{COP}_{\mathrm{i}}$. A representação do serviço 
S fica da seguinte maneira:

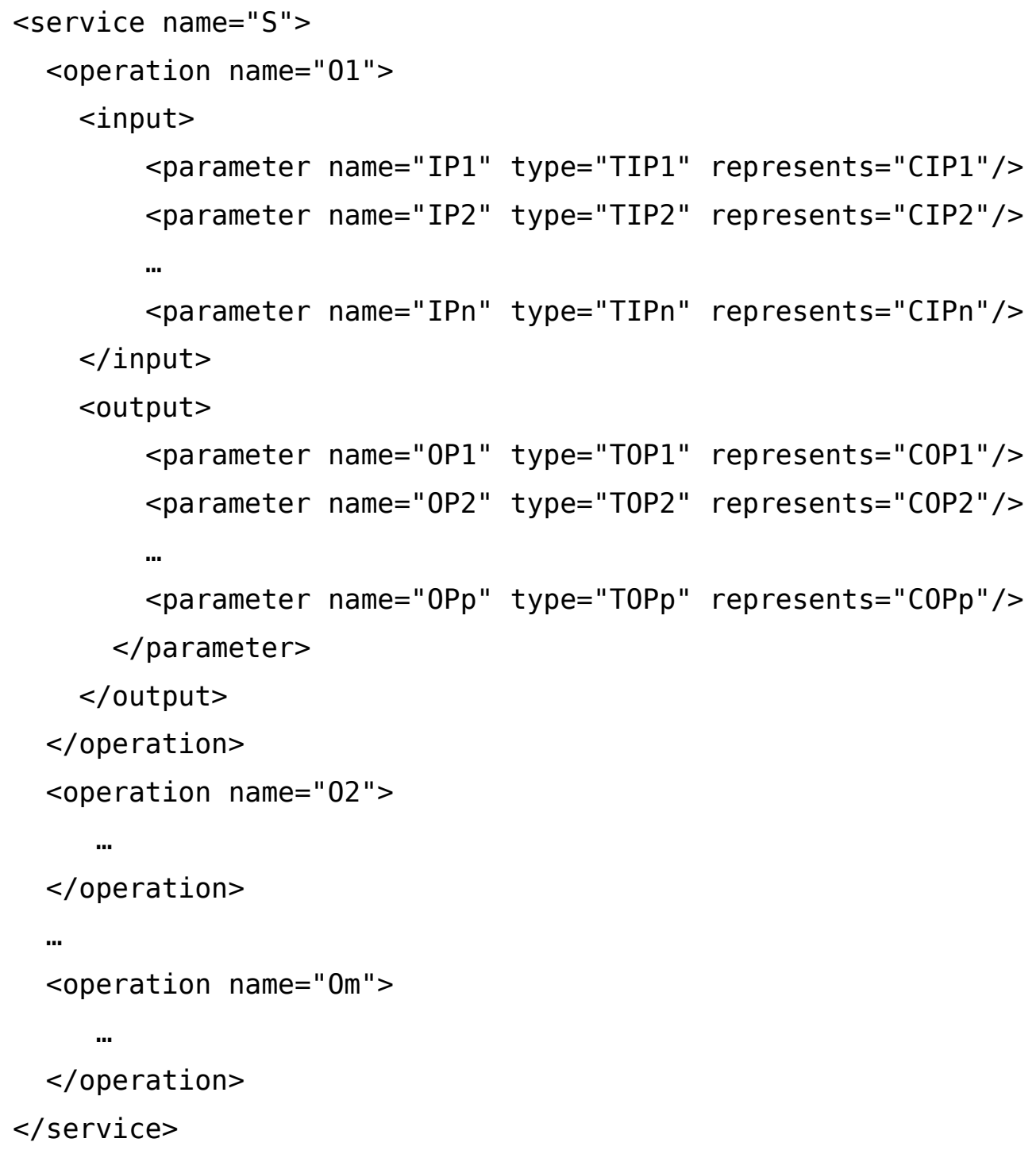

A tag "service" é utilizada para delimitar o serviço, e pode conter uma ou mais seções com a tag "operation", que delimita uma operação. A seção de tag "operation", por sua vez, pode conter uma ou mais seções com a tag "input" e uma ou mais seções com a tag "output”, representando respectivamente sua interface de entrada e saída. Cada seção do tipo "input" ou "output" poderá conter uma ou mais linhas do tipo "parameter", que representam um parâmetro (seja de entrada ou saída), com tipo de dado e conceito ontológico representado pelos atributos "type" e "represents", respectivamente. 


\subsection{OPERAÇÃO DO MODELO}

Nesta seção serão detalhadas as etapas da operação do modelo.

3.3.1 Obtenção da requisição em linguagem natural

No modelo proposto a requisição deve ser passada pelo usuário em linguagem natural e é mapeada para conceitos da ontologia. A requisição deve obedecer à regra de construção fixa:

\section{Requisição $=$ Verbo Substantivo (Ligação Substantivo) ${ }^{*}$}

A requisição passada em linguagem natural é quebrada como no padrão acima. Tem-se então um verbo, um substantivo e zero ou mais conjuntos de um substantivo seguido de uma ligação, ou seja, pode-se dizer que $R=V_{0} S_{0} L_{1} S_{1} L_{2} S_{2} \ldots L_{n} S_{n}$. $R$ é a requisição, $V_{0}$ é o verbo, $S_{0}$ é o primeiro substantivo e $L_{n}$ e $S_{n}$ são as ligações seguidas de substantivos, com a condição que $V_{0}$ e $S_{0}$ não podem ser nulos.

Imediatamente são buscados os conceitos da ontologia cujo nome é igual às palavras da requisição, ou seja, conceitos cujos nomes são exatamente: $V_{0}, S_{0}, L_{1}, S_{1}, L_{2}, S_{2} \ldots, L_{n}$ e $S_{n}$

3.3.2 Aplicação da similaridade semântica da requisição

Dadas as palavras da requisição e os conceitos de mesmo nome, deve-se definir de que 
maneira as palavras da requisição deverão variar semanticamente (isto é, conceitos similares deverão ser encontrados) de maneira a encontrar-se composições alternativas.

\subsubsection{Critério para a variação semântica}

A utilização de similaridade nesta pesquisa visa gerar composições que possam atender a uma requisição de diversas maneiras distintas. Isto significa que o usuário pode aceitar composições de serviço, mesmo que essas composições de serviço não resolvam a requisição original tal como é escrita, podendo resolver a requisição parcialmente ou mesmo prover serviços substitutos que alteram ligeiramente a semântica da requisição. Em outras palavras, mesmo que a composição atenda a uma requisição distinta da original, é necessário atendar ao critério da aceitação do desejo, ou seja, a composição oferecida deve de alguma forma satisfazer o usuário.

Dado um usuário a (agente), um conjunto de estados $S$, uma requisição $R$ representada por desejos $D(a)$ e mudanças de estado diferentes entre si $M(a)=\left\{m_{1}, m_{2}, \ldots, m_{i}, \ldots, m_{n}\right\}$ que fazem com que $R$ seja atendida, pode-se dizer que uma composição de serviços será uma solução alternativa para a requisição $\mathrm{R}$ se:

- A composição de serviços satisfizer o desejo $\mathrm{D}(\mathrm{a})$ do usuário (preservação do desejo)

- A composição de serviços realizar mudanças de estado $M^{\prime}(a)=\left\{m_{1}, m_{2}, \ldots, m_{i-1}\right.$, $\left.m_{i+q}, \ldots, m_{n}\right\}(q \geq 1)$ ou $M^{\prime \prime}(a)=\left\{m_{1}, m_{2}, \ldots, m_{i-1}, m_{i}, m_{k}, m_{k+1}, . ., m_{k+p}, m_{i+1}, \ldots, m_{n}\right\}$ $\left(m_{k} \neq m_{i}\right)$, ou $M^{\prime \prime \prime}(a)=\left\{m_{1}, m_{2}, \ldots, m_{i-1}, m_{k}, m_{k+1}, . ., m_{k+p}, m_{i+q}, \ldots, m_{n}\right\}\left(m_{k} \neq m_{i}\right)$, ou seja:

- a composição realizar as mesmas das mudanças de estado que satisfazem a requisição, menos $q$ das mudanças de estado de $M(a)(q \geq 1)$ - caso $M^{\prime}$

- a composição realizar as mesmas mudanças de estado que satisfazem a 
requisição, mais $p$ novas mudanças de estado $(p \geq 1)$ - caso M"

- a composição realizar as mesmas mudanças de estado que satisfazem a requisição, menos $q$ das mudanças de estado de $M(a)$, mais $p$ novas mudanças de estado $(p \geq 1)$ - caso M"'

Ou seja, desde que se preserve a aceitação do desejo por parte do usuário, pode haver mais mudanças de estado do que a composição original, menos mudanças de estado, ou ainda variações nas mudanças originais.

\subsubsection{Operação da similaridade semântica e descoberta de serviços}

Quando se busca por conceitos similares aos das palavras da requisição se está alterando ligeiramente a semântica da requisição passada. Ao alterar os conceitos associados à requisição, está-se alterando também os serviços que serão descobertos. Ao se alterar os serviços descobertos (e consequentemente as composições), pode-se estar alterando também os processos de negócio associados às composições.

A pesquisa de Kenny (1966) mostra desejos e mudanças associados a uma lógica imperativa numa frase, como mostrado anteriormente, que é o tipo de frase utilizado para representar uma requisição. Os desejos representam sempre um anseio de mudança de estado sobre um objeto: objeto vai do estado $s$ para o estado $t$. As mudanças representam um efeito que recai sobre este objeto: mude o objeto. Em ambos os casos, é o objeto que sofre os efeitos do desejo do imperador. Numa requisição com formato Verbo Substantivo (Ligação Substantivo)*, o primeiro substantivo é o objeto que sofrerá as mudanças e sobre o qual recaem os desejos principais. Pode-se dizer que o verbo produz uma mudança no substantivo.

Em propostas cuja similaridade não é um dos objetivos principais, como em Fujii e Suda 
(2009), a interpretação da requisição e a busca pelos conceitos associados segue a mesma ordem das palavras da requisição, como mostrado no capítulo 2. Inicia-se por complementar os serviços associados ao verbo e então aplica-se o algoritmo de complementação de entradas de maneira sucessiva.

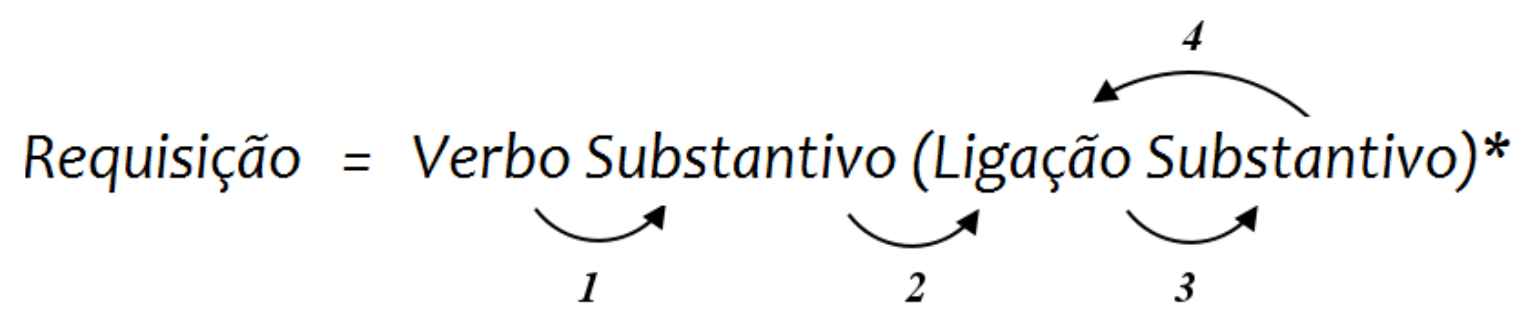

Figura 18. Ordem de busca conceitual em abordagens não focadas em similaridade

Porém, a partir da pesquisa de Kenny (1966) identificou-se o primeiro substantivo como elemento que sofre as mudanças e sobre o qual os desejos estão ligados. Para causar uma ligeira variação semântica na requisição, será necessário variar o significado das palavras da requisição, isto é, os conceitos associados ao verbo, substantivo ou ligações. Variando-se os conceitos que serão buscados, variar-se-á, também, as composições geradas.

Sendo assim, foi feita uma alteração nos passos de descoberta e composição de serviços, em comparação com Fujii e Suda (2009), de maneira que o primeiro substantivo também seja variado através de conceitos similares e então são buscados os serviços cujas operações utilizam os conceitos similares ou o conceito original, desta forma buscando-se por novas mudanças.

Na proposta do modelo da presente pesquisa, o primeiro substantivo da requisição é variado de acordo com um grau mínimo de similaridade $\sigma_{\min }$. São buscados na ontologia todos os conceitos cuja similaridade com o primeiro substantivo seja igual ou maior que $\sigma_{\min }$. Em seguida, são descobertos todos os verbos (operações de serviços) que podem utilizar os conceitos similares como entrada ou saída. Para cada verbo encontrado, é realizada a complementação de entradas conforme descrito anteriormente. 
Conforme se vê na figura 19, em comparação à figura 18, o componente de descoberta começa pela busca de serviços associados ao primeiro substantivo, e só então inicia a complementação de entradas para cada operação encontrada, associada ao verbo da requisição.

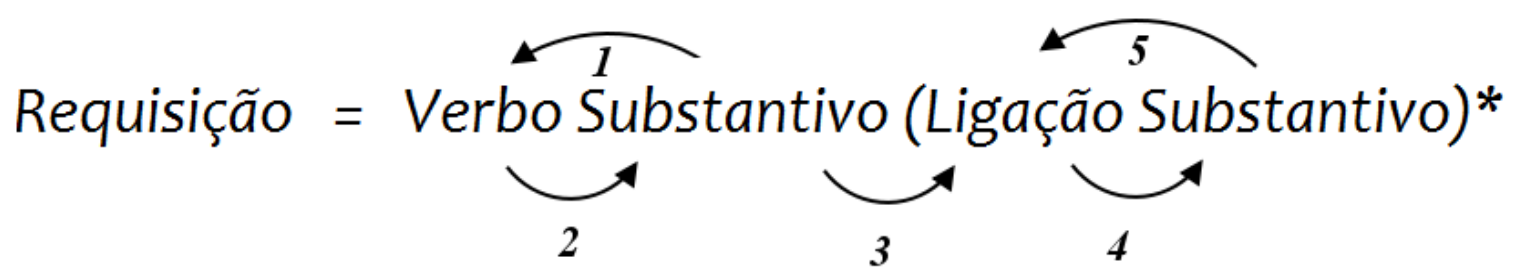

Figura 19. Proposta de nova ordem de busca conceitual

3.3.3 Visão completa da composição automática de serviços com variação semântica

Nesta seção será descrito o funcionamento do modelo de composição automática desde a expressão da requisição até a composição dos serviços.

1. Seja uma requisição $R=V_{0} S_{0} L_{1} S_{1} L_{2} S_{2} \ldots L_{n} S_{n}$

2. São buscados substantivos similares a $S_{0}$ com grau de similaridade mínimo $\sigma_{\min }$ : $\mathrm{S}_{0}{ }^{\prime}, \mathrm{S}_{0}{ }^{\prime \prime}, \mathrm{S}_{0}{ }^{\prime \prime}, \ldots, \mathrm{S}_{0}{ }^{{ }^{\prime \prime}}$. Seja $\mathrm{S}=\left\{\mathrm{S}_{0}, \mathrm{~S}_{0}{ }^{\prime}, \mathrm{S}_{0}{ }^{\prime \prime}, \ldots, \mathrm{S}_{0}{ }^{{ }^{\prime \prime}}\right\}$

3. São buscados os serviços que retornam $S_{i}$ como saída ou recebem $S_{i}$ como entrada $\mathrm{V}\left(\mathrm{S}_{\mathrm{i}}\right)$ para cada $\mathrm{S}_{\mathrm{i}}$ pertencente a $\mathrm{S}$.

- Para cada $S_{i}$ : para cada serviço $V_{j}$ pertencente a $V\left(S_{i}\right)$ que contem conjunto de entradas $E\left(V_{j}\right)=\left\{E_{0}, E_{1}, \ldots, E_{k}\right\}$, são buscados serviços que recebem ao menos uma das entradas $E_{i}$ em uma de suas operações.

- Para cada $S_{i}$ : para cada serviço $V_{j}$ pertencente a $V\left(S_{i}\right)$ que contem conjunto de saídas $X\left(V_{j}\right)=\left\{X_{0}, X_{1}, \ldots, X_{m}\right\}$, são buscados serviços que fornecem ao menos uma das saídas $X_{i}$ em uma de suas operações.

4. Neste passo aplica-se a composição como em Fujii e Suda (2009). Realiza-se a complementação de entradas em todos os serviços encontrados no passo 3 , que são um conjunto distinto de serviços que seriam encontrados sem a utilização ode 
similaridade

5. Realizar a verificação semântica das ligações e substantivos (exceto o primeiro) em relação à requisição.

O algoritmo completo para composição automática de serviços utilizando similaridade, como descrito nos passos acima, fica da seguinte maneira:

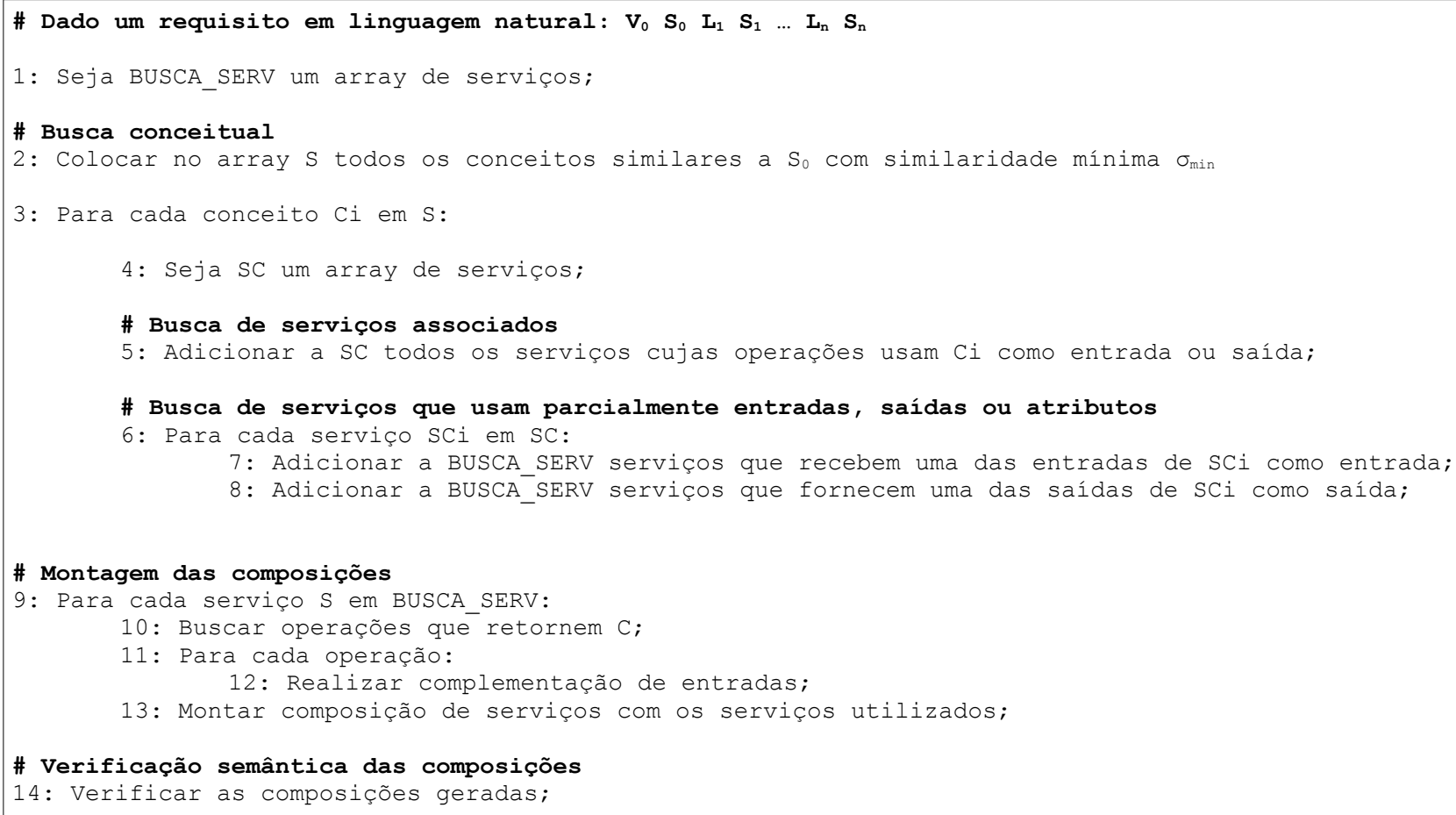

$\mathrm{Na}$ linha (1) do algoritmo declara-se um conjunto de serviços que serão utilizados posteriormente como candidatos a requisição. Estes serviços terão suas entradas complementadas como em Fujii e Suda (2009).

Na linha (2) aplica-se o cálculo de similaridade conceitual, como em Ganjisaffar et al. (2006), para o primeiro substantivo da requisição. Esta decisão é justificada pela teoria linguística de Kenny (1966).

$\mathrm{Na}$ linha (3) do algoritmo itera-se cada um dos conceitos encontrados na linha (2), e na linha (4) declara-se um conjunto de serviços para cada um desses conceitos. Na linha (5) 
são buscados todos os serviços que de alguma maneira se relacionam com os conceitos encontrados em (2), ou seja, todos os serviços que usam os conceitos como entrada e/ou como saída. Esses conceitos são então adicionados ao conjunto de serviços candidatos (que serão complementados) nas linhas (7) e (8).

Finalmente, nas linhas 9-13 é aplicado sucessivamente o algoritmo de complementação de entradas como em Fujii e Suda (2009), usando os serviços armazenados no conjunto de serviços do passo (1).

Na linha (14) verifica-se cada uma das composições de acordo com os conjuntos ligaçãosubstantivo vindos da requisição. É importante ressaltar que este passo apenas é executado quando possível, pois a partir da variação semântica dos conceitos encontrados na linha (2) pode ser que encontre-se conceitos que não possuam as mesmas ligações passadas pela requisição. O próprio fato da semântica ser variada permite também que nem toda a requisição seja verificada com exatidão.

\subsection{MAPEAMENTO ENTRE SERVIÇOS E PROCESSOS DE NEGÓCIO}

Como se deseja avaliar se a utilização de similaridade conceitual gera novos processos de negócio, fez-se necessário estudar as propostas de mapeamento entre composições de serviços e processos de negócio, para obter uma base de comparação entre dois processos de negócio gerados através de similaridade. Caso uma mesma requisição gere duas composições diferentes devido à similaridade, pode-se mapear essas composições para seus respectivos processos de negócio e então definir se os processos de negócio são iguais ou diferentes.

Guo, Chen-Burger e Robertson (2004) propõem um método de mapeamento entre serviços semânticos especificados em OWL-S e processos de negócio em uma linguagem de notação de processos de negócio chamada FBPML. Os autores usaram os elementos formalmente descritos nas normas das duas linguagens e definiram funções de transformação. A partir da decomposição dos elementos OWL-S, aplica-se as funções 
de transformação e obtém-se como produto a estrutura correspondente em FBPML, e vice-versa.

Dada a abrangência da pesquisa, como se trata de um modelo básico de arquitetura de composição automática com similaridade, não se está utilizando nenhuma linguagem formal para descrever os serviços, composições ou processos de negócio. Definir-se-á, portanto, um conjunto básico de elementos de processos de negócio baseado na linguagem BPMN (OBJECT MANAGEMENT GROUP, 2011). A linguagem BPMN foi escolhida visando permitir maior legibilidade durante o mapeamento, por possuir uma especificação de representação gráfica. Outras propostas, como por exemplo o BPEL (OASIS, 2007) são mais adequadas para a utilização direta pela máquina, tendo como características uma linguagem própria de marcação e a falta de uma norma de representação gráfica.

Os elementos básicos que serão levados em consideração para descrever processos de negócio são:

- Atividade: uma ação ou conjunto de ações executada por um participante (raia) em um processo de negócio

- Conector: representa a passagem de uma atividade para outra, sendo representado como uma seta com origem na atividade terminada e destino na atividade que está por começar

- Raia (lane): representa um participante (aquele que realiza uma atividade). Uma raia consiste em um retângulo horizontal nomeado com o nome do participante e uma atividade dentro de uma raia é realizada pelo participante daquela raia

- Evento de início: representa o início do processo de negócio

- Evento de fim: representa o fim do processo de negócio

Sendo assim, na figura 20 abaixo temos dois participantes e 5 atividades conectadas entre si. O processo de negócio se inicia com a atividade 1 , realizada pelo participante 1 , e passa sequencialmente pelas atividades 2,3 e 4, finalizando na atividade 5 realizada pelo participante 2 . 
Esse será o modelo simplificado de processo de negócio utilizado como base para comparar os processos de negócio associados às composições de serviço geradas automaticamente.

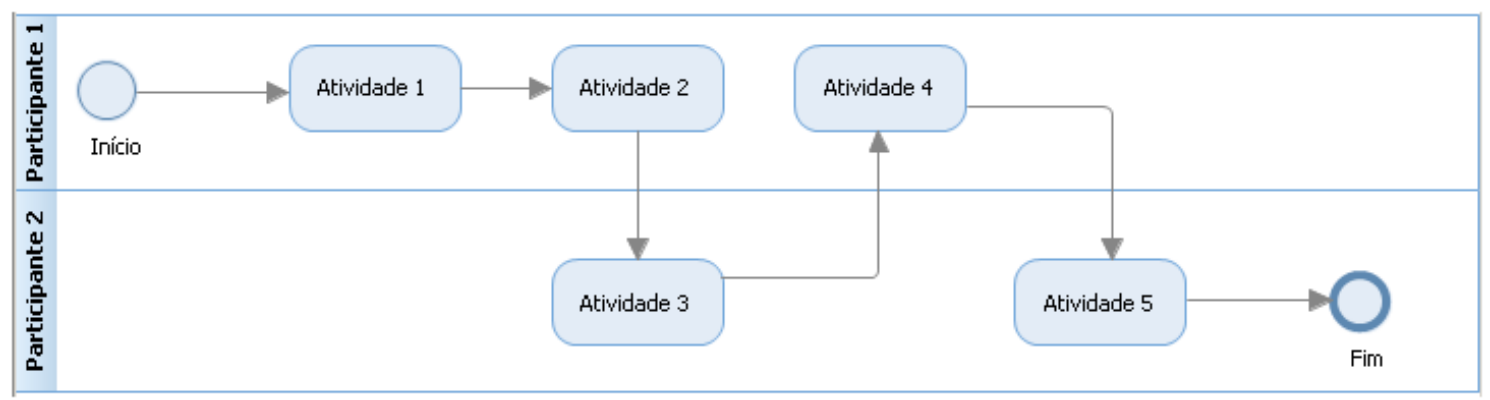

Figura 20. Exemplo de processo de negócio simplificado

O mapeamento das composições de serviço geradas para o processo de negócio simplificado descrito acima se dá da seguinte maneira:

- Cada provedor de serviço será um participante (raia)

- Cada serviços será uma atividade

- As atividades serão conectadas em ordem de acordo com a complementação de entradas: a primeira atividade (correspondente ao primeiro serviço) é aquela que não recebe complemento de entradas ou cujo complemento se encontra nas próprias palavras da requisição. A segunda atividade corresponderá ao serviço complementado pela saída do serviço da primeira atividade, e assim por diante 


\section{APLICAÇÃO EXPERIMENTAL}

Neste capítulo será descrito o experimento utilizado na pesquisa. Foi adotado um modelo de engenharia de software experimental, e as etapas executadas no experimento serão detalhadas nas seções que se seguem.

\subsection{ENGENHARIA DE SOFTWARE EXPERIMENTAL}

Foi implementado um protótipo do modelo de composição automática de serviços com similaridade. Buscou-se exercitar o protótipo de acordo com um modelo experimental para engenharia de software que permitisse coletar evidências empíricas de que o problema da pesquisa foi solucionado, além de viabilizar a comparabilidade com estudos similares e minimizar conclusões inconscientemente tendenciosas dos pesquisadores. Baseou-se a experimentação no modelo proposto por Goulão et al. (2007), que foi criado através do estudo das melhores práticas na área de engenharia de software experimental e alinhado com propostas de disseminação de dados experimentais.

A experimentação se deu em seis etapas: definição de requisitos do experimento, planejamento do projeto, execução do experimento e análise de dados. As etapas são seguidas nesta ordem, podendo a execução do experimento influenciar tanto o planejamento do projeto como a definição de requisitos, necessitando um recomeço na iteração como mostrado na figura 21.

- a fase de definição dos requisitos do experimento busca definir quais são o problema, os objetivos e o contexto do experimento

- o planejamento do projeto refina a fase anterior, dizendo como o experimento será executado, além de detalhar o contexto do experimento 
- na fase de execução do experimento a experimentação em si ocorre e os dados relevantes para análise são selecionados

- na fase de análise os dados são processados e analisados

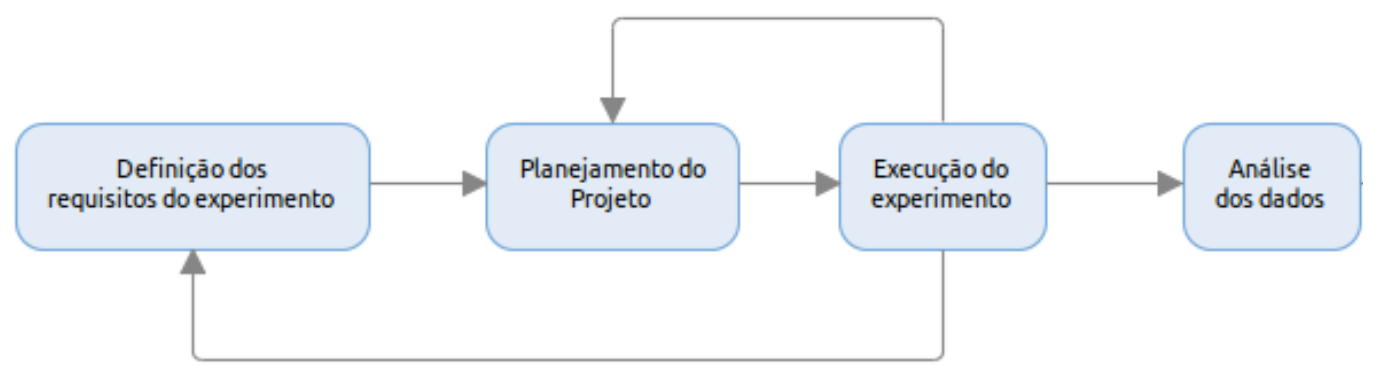

Figura 21. Processo experimental para Engenharia de Software

Extraído de GOULÃO et al. (2007)

\subsection{PROTÓTIPO DE COMPOSIÇÃO AUTOMÁTICA COM SIMILARIDADE}

O protótipo implementado consiste em um portal web onde a requisição em linguagem natural é expressa, bem como o grau mínimo de similaridade a ser utilizado, que limita o conjunto de conceitos similares às palavras da requisição que serão buscados. 0 protótipo consiste também de uma ontologia e um repositório de serviços associados aos conceitos da ontologia.

A requisição e o grau mínimo de similaridade são passados pelo usuário para o componente de requisição, conforme mostrado no diagrama de componentes UML da figura 22.

O componente de requisição separa as palavras da requisição e as categoriza como verbo, substantivo e ligação de acordo com a regra de construção fixa: Requisição = Verbo Substantivo (Ligação Substantivo)*.

As palavras da requisição e o grau mínimo de similaridade são transmitidos ao 
componente de variação semântica, que varia cada palavra da requisição de acordo com o grau mínimo de similaridade passado.

O componente de descoberta busca os serviços associados às palavras da requisição e similares no repositório de serviços. Este conjunto de serviços é então passado para o componente de composição automática.

O componente de composição automática compõe os serviços vindos do componente de descoberta, utilizando um algoritmo para complementar sucessivamente as entradas dos serviços encontrados.

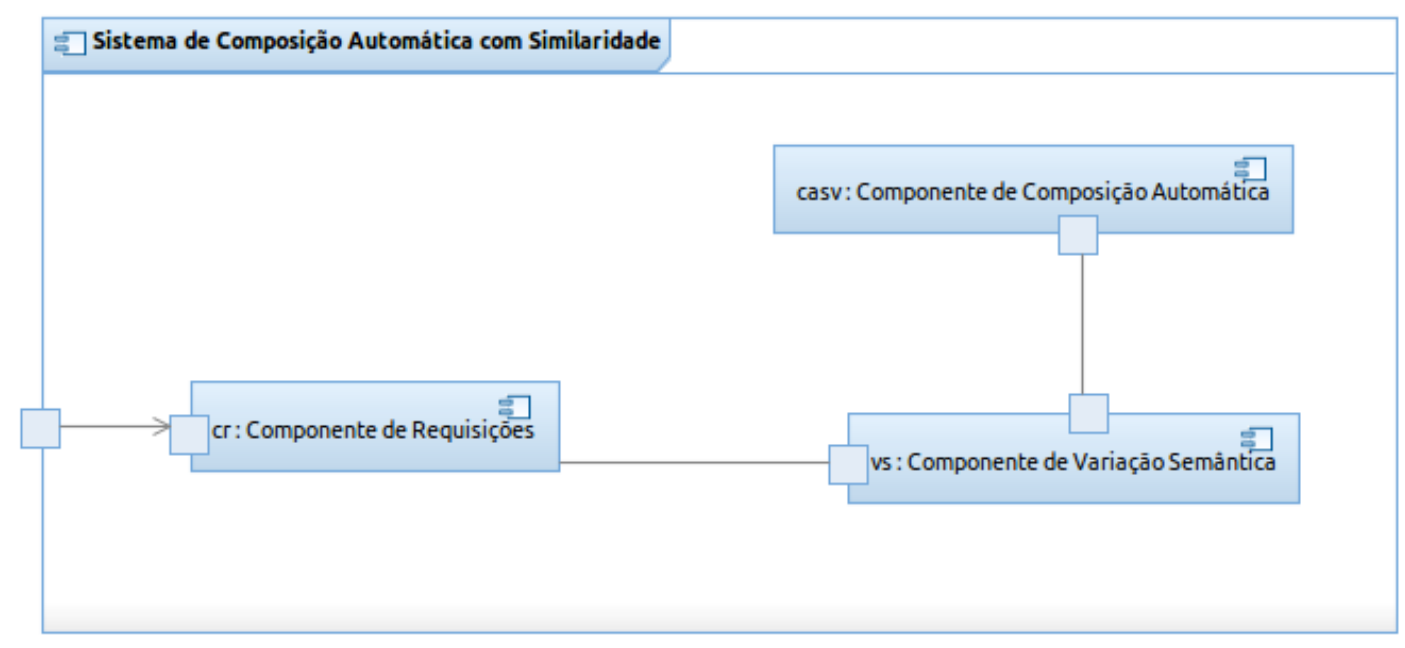

Figura 22. Diagrama representando o protótipo criado

\subsection{DOMÍNIO DO TURISMO}

O turismo foi selecionado como domínio de aplicação da pesquisa. BUHALIS (1998, 2001, 2003) aponta algumas características históricas da utilização de tecnologia para o provimento de serviços no domínio do turismo, desde a adoção por companhias aéreas de sistemas de reserva por computador na década de 50, a extensão dos sistemas de reserva na década de 80 , os chamados sistemas globais de distribuição (que permitiam 
que bilhetes de múltiplas companhias pudessem ser comprados em um único sistema, inclusive por agências de turismo), os sistemas de gerenciamento de propriedades, comumente utilizados por hotéis alguns anos depois, a adoção do modelo de $e$ Commerce na década de 90. Dados os diversos serviços providos por companhias locais nos diversos pontos turísticos do mundo, o domínio do turismo caracteriza-se por alta heterogeneidade de serviços e provedores. Além disso, O'Brien (2001) aponta que uma característica do domínio do turismo é a maneira não-estruturada e heterogênea por parte dos usuários ao expressar suas requisições, o que vai de encontro ao uso da linguagem natural.

Num contexto de viagem, por exemplo, um turista via de regra deve se preocupar com diversos serviços: transporte, acomodação, alimentação, lazer, entre outros. Muitas vezes esses serviços devem ser sincronizados e por isso agendados em conjunto, o que vai de encontro com a composição automática de serviços. Além disso, muitos consumidores não estão sequer cientes de qual produto ou serviço concreto eles estão procurando (BILBAO e HERRERO, 2009), o que também vai de encontro ao uso da similaridade como forma de encontrar diversas alternativas relacionadas até certo ponto, que será limitado pelo grau de similaridade adotado.

Diversos sistemas de composição automática de serviços para o domínio do turismo foram analisados e citados anteriormente, como em Bilbao e Herrero (2009), Tran e Tsuji (2009), Choi et al. (2006), Paganelli, Parlanti e Giuli (2010), Liu, Peng e Chen (2006), Zachos e Maiden (2008), entre outros. Estes sistemas em geral são guias turísticos que compõem serviços em tempo de execução para atender a uma demanda idealmente de maneira instantânea. Nenhum desses sistemas, porém, sugere composições que definem novos processos de negócio, embora utilizem serviços similares no caso de indisponibilidade de algum serviço essencial à composição de serviços. 


\subsection{OPERAÇÃO DA APLICAÇÃO EXPERIMENTAL}

Nesta seção serão abordadas as questões práticas levadas em conta na experimentação do protótipo.

\subsubsection{Definição dos Requisitos}

A fase de definição dos requisitos busca definir quais são o problema, os objetivos e o contexto do experimento.

Declaração do problema. Considerando-se que composições de serviço estão associadas a processos de negócio, observou-se que há um uso limitado de similaridade na área da composição automática de serviços, que pode ser estendido através da utilização de similaridade conceitual visando a geração de composições associadas a processos de negócio diferentes dos processos de negócio gerados num modelo de composição automática sem similaridade.

Definição de contexto. O contexto experimental da pesquisa será um subconjunto limitado do domínio do turismo que será exercitado através do protótipo, que poderá operar com a utilização de similaridade ou sem a utilização de similaridade. $O$ experimento conterá uma ontologia do domínio do turismo, um conjunto de serviços associados aos conceitos dessa ontologia e um conjunto de requisições criadas de maneira a estimular o protótipo a gerar composições contendo os serviços. A partir da análise das composições criadas, serão identificados também os processos de negócio que estão associados a tais composições, podendo-se estabelecer uma base de comparação entre os processos de negócio gerados sem a habilitação da similaridade e com a habilitação da similaridade. 
Definição de objetivos. O experimento tem como objetivo avaliar se o uso de similaridade com composição automática de serviços permite aumentar o número de composições de serviços associadas a novos processos de negócio, se comparado com a composição automática de serviços sem similaridade. Em caso afirmativo, também determinar se os novos processos de negócio gerados continuam atendendo à requisição expressa.

Na figura 23 pode-se ver um diagrama que mostra duas camadas de abstração: a camada dos processos de negócio (mais abstrata) e a camada de serviços (menos abstrata). Um usuário passa sua requisição para o sistema de composição automática de serviços com similaridade, que gera diversas composições de serviço. Cada composição de serviços (camada inferior) automatiza um processo de negócio específico (camada superior). Supondo-se que, dada uma requisição, num sistema de composição automática de serviços sem similaridade encontra-se a composição $\mathrm{C} 1$, associada ao processo de negócio PN1, busca-se provar que através do uso da similaridade conceitual pode-se gerar composições associadas a outros processos de negócio (por exemplo, a composição C2 que está associada ao processo de negócio PN2) que não satisfazem completamente a requisição expressa ou a satisfaz de maneira alternativa.

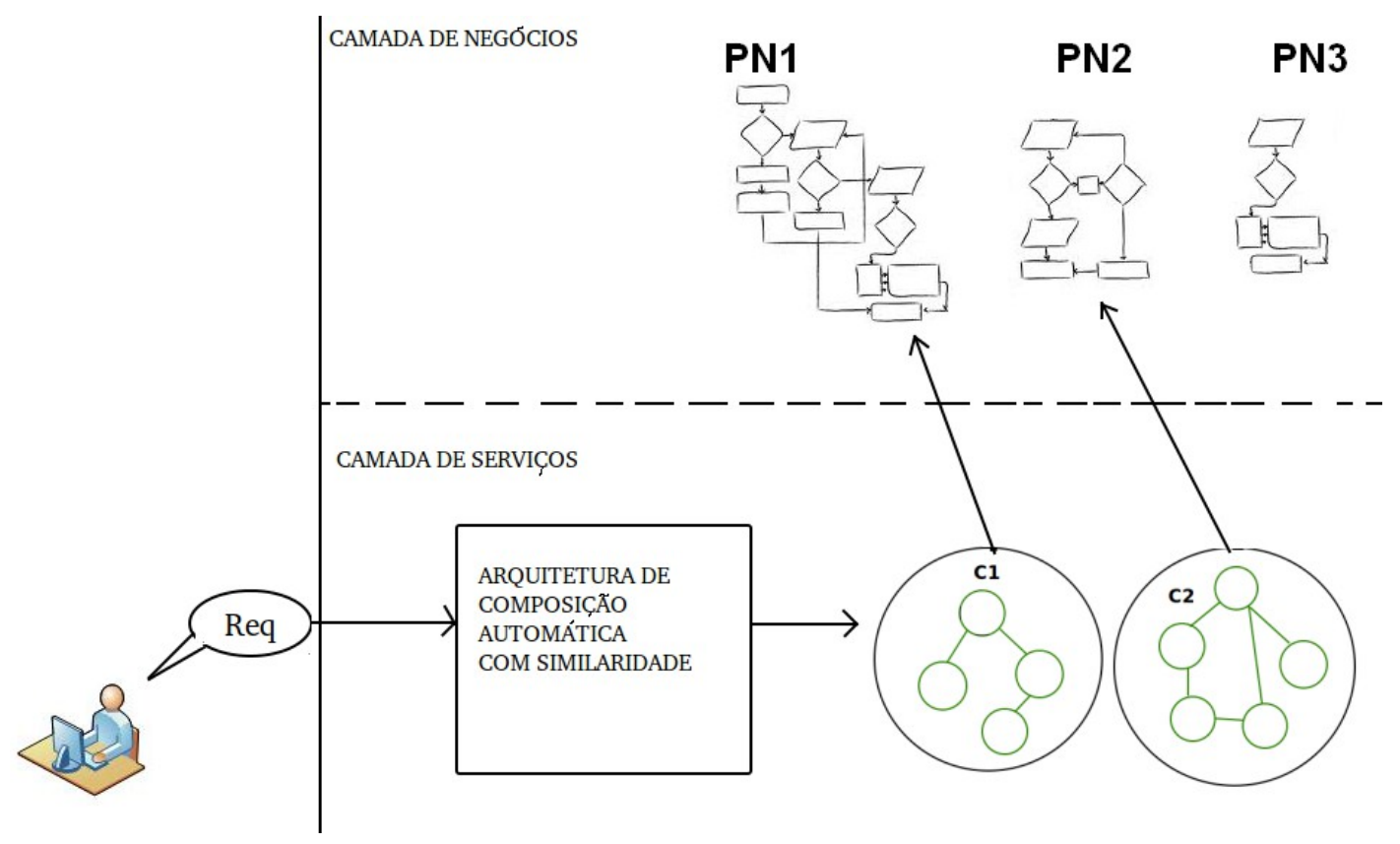

Figura 23. Similaridade gerando novos processos de negócio 
Caso identifique-se que o modelo é capaz de gerar composições associadas a processos de negócio alternativos, outro objetivo é determinar se os novos processos de negócio não rompem com a requisição passada, isto é, se o desejo expresso pela requisição continua a ser atendido, mesmo com a utilização do processo de negócio alternativo.

\subsubsection{Planejamento do Projeto}

O planejamento do projeto refina a fase de definição de requisitos, dando detalhes internos da execução do experimento.

Definição de parâmetros de contexto. Durante o experimento, os parâmetros do contexto permanecem estáveis, e portanto pode-se assumir que as variações observadas durante a execução do experimento não se dão devido aos parâmetros do contexto. Por outro lado, durante a execução as variáveis sofrerão mudanças diversas, com o objetivo de observar-se a diferença nas evidências empíricas de acordo com os valores que as variáveis assumem.

Nesta seção definem-se os parâmetros de contexto, isto é, as características e restrições que não serão alteradas durante o experimento. Os parâmetros do contexto da experimentação são:

- a ontologia do domínio: a ontologia não sofreu alterações e, desta forma, garantiuse que a execução do protótipo com similaridade esteve sujeita ao mesmo contexto da execução sem a similaridade. A ontologia é dada abaixo:

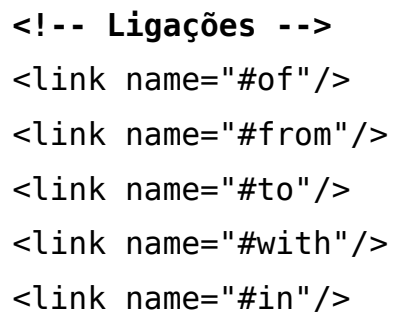




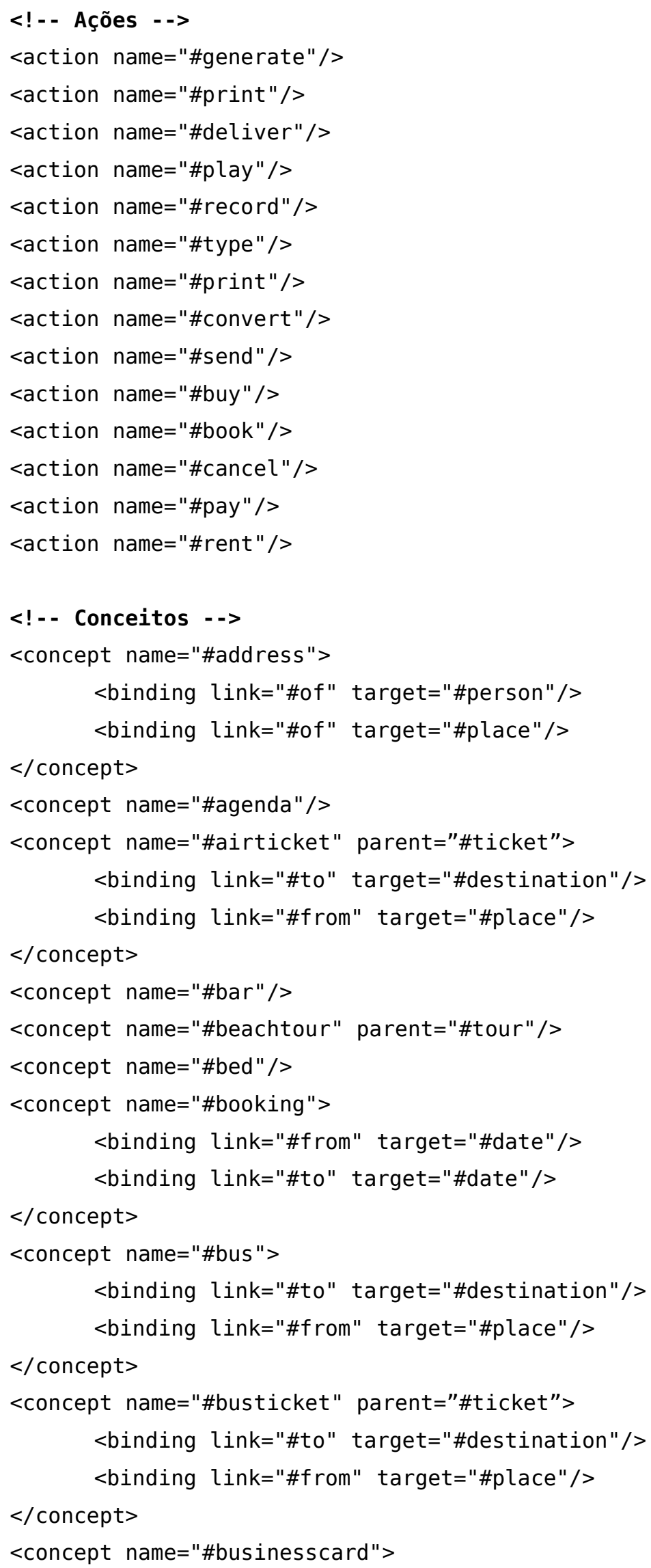


<binding link="\#of" target="\#person"/>

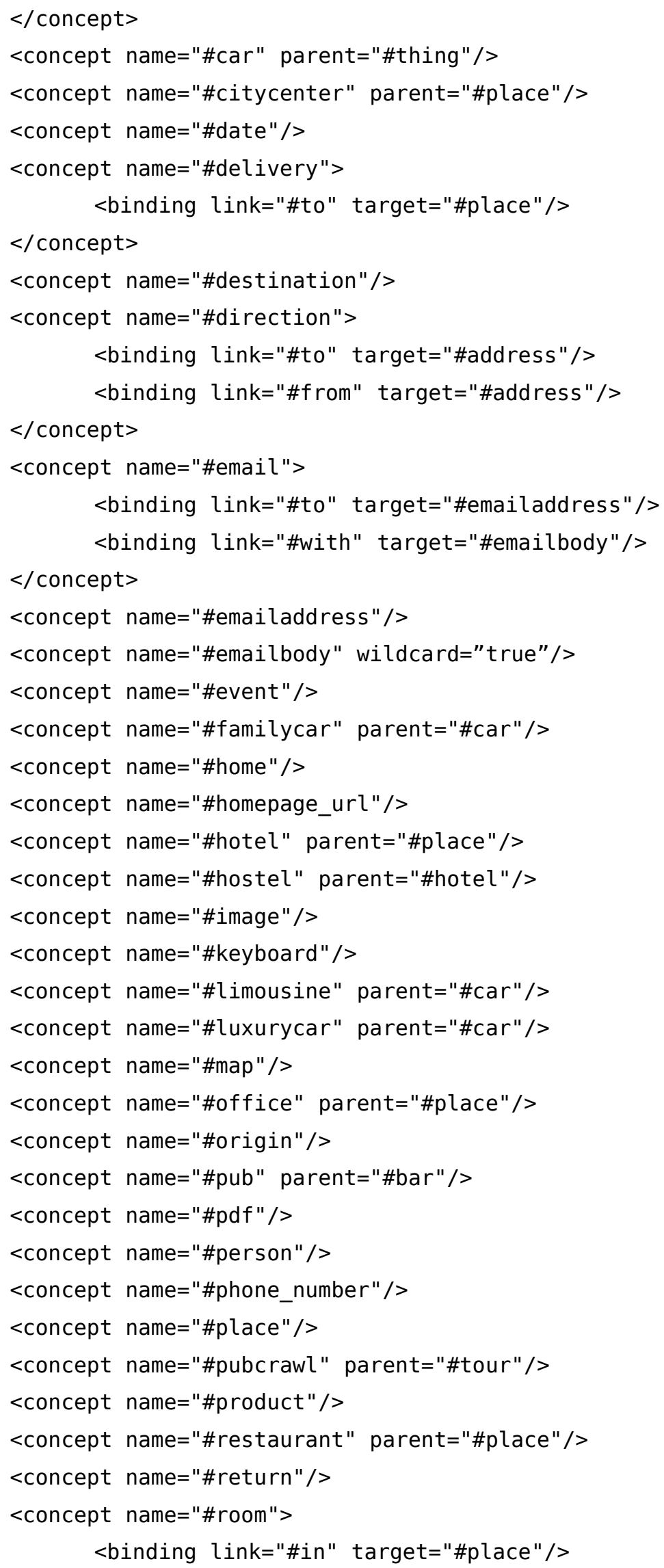




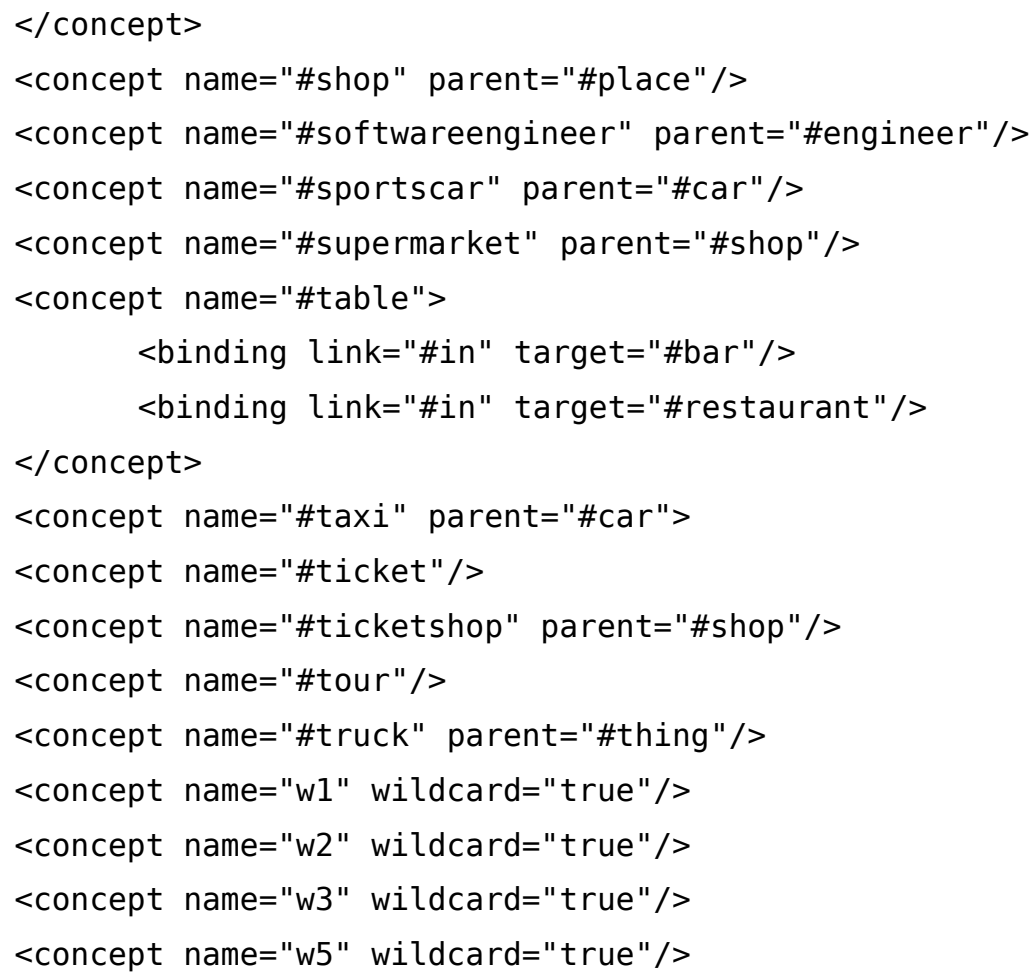

- o conjunto de serviços associados aos conceitos da ontologia permaneceu estável durante todo o experimento, isto é, não foram criados novos serviços à medida que o experimento ocorreu, portanto o conjunto de serviços é um parâmetro do contexto. A amostra de serviços é dada na tabela 2.

Tabela 2. Serviços utilizados no experimento

\begin{tabular}{|l|l|}
\hline Nome & Tipo de serviço prestado \\
\hline agenda & Serviço que retorna endereços \\
\hline airticket & Compra de passagens aéreas \\
\hline bookbartable & Reserva em mesas de bar \\
\hline bookhostel & Reserva de quartos de albergue \\
\hline bookhotel & Reserva de quartos de hotel \\
\hline bookrestaurant & Reserva de mesas de restaurante \\
\hline bookstore & Livraria \\
\hline busticket & Compra de passagens de ônibus \\
\hline buytour & Compra de tours \\
\hline carrenter & Aluguel de carros \\
\hline directiongenerator & Gerador de mapas com direções entre origem e destino \\
\hline email & Serviço de e-mail \\
\hline mapgenerator & Serviço que gera um mapa ao redor de uma origem \\
\hline
\end{tabular}




\begin{tabular}{|l|l|}
\hline pubcrawl & Pub Crawl - tour por bares na cidade \\
\hline rentlimo & Aluguel de limousine \\
\hline supermarket & Compras em supermercado \\
\hline taxibooker & Serviço que pede um táxi com hora definida \\
\hline ticketshop & Serviço de compra de ingressos para apresentações \\
\hline
\end{tabular}

O experimento foi feito de maneira a exercitar o modelo dentro desse contexto particular, com os parâmetros de contexto dados acima. É possível estender a ontologia e o conjunto de serviços criados de maneira a exercitar o protótipo em um contexto mais amplo, porém tal extensão ultrapassa o limite experimental planejado para a pesquisa e poderá ser realizada em trabalhos futuros.

Seleção de variáveis: Uma variável é um elemento que será alterado propositalmente durante a execução, com o objetivo de poder observar-se como os resultados irão variar de acordo com as alterações das variáveis. As variáveis do experimento são:

- o grau mínimo de similaridade: como o objetivo do experimento é avaliar se a similaridade permite gerar novos processos de negócio, uma variável importante definida para a experimentação é o grau mínimo de similaridade a que os conceitos serão submetidos. A experimentação foi realizada variando-se o grau mínimo de similaridade entre os valores: 0,2;0,4;0,6;0,8 e 1. Buscou-se avaliar, desta forma, o quanto o grau mínimo de similaridade impacta na geração de processos de negócio alternativos. Outro objetivo foi o de determinar se os novos processos de negócio gerados continuam atendendo à requisição expressa e, para tal, foi utilizada uma abordagem qualitativa, como será detalhado na seção de projeto experimental.

- a razão de mudança: a variável mais importante da aplicação experimental é a razão de mudança. Chame-se processo de negócio original o processo de negócio relativo à composição de serviços gerada sem similaridade para uma dada requisição.

Projeto experimental. O projeto experimental condiciona as abordagens estatísticas 
válidas a serem seguidas para analisar os dados coletados no experimento, a prescreve a divisão da amostra em um conjunto de grupos, de acordo com uma estratégia (GOULÃO ET AL., 2007).

Os principais dados coletados no experimento são relativos aos processos de negócios gerados (com e sem similaridade). Uma composição está sempre associada a um processo de negócio, pois é uma maneira de se instanciar um processo de negócio, automatizando-o. Quando se gera uma composição associada a uma dada requisição sem o uso de similaridade, está-se criando uma composição que irá automatizar um processo de negócio que atende aquela requisição. Ao se gerar variações na semântica da composição através de similaridade, varia-se também os serviços que fazem parte da composição e, consequentemente, os processos de negócio automatizados pela composição. Desta forma, a similaridade propõe novos processos de negócio para resolver uma requisição. O projeto experimental foi feito para avaliar-se como a similaridade altera os processos de negócio, e para isso duas abordagens foram utilizadas: uma quantitativa e outra qualitativa.

A abordagem quantitativa teve como objetivo variar o grau mínimo de similaridade de maneira a variar os processos de negócio gerados. A abordagem qualitativa teve como objetivo avaliar se a requisição expressa continua a ser atendida após a geração de novos processos de negócio, isto é, se a variação do processo de negócio não descaracterizou a requisição.

$\mathrm{Na}$ abordagem quantitativa foram passadas diversas requisições para o protótipo, criadas com base nos serviços existentes, de maneira a exercitar os serviços e as possíveis composições. Para cada requisição foram analisadas as composições com e sem similaridade e seus processos de negócio correspondentes, bem como os provedores dos serviços. Para conduzir a abordagem quantitativa, foi necessário definir o que diferencia um processo de negócio de outro processo de negócio, de maneira a determinar se o uso de similaridade de fato significou uma mudança no processo de negócio gerado. A tabela 3 mostra os critérios levados em conta para considerar-se dois processos de negócio equivalentes ou diferentes. 
Para cada requisição foram observados o número de atividades no processo de negócio gerado sem similaridade e nos processos de negócio gerados através de similaridade. Se o número de atividades for o mesmo, deverá-se observar se as atividades dos dois processos são as mesmas, ou seja, se produzem os mesmos efeitos.

Para uma dada requisição foram observados também o número de provedores no processo de negócio gerado sem similaridade e nos processos de negócio gerados através de similaridade. Se o número de provedores for o mesmo, deverá-se observar se os provedores dos dois processos são os mesmos.

Tabela 3. Variáveis observadas no experimento

\begin{tabular}{|c|c|c|}
\hline Variável & Descrição & Objetivo \\
\hline $\begin{array}{l}\text { Número de atividades com } \\
\text { similaridade }\end{array}$ & $\begin{array}{l}\text { Número de atividades de um determinado } \\
\text { processo de negócio gerado através de } \\
\text { similaridade }\end{array}$ & \multirow{2}{*}{$\begin{array}{l}\text { Avaliar o quanto a } \\
\text { utilização de serviços } \\
\text { similares levou a um } \\
\text { número diferente de } \\
\text { atividades }\end{array}$} \\
\hline $\begin{array}{l}\text { Número de atividades sem } \\
\text { similaridade }\end{array}$ & $\begin{array}{l}\text { Número de atividades de um determinado } \\
\text { processo de negócio gerado sem similaridade }\end{array}$ & \\
\hline $\begin{array}{l}\text { Número de atividades } \\
\text { equivalentes }\end{array}$ & $\begin{array}{l}\text { Número de atividades equivalentes entre um } \\
\text { processo de negócio gerado através de } \\
\text { similaridade e um processo de negócio gerado } \\
\text { sem similaridade }\end{array}$ & $\begin{array}{l}\text { Avaliar se a utilização de } \\
\text { serviços similares levou a } \\
\text { atividades diferentes, } \\
\text { mesmo que o número de } \\
\text { atividades seja o mesmo } \\
\text { entre os dois processos }\end{array}$ \\
\hline $\begin{array}{l}\text { Número de provedores } \\
\text { (raias) antes da } \\
\text { similaridade }\end{array}$ & $\begin{array}{l}\text { Número de provedores (raias) de um } \\
\text { determinado processo de negócio gerado } \\
\text { através de similaridade }\end{array}$ & \multirow{2}{*}{$\begin{array}{l}\text { Avaliar o quanto a } \\
\text { utilização de serviços } \\
\text { similares levou a um } \\
\text { número diferente de } \\
\text { provedores de serviço }\end{array}$} \\
\hline $\begin{array}{l}\text { Número de provedores } \\
\text { (raias) depois da } \\
\text { similaridade }\end{array}$ & $\begin{array}{l}\text { Número de provedores (raias) de um } \\
\text { determinado processo de negócio gerado sem } \\
\text { similaridade }\end{array}$ & \\
\hline $\begin{array}{l}\text { Número de provedores } \\
\text { (raias) de mesma natureza }\end{array}$ & $\begin{array}{l}\text { Número de provedores (raias) de mesma } \\
\text { natureza entre um processo de negócio gerado } \\
\text { através de similaridade e um processo de } \\
\text { negócio gerado sem similaridade. Provedores } \\
\text { de mesma natureza são aqueles que servem } \\
\text { um mesmo propósito }\end{array}$ & $\begin{array}{l}\text { Avaliar se a utilização de } \\
\text { serviços similares levou a } \\
\text { provedores diferentes, } \\
\text { mesmo que o número de } \\
\text { provedores seja o mesmo } \\
\text { entre os dois processos }\end{array}$ \\
\hline
\end{tabular}

A partir da comparação entre os processos de negócio com e sem similaridade, pôde-se mensurar o quanto os processos de negócio sofreram alterações devido ao uso de 
similaridade. Considera-se que dois processos de negócio são equivalentes se as atividades são as mesmas e os provedores são os mesmos, ou se o número de atividades é o mesmo e os provedores são de mesma natureza. Provedores de mesma natureza são aqueles que proveem um serviço de mesmo propósito com diferenças na qualidade de serviço. Por exemplo, um hotel 5 estrelas e um hotel 4 estrelas são provedores de mesma natureza. Um serviço de reserva de passagens de avião e um serviço de reserva de passagens de ônibus também são considerados de mesma natureza.

Em todos os demais casos, considera-se que os processos de negócio são diferentes. Partindo destes critérios, detalhados na tabela 4, estabelece-se uma base de comparação entre processos de negócio gerados com e sem similaridade.

Tabela 4. Critérios para definir a diferença entre processos de negócio

\begin{tabular}{|l|l|}
\hline Critério & Considerações \\
\hline $\begin{array}{l}\text { Número de atividades com similaridade } \\
\text { diferente do número de atividades sem } \\
\text { similaridade }\end{array}$ & Processos de negócio são diferentes \\
\hline $\begin{array}{l}\text { Número de provedores com similaridade } \\
\text { diferente do número de provedores sem } \\
\text { similaridade }\end{array}$ & Processos de negócio são diferentes \\
\hline $\begin{array}{l}\text { Número de provedores de uma } \\
\text { determinada natureza é diferente no } \\
\text { processo com similaridade em relação ao } \\
\text { processo sem similaridade }\end{array}$ & Processos de negócio são diferentes \\
\hline $\begin{array}{l}\text { Nenhuma das condições acima foi } \\
\text { verificada }\end{array}$ & Processos de negócio são equivalentes \\
\hline
\end{tabular}

Para a abordagem qualitativa foi realizada uma pesquisa investigativa com praticantes reais do domínio do turismo. Foram selecionados 23 indivíduos vindos de 11 países, com idades entre 17 e 42 anos, que receberam treinamento e foram expostos ao software em campo. Os problemas experimentados foram todos reais à medida que exploravam uma região da cidade de São Paulo. O repositório de serviços continha os mesmos serviços da experimentação feita pela abordagem quantitativa. No final da experimentação os praticantes responderam a uma pesquisa de opinião cujo objetivo era definir se o desejo 
embutido na requisição continuava a ser atendido, mesmo com a mudança no processo de negócio. As perguntas respondidas eram: 1) se as composições atendiam totalmente, 2) parcialmente ou 3) não satisfatoriamente às requisições passadas.

\subsubsection{Execução do experimento}

Na fase de execução o experimento em si é executado e as variáveis selecionadas são coletadas para futura análise.

O protótipo foi feito através de um sistema web em Java e JavaServer Pages (JSP), composto de cinco páginas, cada uma representando um dos passos da composição.

$\mathrm{Na}$ execução da abordagem quantitativa a execução seguiu os passos mostrados na figura 24: elaboração da requisição, obtenção da composição com e sem similaridade, identificação dos processos de negócio para cada composição e comparação dos processos de negócio identificados (para determinar se houve mudança).

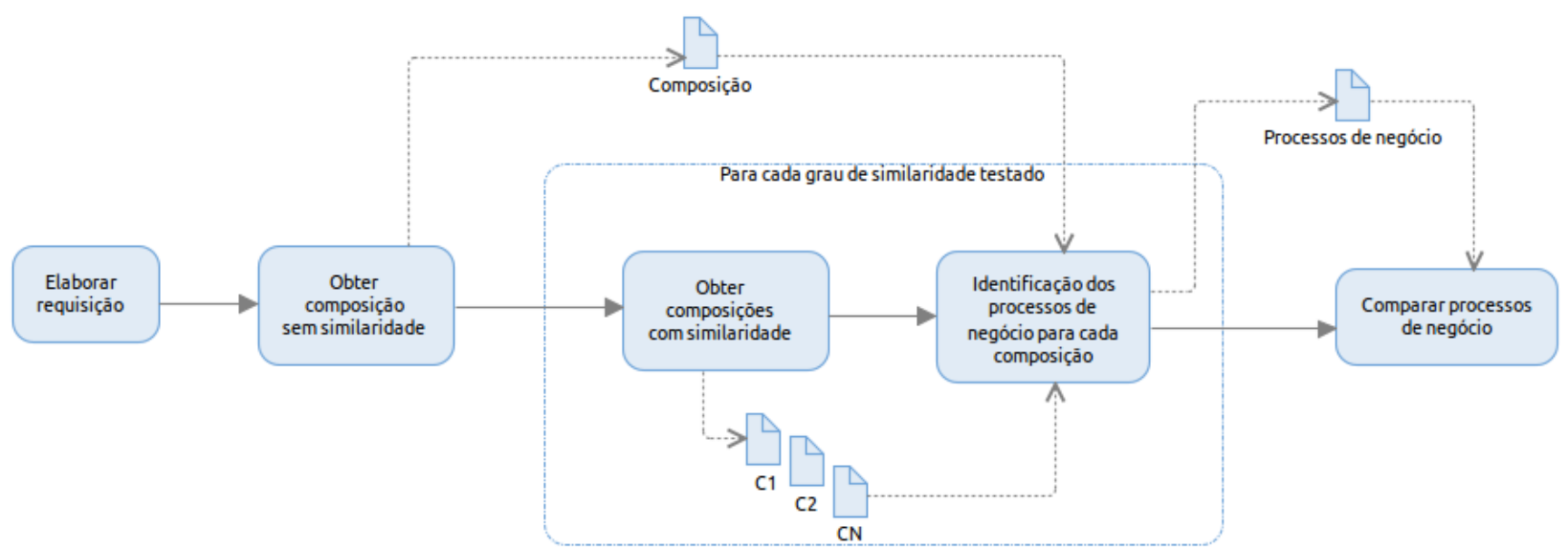

Figura 24. Passos executados na abordagem quantitativa

Primeiramente elaborou-se cada requisição de maneira a utilizar os serviços e conceitos 
definidos na ontologia, e na primeira página do protótipo essa requisição é expressa com o grau de similaridade mínimo desejado na primeira página do protótipo, mostrada na figura 25.

Insira o grau de similaridade desejado entre 0 e 1 ( 0 =grau mínimo de similaridade; 1 =apenas conceitos equivalentes): 0.9

Insira o seu requisito abaixo em inglês:

print direction from office to restaurant

Figura 25. Tela do protótipo onde a requisição é expressa

Utilizou-se o protótipo sem similaridade e os graus mínimos de similaridade: 1,0;0,8;0,6; 0,4 e 0,2. O processo de obtenção de composições com similaridade se dá como na figura 26.

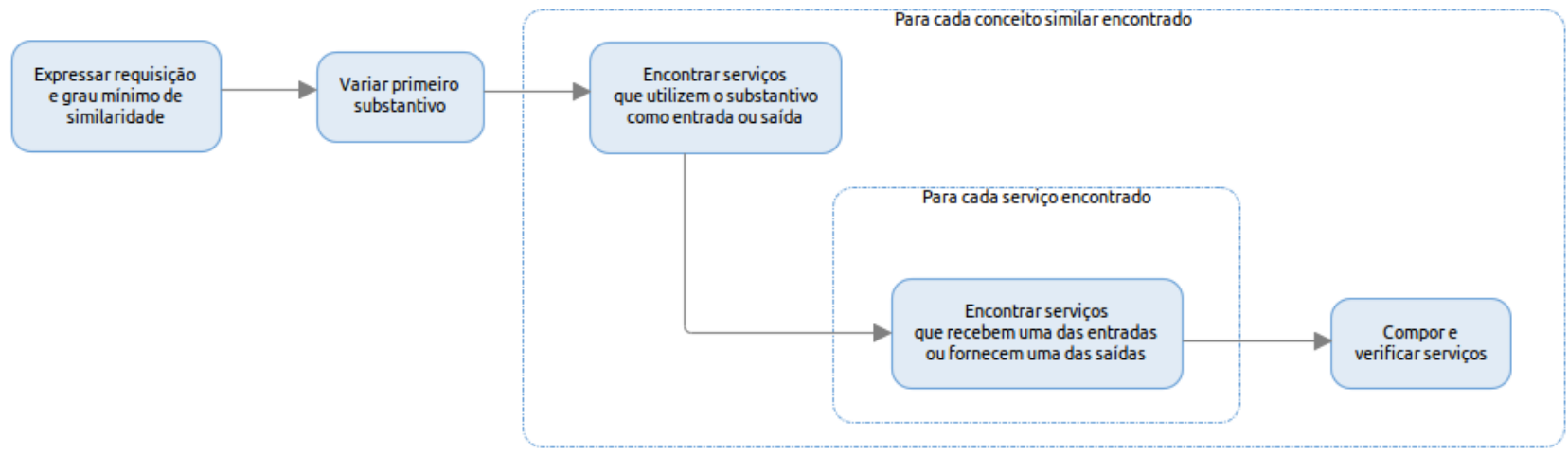

Figura 26. Obtenção de composições com similaridade

Primeiramente são identificados todos os conceitos similares ao conceito do primeiro substantivo da requisição, com similaridade mínima definida pelo usuário. São encontrados todos os conceitos similares ao primeiro substantivo da requisição, o que inclui também conceitos curinga, como mostrado na figura 27. 


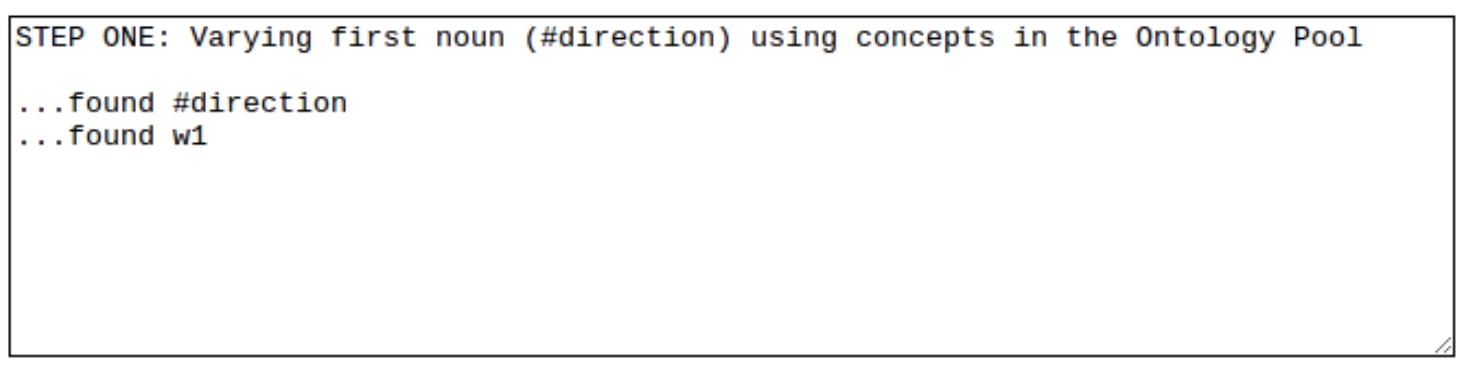

Continuar

Figura 27. Primeiro passo: variação do primeiro substantivo

Após a identificação dos conceitos similares ao primeiro substantivo, busca-se todos os serviços que usam o primeiro substantivo como entrada ou saída, como mostrado na figura 28.

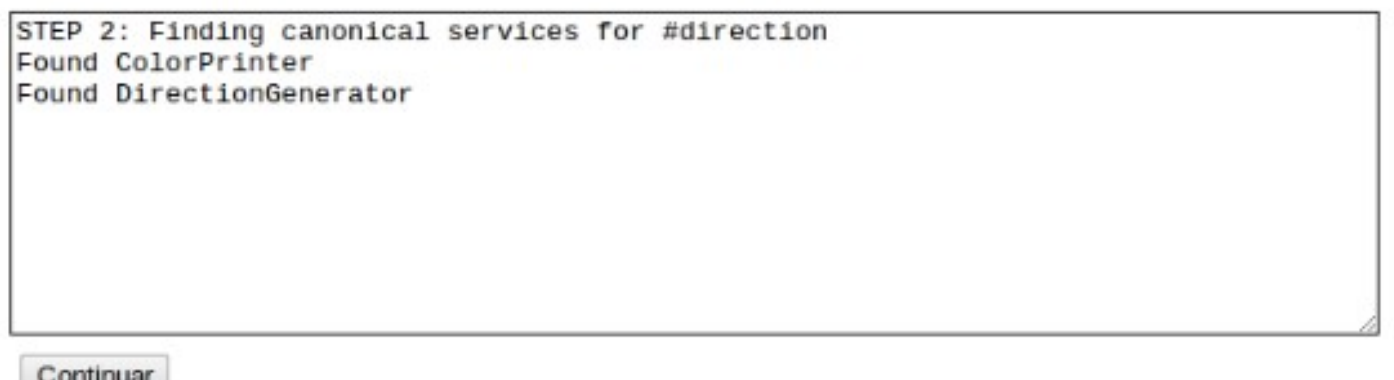

Continuar

Figura 28. Serviços associados aos conceitos encontrados no passo anterior

Para cada serviço encontrado, são buscados, então, todos os serviços que recebem pelo menos uma das entradas e/ou fornecem uma das saídas de suas operações (figura 29).

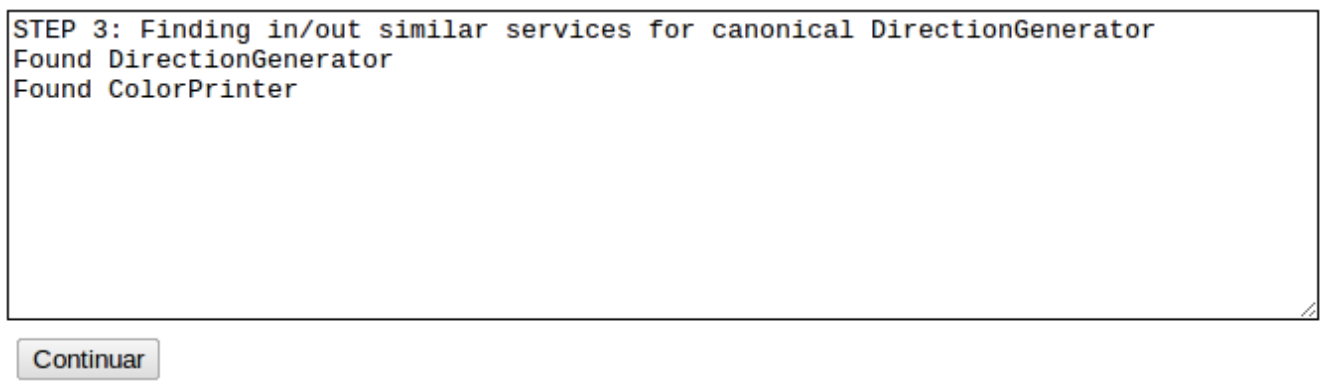

Figura 29. Serviços com entradas e saídas similares aos encontrados no passo 2 
É feita então a complementação de entradas para os serviços encontrados nos dois passos anteriores (figura 30 ).

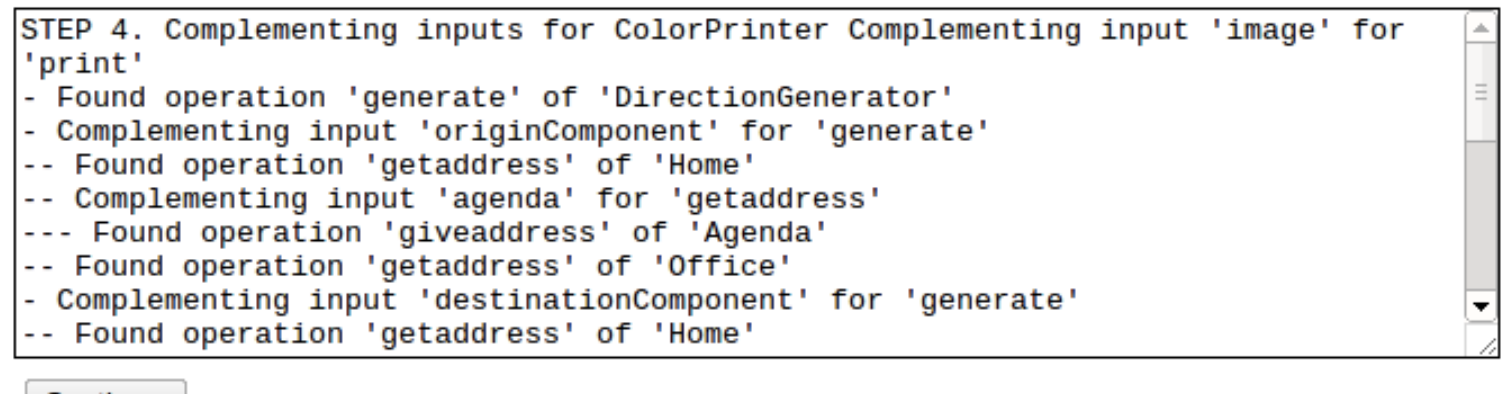

\section{Continuar}

Figura 30. Complementação de entradas

Finalmente, após todas as entradas serem complementadas, os serviços são combinados em diversas composições diferentes que podem atender à requisição do usuário, como mostrado na figura 31 .

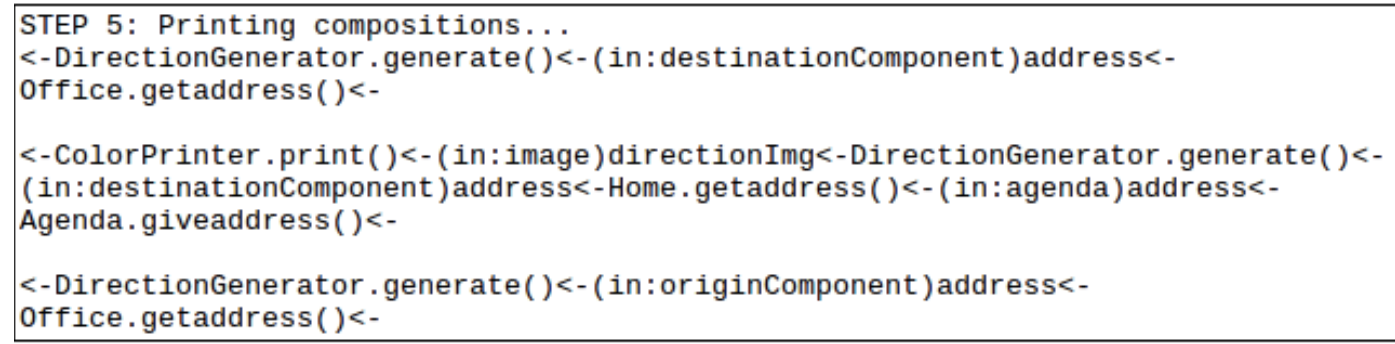

Figura 31. Composições geradas automaticamente são mostradas no protótipo

De posse das composições geradas, identifica-se os processos de negócio associados a cada composição de acordo com os serviços pertencentes a cada requisição. Os processos de negócio das composições geradas com similaridade são comparados com o processo de negócio sem similaridade de acordo com os critérios da tabela 4.

Na execução da abordagem qualitativa o processo de obtenção das composições é o mesmo, porém não são identificados os processos de negócio diretamente, como 
mostrado na figura 32 .

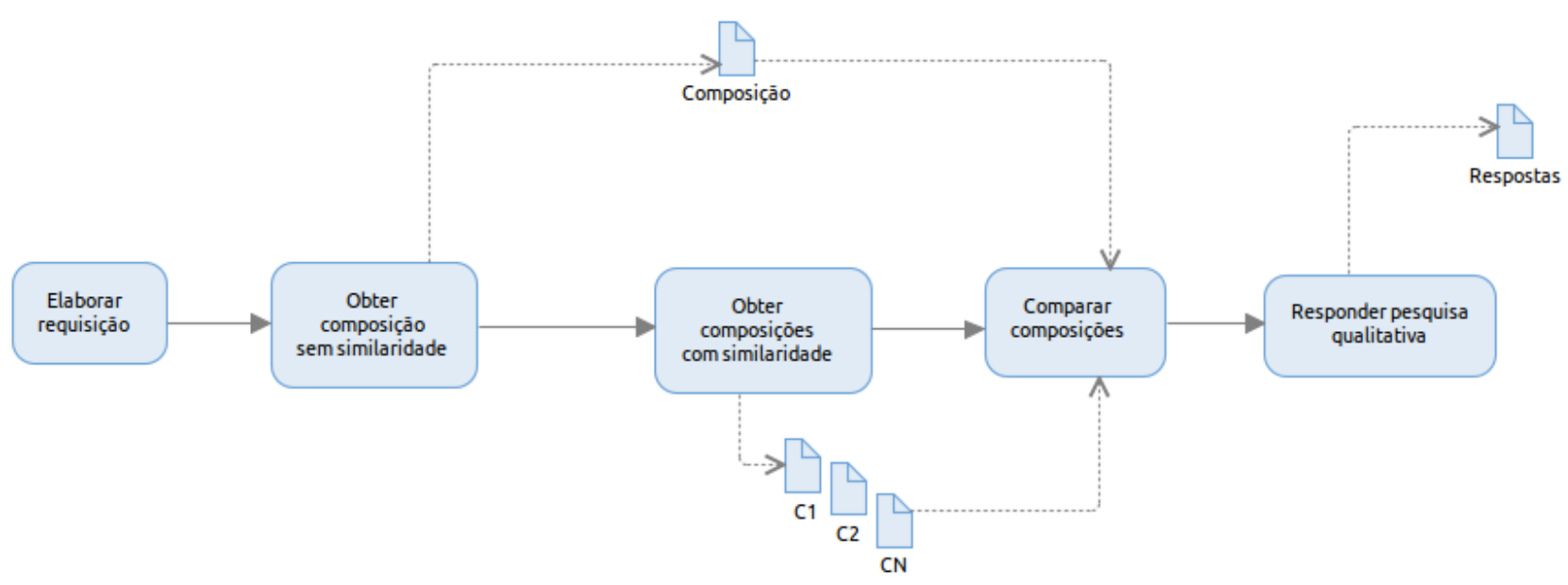

Figura 32. Passos executados na abordagem qualitativa

Os praticantes do domínio comparam a composição oferecida com similaridade às composições oferecidas sem similaridade, e através da pesquisa qualitativa expressam de maneira intuitiva sua percepção sobre a diferença entre as composições. Dadas as respostas à pesquisa, determina-se a percepção que os usuários tem de quanto as composições geradas com similaridade (que podem estar associadas a novos processos de negócio) atendem à requisição original passada.

\subsubsection{Análise dos dados}

$\mathrm{Na}$ fase de análise os dados são analisados e descritos. Será feita a análise nas duas abordagens definidas pelo experimento.

Descrição dos dados. Os dados relativos a todas as composições geradas foram armazenados automaticamente pelo protótipo. Estes dados coletados foram interpretados de acordo com os processos de negócio que automatizam, para avaliar o impacto do uso da similaridade sobre os processos de negócio. 
$\mathrm{Na}$ abordagem quantitativa foram criadas requisições que geraram um total de 181 composições variando-se a similaridade entre 0,2 e 1,0. Para cada composição de serviço foi identificado o processo de negócio correspondente, que foi comparado ao processo de negócio gerado sem a utilização de similaridade, e então foi calculada a razão de mudança para cada requisição e cada grau de similaridade mínimo. Como a ontologia foi criada em língua inglesa visando a experimentação qualitativa (realizada por turistas estrangeiros), a abordagem quantitativa continha requisições também em inglês.

As seguintes requisições foram passadas para o protótipo:

book room in hostel from 2012-03-15 to 2012-04-15

book hotel from 2012-03-15 to 2012-04-15

book table in bar

book table in restaurant

rent familiycar

rent limousine

rent truck

buy tour

buy ticket to event

buy pubcrawl in citycenter

buy airticket from SaoPaulo to Rio

buy airticket from Rio to SaoPaulo

deliver book to hotel

buy busticket from SaoPaulo to Rio

buy busticket from Rio to SaoPaulo

print directions from Rio to SaoPaulo

print directions from hotel to bar

book taxi at 11:50

print map near event

print map near bar

book taxi from hotel to pubcrawl

send email to Phil with map near hostel 
Após a análise de todas as composições geradas as razões de mudança obtidas para cada nível de similaridade ficou conforme a figura 33:
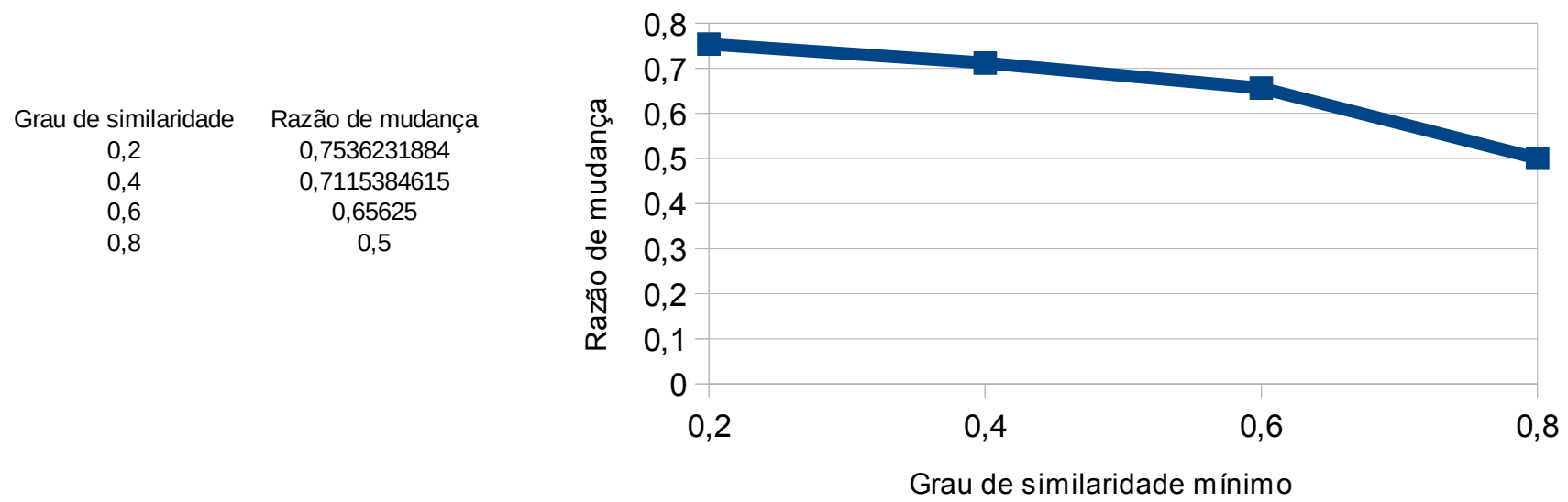

Figura 33. Razão de mudança para os diferentes graus de similaridade testados

Os resultados das comparações entre os processos de negócio com e sem similaridade são mostrados abaixo nas figuras 34 a 40 . Na figura 34 vê-se o resultado para todas as composições geradas. Das 181 composições geradas através de similaridade, portanto, 122 representavam uma mudança em relação ao processo de negócio associado à composição de serviços que era gerada sem similaridade, enquanto 59 composições representavam o mesmo processo de negócio, porém com serviços diferentes.

Mudança nos PNU

Sem mudança nos PNU
122

59

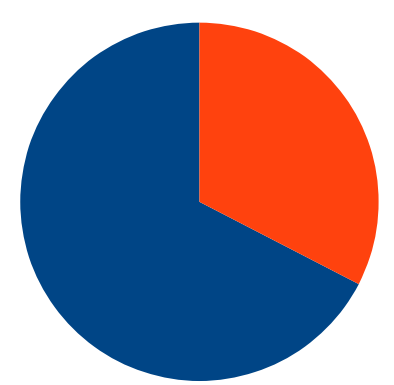

Mudança nos

PNU

Sem mudança nos

PNU

Figura 34. Distribuição das composições geradas de acordo com as mudanças nos processos de negócio do usuário 
Nas figuras 35 a 40 pode-se ver os resultados do impacto da similaridade sobre a camada de negócios para cada nível de similaridade testado, isto é, a quantidade de novos processos de negócio gerados quando a similaridade esteve habilitada.

Com similaridade 0,2 (figura 35), pode-se ver que das 69 composições geradas com similaridade, $75,4 \%$ (52 composições) representavam uma mudança no nível de processos de negócio em relação à composição de serviços gerada sem similaridade e 24,6\% (17 composições) não representavam mudança no nível de processos de negócio.

Mudança nos PN

Sem mudança nos PN
52

17

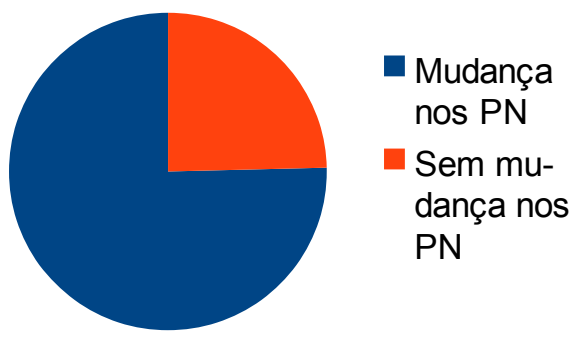

Figura 35. Distribuição das composições geradas de acordo com as mudanças nos processos de negócio do usuário utilizando grau de similaridade 0,2

Com similaridade 0,4 (figura 36), pode-se ver que das 52 composições geradas com similaridade, $71,1 \%$ (37 composições) representavam uma mudança no nível de processos de negócio em relação à composição de serviços gerada sem similaridade e 28,9\% (15 composições) não representavam mudança no nível de processos de negócio.

Mudança nos PN

Sem mudança nos PN
37

15

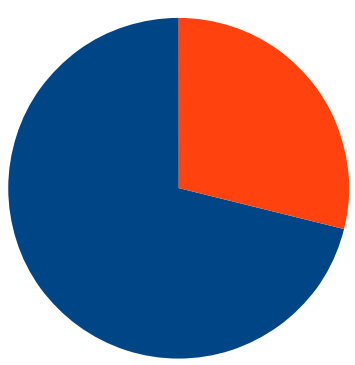

- Mudança nos PN

Sem mudança nos $\mathrm{PN}$

Figura 36. Distribuição das composições geradas de acordo com as mudanças nos processos de negócio do usuário utilizando grau de similaridade 0,4 
Com similaridade 0,6 (figura 37), pode-se ver que das 31 composições geradas com similaridade, 67,7\% (21 composições) representavam uma mudança no nível de processos de negócio em relação à composição de serviços gerada sem similaridade e 33,3\% (11 composições) não representavam mudança no nível de processos de negócio.

Mudança nos PN $\quad 37$

Sem mudança nos PN 15

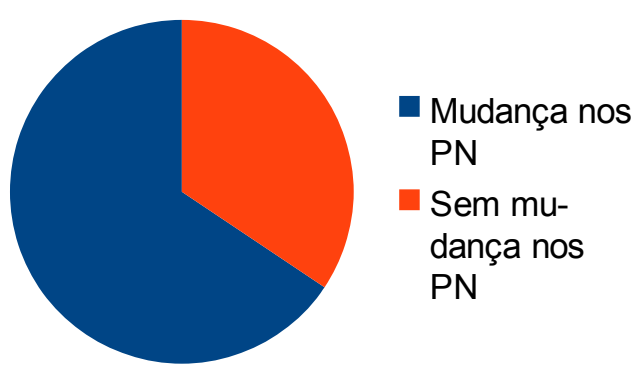

Figura 37. Distribuição das composições geradas de acordo com as mudanças nos processos de negócio do usuário utilizando grau de similaridade 0,6

Com similaridade 0,8 (figura 38), pode-se ver que das 18 composições geradas com similaridade, $50 \%$ (9 composições) representavam uma mudança no nível de processos de negócio em relação à composição de serviços gerada sem similaridade e 50\% (9 composições) não representavam mudança no nível de processos de negócio.

Mudança nos PN

Sem mudança nos PN

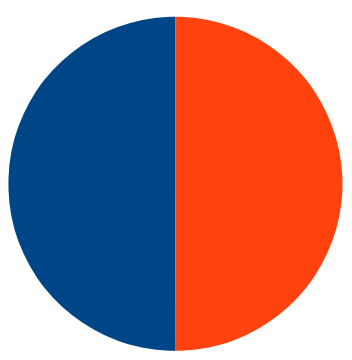

Mudança nos PN

- Sem mudança nos PN

Figura 38. Distribuição das composições geradas de acordo com as mudanças nos processos de negócio do usuário utilizando grau de similaridade 0,8

Com similaridade 0,8 (figura 39), pode-se ver que das 18 composições geradas com similaridade, $50 \%$ (9 composições) representavam uma mudança no nível de processos 
de negócio em relação à composição de serviços gerada sem similaridade e $50 \%$ (9 composições) não representavam mudança no nível de processos de negócio.

Mudança nos PN

Sem mudança nos PN

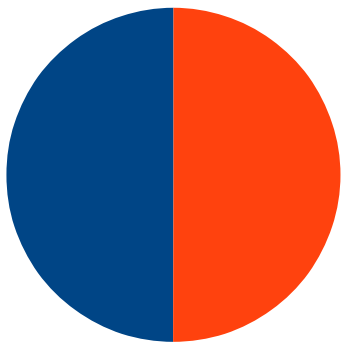

Mudança nos

PN

- Sem mudança nos PN

Figura 39. Distribuição das composições geradas de acordo com as mudanças nos processos de negócio do usuário utilizando grau de similaridade 0,8

Com similaridade 1,0 (figura 40), pode-se ver que das 10 composições geradas com similaridade 1, 100\% (10 composições) não representavam mudança no nível de processos de negócio. Deve-se ressaltar que o uso da similaridade 1,0 é diferente do uso sem similaridade, pois com a similaridade habilitada em 1,0 o mecanismo de composição automática de serviços busca também por provedores equivalentes, enquanto oferece unicamente a primeira composição de serviços feita com sucesso quando a similaridade está desabilitada.

Mudança nos PN

Sem mudança nos PN
0

10

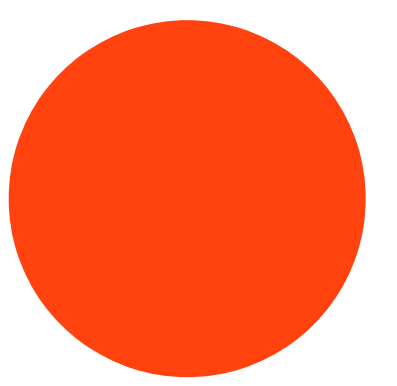

Mudança nos

PN

Sem mudança nos PN

Figura 40. Distribuição das composições geradas de acordo com as mudanças nos processos de negócio do usuário utilizando grau de similaridade 1,0 (sem similaridade)

Nota-se que a razão de mudança altera-se significativamente à medida que o grau 
mínimo de similaridade é variado: com os parâmetros de contexto utilizados, aplicando-se grau de similaridade 0,8 , apenas $50 \%$ das composições de serviço geradas eram composições associadas a processos de negócio alternativos (que não seriam gerados caso a similaridade não fosse aplicada), enquanto a taxa chega a $75 \%$ quando a similaridade mínima é de 0,2. Embora essa coleta de dados permita avaliar a curva sob a qual novas composições são geradas, resta ainda a questão levantada pelo critério de aceitação do desejo explanado por Kenny (1966) nas pesquisas de frases imperativas. Parte das novas composições de serviços geradas podem ser associadas a outros processos de negócio mas nada ter a ver ou não satisfazerem de maneira suficiente a requisição expressa. É necessário determinar-se, portanto, das novas composições geradas, quantas são de fato satisfatórias em relação à requisição original. Principalmente por tratar-se de uma questão subjetiva, tal resposta pode ser dada através de abordagem qualitativa, onde os próprios criadores das requisições determinam se as composições geradas satisfazem seus desejos.

Para a abordagem qualitativa, portanto, os praticantes foram expostos a uma pesquisa investigativa que continha seis perguntas:

1. COM a similaridade habilitada (similaridade entre 0,2 e 0,8) - Quantas composições sugeridas pelo software não corresponderam exatamente às suas expectativas, mas eram alternativas que satisfaziam suas necessidades?

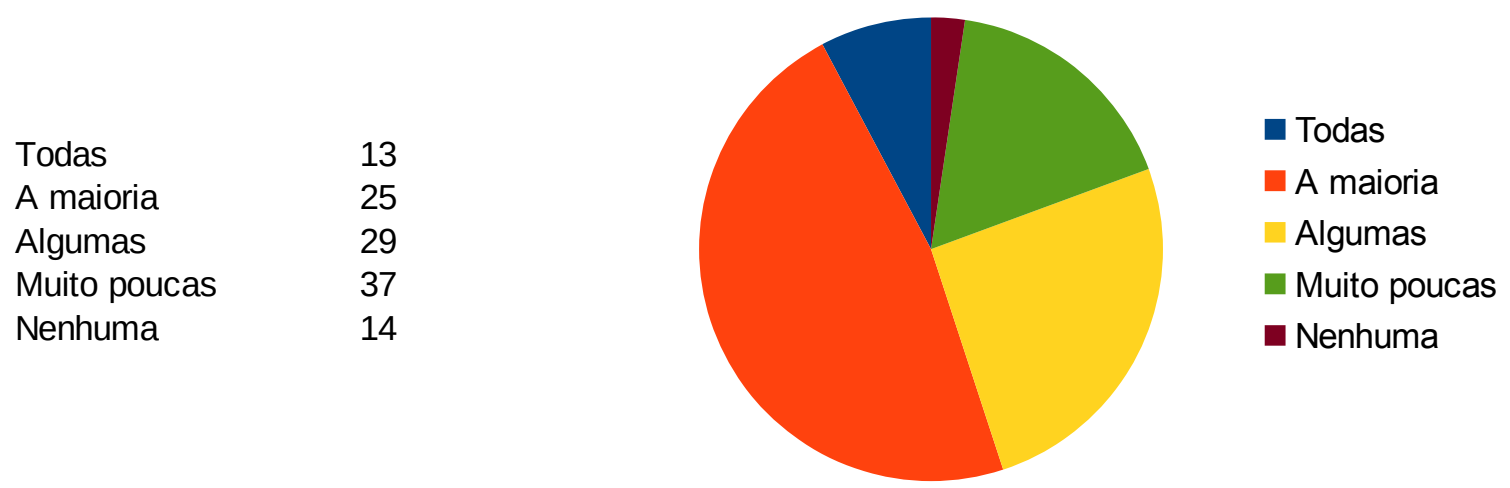

Figura 41. Composições que não correspondiam ao requisito, mas satisfaziam a necessidade COM similaridade 
2. COM a similaridade habilitada (similaridade entre 0,2 e 0,8) - Quantas composições sugeridas pelo software correspondiam exatamente às suas expectativas?

$\begin{array}{lr}\text { Todas } & 4 \\ \text { A maioria } & 14 \\ \text { Algumas } & 53 \\ \text { Muito poucas } & 47 \\ \text { Nenhuma } & 4\end{array}$

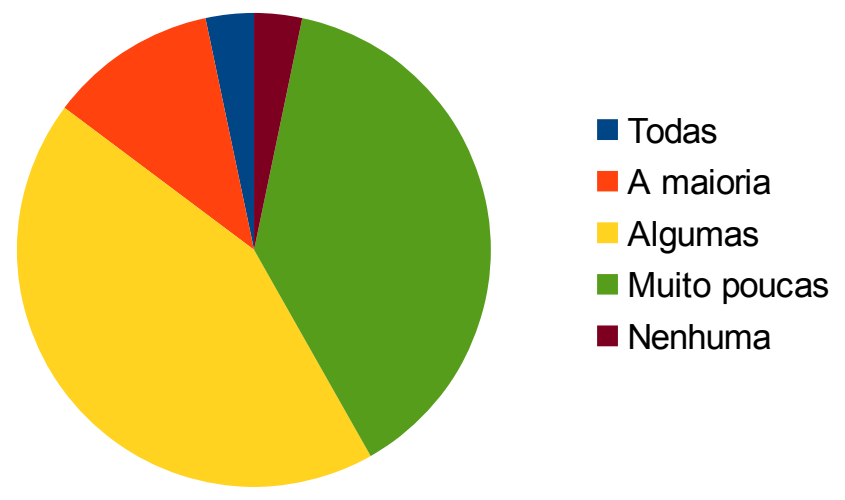

Figura 42. Composições que correspondiam exatamente a necessidade COM similaridade

3. COM a similaridade habilitada (similaridade entre 0,2 e 0,8) - Quantas composições sugeridas pelo software satisfaziam suas expectativas parcialmente? (isto é, satisfaziam algumas das suas necessidades, porém não todas)

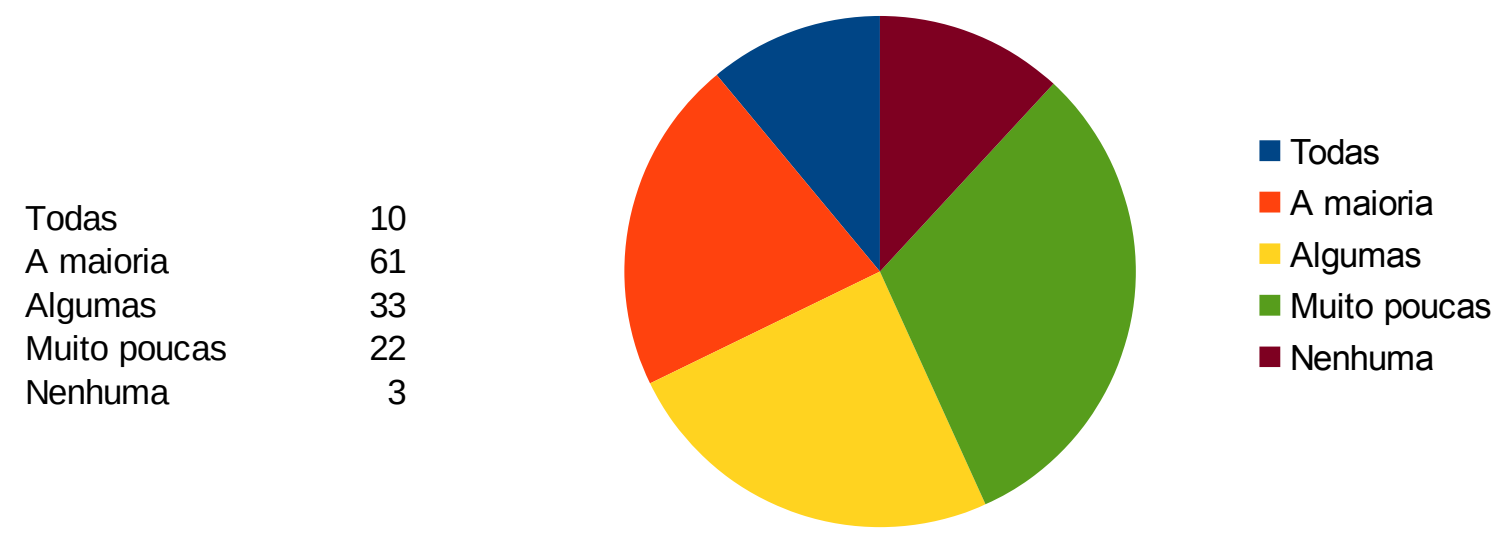

Figura 43. Composições que satisfaziam parcialmente a necessidade COM similaridade

4. SEM a similaridade habilitada - Quantas composições sugeridas pelo software não corresponderam exatamente às suas expectativas, mas eram alternativas que satisfaziam 
suas necessidades?

Todas

A maioria

Algumas

Muito poucas

Nenhuma

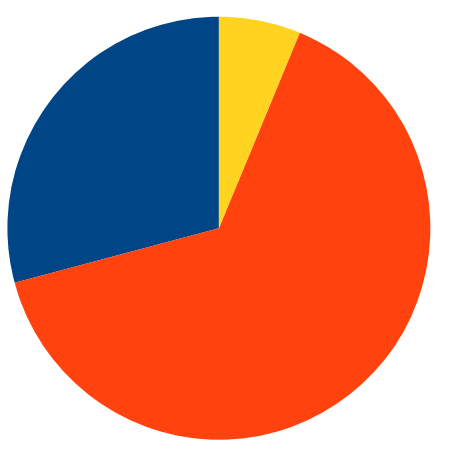

Todas

A maioria

Algumas

Muito poucas

- Nenhuma

Figura 44. Composições que não correspondiam ao requisito, mas satisfaziam a necessidade SEM similaridade

5. SEM a similaridade habilitada - Quantas composições sugeridas pelo software correspondiam exatamente às suas expectativas?

Todas

A maioria

Algumas

Muito poucas

Nenhuma
57

5

1

0

0

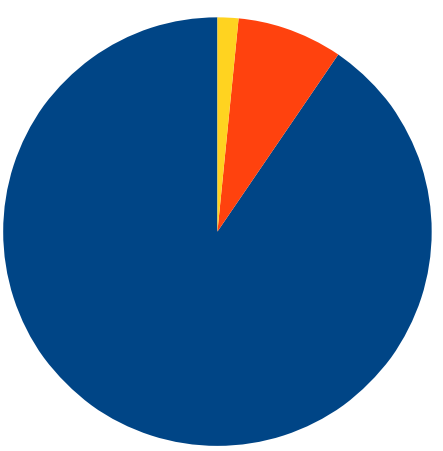

- Todas

- A maioria

Algumas

Muito poucas

- Nenhuma

Figura 45. Composições que correspondiam exatamente a necessidade SEM similaridade

6. SEM a similaridade habilitada - Quantas composições sugeridas pelo software satisfaziam suas expectativas parcialmente? (isto é, satisfaziam algumas das suas necessidades, porém não todas) 
Todas

A maioria

Algumas

Muito poucas

Nenhuma

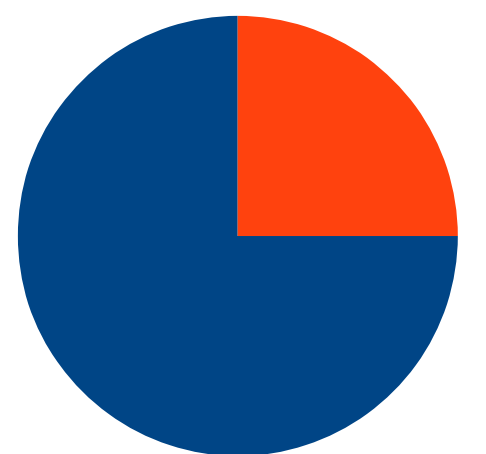

Todas

A maioria

Algumas

Muito poucas

Nenhuma

Figura 46. Composições que satisfaziam parcialmente a necessidade SEM similaridade

Os resultados da abordagem qualitativa permitem observar-se o critério da aceitação do desejo. Nota-se uma diferença expressiva entre os resultados com e sem similaridade para uma mesma questão (ou seja, comparando-se duas a duas as respostas às questões 1 e 4; 2 e 5; e 3 e 6), onde não apenas a similaridade permitiu um maior número de composições geradas como também uma maior satisfação (seja integral ou parcial) relativa ao desejo expresso pelo usuário. Como esperado, nota-se que sem a similaridade o número de composições que correspondiam exatamente à requisição do usuário é maior do que o número de composições que correspondiam parcialmente à requisição, ou seja, há maior acurácia na composição sem similaridade.

O objetivo da questão 2 foi compreender o quanto o uso da similaridade não impacta num sistema de composição automática, ou seja, o quanto uma requisição pode ser considerada integralmente atendida mesmo que conceitos similares tenham sido usados para tal. Nesse sentido nota-se também, ao comparar-se os resultados das questões 1 e 3 (respectivamente, as composições que satisfaziam as necessidades, ainda que não precisamente como foram passadas, e as composições que satisfaziam parte das necessidades), que a tolerância com a utilização de conceitos e serviços similares faz com que seja mais comum que uma composição alternativa satisfaça um desejo do que apenas parte dele - ou seja, ainda que uma dada composição não corresponda precisamente à requisição passada, os experimentadores consideraram as composições alternativas como tendo atendido integralmente (e não apenas parcialmente) suas requisições. 


\section{CONSIDERAÇÕES FINAIS}

Neste capítulo são mostradas as conclusões da pesquisa, bem como os possíveis trabalhos futuros que podem estendê-la.

\subsection{CONCLUSÕES}

A pesquisa propôs-se a avaliar a utilização da similaridade conceitual em sistemas de composição automática de serviços para a geração de novos processos de negócio. Foi utilizado o domínio do turismo como região experimental, e para isso foi criada uma ontologia e um conjunto de serviços.

A partir dos resultados experimentais mostrados no capítulo 4, pode-se ver em números que o modelo de composição automática de serviços com similaridade proposto representa uma adição relevante aos modelos de composição automática de serviços sem similaridade, pois permite que novos processos de negócio sejam gerados a partir de uma mesma composição de serviços.

A integração entre o modelo de composição automática de serviços de Fujii e Suda (2009) com o modelo de similaridade conceitual de Ganjisaffar (2006) provou-se possível, através da criação de um modelo misto que utiliza tanto a similaridade conceitual quanto a composição automática de serviços. Tal integração representou ganhos para a área de pesquisa de composição automática de serviços, pois estendeu os modelos preexistentes provendo uma nova capacidade, a de geração de processos de negócio alternativos através da composição automática de serviços.

No entanto, os resultados da pesquisa investigativa levantam uma questão qualitativa: embora a utilização da similaridade permita que novos processos de negócio sejam gerados, muitos deles não atendem de maneira satisfatória a requisição passada. Desta 
forma, se por um lado exercitou-se o modelo mostrando a geração de novos processos de negócio, por outro existe uma parcela considerável dos novos processos de negócio que não mais atendem à requisição original passada originalmente.

\subsection{TRABALHOS FUTUROS}

A experimentação mostrou que a similaridade aumenta o número de composições alternativas para o usuário ter seu requisito atendido. No entanto, é necessário realizar uma experimentação mais extensa para determinar um ponto ótimo de similaridade.

Acredita-se que a utilização da similaridade deve ser avaliada em relação à preservação do desejo, e seria necessário um foco maior visando encontrar um ponto ótimo, onde a relação entre preservação de desejo e descarte de composição de serviços seja máximo, como mostrado na figura 47.

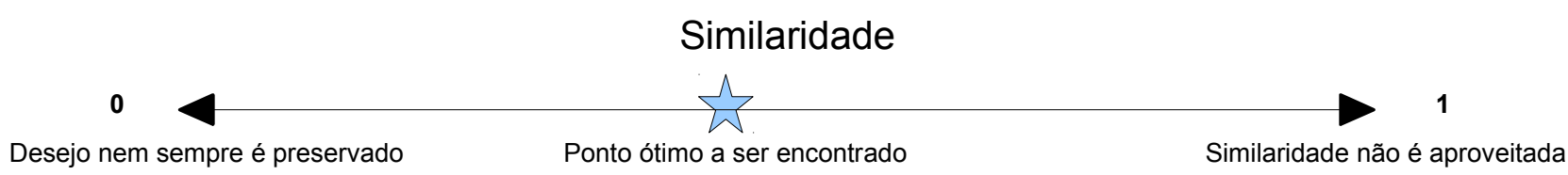

Figura 47. A utilização da similaridade deve ter um ponto ótimo entre 0 e 1

A experimentação foi realizada no domínio do turismo, porém seria interessante avaliar a aplicação do mesmo modelo para outros domínios. Enquanto o turismo se mostrou um contexto experimental interessante devido às características do domínio, acredita-se que outras áreas também podem beneficiar-se do modelo aqui proposto.

Além disso, dado que a utilização de similaridade conceitual fez com que a variação semântica se tornasse tão marcante, a ponto do critério da aceitação do desejo não ser atendido, pode-se citar como objeto de estudo um componente adicional ao modelo de arquitetura proposto, com objetivo de permitir que os usuários categorizem de maneira qualitativa as composições geradas, e os sistemas criados em conformidade com o 
modelo de arquitetura possam ter um mecanismo de aprendizagem, descartando algumas das composições geradas ou oferecendo as composições mais aceitas no topo da lista de composições oferecidas. 


\section{REFERÊNCIAS BIBLIOGRÁFICAS}

BILBAO, Sonia. HERRERO, Jesús. "Semantic Platform for the Composition of Tourism Products and Services ". IEEE 2009 Fourth International Workshop on Semantic Media Adaptation and Personalization.

BUHALIS, Dimitrios. "Strategic use of information technology in the tourism industry". Tourism Management, 1998, 19(5): 409-421.

BUHALIS, Dimitrios. "Marketing the Competitive Destination of the Future". Tourism Management, 2001, (21): 97-116.

BUHALIS, Dimitrios. eTourism: Information Technology for Strategic Tourism Management. London: Pearson Prentice Hall, 2003.

$\mathrm{CHOI}$, Chang. $\mathrm{CHO}$, Miyoung. KANG, Eui-young. KIM, Pankoo. The 8th International Conference on Advanced Communication Technology. ICACT 2006.

DOSHI, P. GOODWIN, R. AKKIRAJU, R. VERMA, K. "Dynamic workflow composition using Markov decision processes". Proceedings of the 2nd International Conference on Web Services (ICWS), 2004.

EID, Mohamad. ALAMRI, Atif. EL SADDIK, Abdulmotaleb. "A reference model for dynamic web service composition systems". Int. J. Web and Grid Services, Vol. 4, No. 2, 2008.

ERL, Thomas. "Service Compositions". http://www.whatissoa.com/p12.php, acessado em 03/09/2011.

FREIMUT, B. PUNTER, T. BIFFL, S. CIOLKOWSKI, M. "State-of-the-art in empirical studies". Virtuelles Software Engineering Kompetenzzentrum, 2002. 
FUJII, Keita. SUDA, Tatsuya. "Dynamic Service Composition Using Semantic Information". ACM ICSOC, novembro de 2004.

FUJII, Keita. SUDA, Tatsuya. "Semantics-based Context-aware Dynamic Service Composition". ACM Transactions on Autonomous and Adaptive Systems, Vol. 4, No. 2, Article 12, maio de 2009.

GARTNER GROUP. IT Glossary: Business Process. http://www.gartner.com/itglossary/business-process/, acessado em janeiro de 2013.

GANJISAFFAR, Yasser. ABOLHASSANI, Hassan. NESHATI, Mahmood. JAMALI, Mohsen. "A Similarity Measure for OWL-S Annotated Web Services". Proceedings of the 2006 IEEE/WIC/ACM International Conference on Web Intelligence (WI 2006 Main Conference Proceedings) (WI'06).

GOULÃO, Miguel. BRITO e ABREU, Fernando. "Modeling the Experimental Software Engineering Process". IEEE Sixth International Conference on the Quality of Information and Communications Technology. 2007

GRUBER, T. R. "Toward principles for the design of ontologies used for knowledge sharing". Padua workshop on Formal Ontology, March 1993. Publicado novamente no International Journal of Human-Computer Studies, Vol. 43, Issues 4-5, November 1995, pp. $907-928$

GUO, Li. CHEN-BURGER, Yun-Heh. ROBERTSON, Dave. "Mapping a business process model to a semantic web service model". Proceedings of the IEEE International Conference on Web Services (ICWS'04)

KENNY, A. J. (1966). Practical Inference. Analysis, 26: 65-75.

KONA, Srividya. BANSAL, Anjay. GUPTA, Gopal. "Automatic Composition of Semantic Web Services". IEEE International Conference on Web Services (ICWS 2007) 
LI, Gexin. DENG, Shuiguang. XIA, Haijiang. LIN, Chuan. "Automatic Service Composition Based on Process Ontology". Third International Conference on Next Generation Web Services Practices, dezembro de 2007.

LI, Rong. HE, Keqing. CHEN, Huafeng. "From Natural Language Requirements to Requirement Ontologies". 2nd International Conference on Future Computer and Communication (ICFCC), IEEE 2010.

LI, Xiaofeng. WU, Chanle. "Research on OWL-S Service Automatic Composition Based on Planning". International Conference on Information Engineering and Computer Science. ICIECS, dezembro de 2009.

LI, Yeqing. QIU, Lirong. ZHAO, Xiaobing. "Information web service composition based on similarity parameters". 2nd International Conference on Information Science and Engineering (ICISE). IEEE, dezembro de 2010.

LIN, Manshan. GUO, Heqing. YIN, Jianfei. "Goal Description Language for Semantic Web Service Automatic Composition". The 2005 Symposium on Applications and the Internet, fevereiro de 2005.

LIU, Chuanchang. PENG, Yong. CHEN, Junliang. "Web Services Description Ontologybased Service Discovery Model". Proceedings of the 2006 IEEE/WIC/ACM International Conference on Web Intelligence (WI 2006 Main Conference Proceedings) (WI'06).

LIU, Xiaoli. "Scenario Elicitation from Natural Language Requirements". 2010 Second International Workshop on Education Technology and Computer Science, IEEE.

MARKOU, G. REFANIDIS, I. "Towards an automatic non-deterministic web Service Composition platform". Computational Aspects of Social Networks (CASoN), 2012 Fourth International Conference on 
O'BRIEN, P. "Dynamic Travel Itinerary Management: The Ubiquitous Travel Agent". Proceedings of the 12th Australasian Conference on Information Systems, Coffs Harbour, Australia, 2001.

OBJECT MANAGEMENT GROUP. "Service oriented architecture Modeling Language (SoaML), Version 1.0.1". http://www.omg.org/spec/SoaML/1.0.1/, acessado em $15 / 07 / 2012$.

ORDONEZ, Armando; CORRALES, Juan C.; FALCARIN, Paolo. "Automated context aware composition for convergent services". System of Systems Engineering (SoSE), 2012 7th International Conference on.

PAGANELLI, Federica. PARLANTI, David. GIULI, Dino. "Message-based Service Brokering and Dynamic Composition in the SAI Middleware". IEEE International Conference on Services Computing (SCC), agosto de 2010.

QU, Xianyang. SUN, Hailong. LI, Xiang. LIU, Xudong. LIN, Wei. "WSSM: A WordNetBased Web Service Similarity Mining Mechanism". 2009 Computation World: Future Computing, Service Computation, Cognitive, Adaptive, Content, Patterns.

SCHWINGER, G. CHRISTOPH, C. Grün. PRÖLL, B. RASINGER, J. RETSCHITZEGGER, W. "A Survey on Mobile Tourism Guides". Handbook of Research in Mobile Multimedia, 2nd edition, Khalil-Ibrahim Ismail (ed.), IGI Global, USA, 2008.

SILVA, Eduardo. LÓPEZ, Jorge Martínez. PIRES, Luís Ferreira. van SINDEREN, Marten. "Defining and Prototyping a Life-cycle for Dynamic Service Composition". 2nd Workshop on Architectures, Concepts and Technologies for Service-Oriented Computing (ACT4SOC). Porto, Portugal, julho de 2008.

SILVA, Eduardo. PIRES, Luís Ferreira. van SINDEREN, Marten. "An Algorithm for Automatic Service Composition". 1st Workshop on Architectures, Concepts and Technologies for Service Oriented Computing (ACT4SOC), 2nd International Conference 
on Software and Data Technologies (ICSOFT). Barcelona, Espanha, julho de 2007.

SIVASHANMUGAM, K. MILLER, J. SHETH, A. VERMA, K. "Framework for Semantic Web process composition", Int. J. Electron. Comm. 9, 2, 71-106, 2004.

STOKES, Donald. "Pasteur's Quadrant". Basic Science and Technological Innovation. Brookings Institution Press, 1997.

TRAN, Vuong Xuan. TSUJI, Hidekazu. "Using Semantic Technologies for Dynamic and Flexible Trip Planning". 3rd IEEE International Conference on Digital Ecosystems and Technologies, 2009. DEST '09.

WOHLIN, C. RUNESON, P. HÖST, M. OHLSSON, M. REGNELL, B. WESSLÉN, A. Experimentation in Software Engineering: An Introduction, vol. 6. Boston, EUA: Kluwer Academic Publishers, 1999.

WU, Bin. WU, Jian. DENG, Shuiguang. LI, Ying. YIN, Jianwei. "Automatic Composition of Semantic Web Services - an Enhanced State Space Search Approach". International Conference on Service Sciences (ICSS), junho de 2010.

W3 CONSORTIUM. "OWL 2 Web Ontology Language Document Overview". http://www.w3.org/TR/owl2-overview/, acessado em 01/12/2012.

W3 CONSORTIUM. "OWL-S: Semantic Markup for Web Services". http://www.w3.org/Submission/OWL-S/, acessado em 01/12/2012.

YUZHANG, Feng; VEERAMINI, A.; KANAGASABAI, R. "Automatic DAG-Based Service Composition: A Model Checking Approach". Web Services (ICWS), 2012 IEEE 19th International Conference on

ZACHOS, Konstantinos. MAIDEN, Neil. "Inventing Requirements from Software: An Empirical Investigation with Web Services". 16th IEEE International Requirements Engineering Conference, 2008. 
ZIMMERMANN, Olaf. KROGDAHL, Pal. GEE, Clive. Elements of Service-Oriented Analysis and Design. http://www.ibm.com/developerworks/library/ws-soad1/, acessado em $30 / 07 / 2011$ 